\title{
A DIAGNOSTIC SYSTEM FOR AIR BRAKES IN COMMERCIAL VEHICLES
}

\author{
A Dissertation \\ by \\ SHANKAR RAM COIMBATORE SUBRAMANIAN
}

\begin{abstract}
Submitted to the Office of Graduate Studies of
Texas A\&M University

in partial fulfillment of the requirements for the degree of

DOCTOR OF PHILOSOPHY
\end{abstract}

May 2006

Major Subject: Mechanical Engineering 


\title{
A DIAGNOSTIC SYSTEM FOR AIR BRAKES IN COMMERCIAL VEHICLES
}

\author{
A Dissertation \\ by \\ SHANKAR RAM COIMBATORE SUBRAMANIAN
}

\author{
Submitted to the Office of Graduate Studies of \\ Texas A\&M University \\ in partial fulfillment of the requirements for the degree of \\ DOCTOR OF PHILOSOPHY
}

Approved by:

Co-Chairs of Committee, K. R. Rajagopal

D. Swaroop

Committee Members, Jo W. Howze

John L. Junkins

Head of Department, Dennis O'Neal

May 2006

Major Subject: Mechanical Engineering 


\begin{abstract}
A Diagnostic System for Air Brakes in Commercial Vehicles. (May 2006)

Shankar Ram Coimbatore Subramanian, B.E., University of Allahabad;

M.S., Texas A\&M University

Co-Chairs of Advisory Committee: Dr. K. R. Rajagopal

Dr. D. Swaroop
\end{abstract}

This dissertation deals with the development of a model-based diagnostic system for air brake systems that are widely used in commercial vehicles, such as trucks, tractor-trailers, buses, etc. The performance of these brake systems is sensitive to maintenance and hence they require frequent inspections. Current inspection techniques require an inspector to go underneath a vehicle to check the brake system for possible faults, such as leaks, worn brake pads, out-of-adjustment of push rods, etc. Such inspections are time consuming, labor intensive and difficult to perform on vehicles with a low ground clearance. In this context, the development of an onboard/handheld diagnostic tool for air brakes would be of significant value. Such a tool would automate the brake inspection process, thereby reducing the inspection time and improving the safety of operation of commercial vehicles. In this dissertation, diagnostic schemes are developed to automatically detect two important and prevalent faults that can occur in air brake systems - leaks and out-of-adjustment of push rods.

These diagnostic schemes are developed based on a nonlinear model for the pneumatic subsystem of the air brake system that correlates the pressure transients in the brake chamber with the supply pressure to the treadle valve and the displacement 
of the treadle valve plunger. These diagnostic schemes have been corroborated with data obtained from the experimental facility at Texas A\&M University and the results are presented.

The response of the pneumatic subsystem of the air brake system is such that it can be classified as what is known as a "Sequential Hybrid System". In this dissertation, the term "hybrid systems" is used to denote those systems whose mathematical representation involves a finite set of governing ordinary differential equations corresponding to a finite set of modes of operation. The problem of estimating the push rod stroke is posed as a parameter estimation problem and a transition detection problem involving the hybrid model of the pneumatic subsystem of the air brake system. Also, parameter estimation schemes for a class of sequential hybrid systems are developed. The efficacy of these schemes is illustrated with some examples. 
To my Parents, Sister and Teachers 


\section{ACKNOWLEDGMENTS}

I am very fortunate to be a student of Professor K. R. Rajagopal and Professor D. Swaroop. It is a great privilege to work under the guidance of Professor K. R. Rajagopal and I convey my sincere thanks to him for providing me with this opportunity. I thank him for spending his valuable time in guiding and motivating me through out the course of this dissertation. I express my sincere gratitude to Professor D. Swaroop for his immense help through out my graduate studies. I thank him for all his weekend lectures on control system theory and optimization. I thank both of them for their patience, support and understanding through out the course of this dissertation. I thank Professor Jo W. Howze and Professor John L. Junkins for kindly agreeing to be members of my dissertation committee.

I am indebted to my parents for their love and blessings. It is due to their never ending support and encouragement that I have been able to reach this position in life. I can never repay them for their sacrifices in bringing me up and allowing me to study in the United States. I feel blessed to have a loving sister, brother-in-law and nephew, and I thank them for their love and affection. I thank all my friends for their love and support. I convey my sincere appreciation to the academic and technical staff in the Department of Mechanical Engineering at Texas A\&M University for their help and assistance. 


\section{TABLE OF CONTENTS}

CHAPTER

INTRODUCTION . . . . . . . . . . . . . . . . . . . . . . . 1

A. Background and motivation ............ . . 2

B. Objectives ................... . . 6

C. Organization of this dissertation . . . . . . . . . . . 9

II A BRIEF DESCRIPTION OF THE AIR BRAKE SYSTEM . . 11

A. The train air brake system . . . . . . . . . . . . . . . 12

B. The air brake system used in commercial vehicles . . . . . 13

C. Improvements to the basic air brake system and emerging technologies . . . . . . . . . . . . . . . . . . 19

III THE EXPERIMENTAL SETUP . . . . . . . . . . . . . 23

A. Brake system components . . . . . . . . . . . . 23

B. Actuation and motion control components . . . . . . . 26

C. Sensing and data acquisition components . . . . . . . . . 28

IV A MODEL FOR PREDICTING THE PRESSURE TRANSIENTS IN THE AIR BRAKE SYSTEM . . . . . . . . . . . . . 36

A. Existing models for air brake systems . . . . . . . . . . 36

B. A model for predicting the pressure transients in the brake chamber . . . . . . . . . . . . . 38

1. Equations governing the mechanics of operation of the treadle valve . . . . . . . . . . . . 38

2. Equations governing the flow of air in the pneumatic subsystem of the brake system . . . . . . . . . 42

C. The air brake system as an example of a sequential hybrid system ................. 53

D. A brief discussion concerning controlling the pressure in the air brake system . . . . . . . . . . . 56

V DETECTION OF LEAKS IN THE AIR BRAKE SYSTEM . . . 60

A. A brief review of existing diagnostic tools for air brake systems . . . . . . . . . . . . . . 
B. A scheme for detecting leaks in air brake systems . . . . 65

C. Determination of thresholds for the detection of leaks . . . 75

VI ESTIMATION OF THE PUSH ROD STROKE . . . . . . 80

A. Effect of push rod stroke on the pressure transients . . . . 80

B. Schemes for estimating the stroke of the push rod . . . . . 84

1. Scheme 1 - Estimation of the push rod stroke by discretization of the possible range of values . . . . . . 84

2. Scheme 2 - Detection of the transition from Mode 2 to Mode $3 \ldots \ldots$. . . . . . . . . . 88

C. Effect of leaks on the estimation of the push rod stroke . . 93

VII PARAMETER ESTIMATION SCHEMES FOR A CLASS OF SEQUENTIAL HYBRID SYSTEMS . . . . . . . . . . . 97

A. The class of systems under study . . . . . . . . . 98

B. The proposed parameter estimation scheme when the transition conditions are known . . . . . . . . . . . . 100

1. Example $1 \ldots \ldots \ldots \ldots$

2. Example 2 . . . . . . . . . . . . . . . . 109

3. Example $3 \ldots \ldots \ldots \ldots$

C. The proposed parameter estimation scheme when the transition conditions are unknown . . . . . . . . . . . 115

1. Example $4 \ldots \ldots \ldots \ldots$

VIII CONCLUSIONS . . . . . . . . . . . . . . . . . . 123

A. Potential impact of this dissertation . . . . . . . . . . . 124

B. Scope of future work . . . . . . . . . . . . . . . . 124

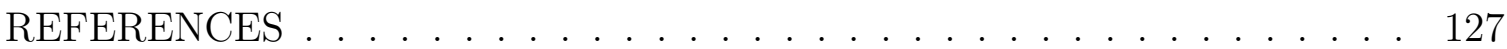

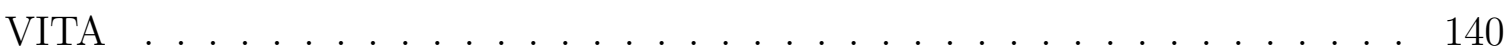




\section{LIST OF TABLES}

TABLE

I Components of the pneumatic subsystem of the air brake system . .

II Components of the mechanical subsystem of the air brake system . .

III Details of the brake system components used in the experimental setup at Texas A\&M University . . . . . . . . . . . . . . . . .

IV Details of the transducers and actuators used in the experimental setup at Texas A\&M University . . . . . . . . . . . . . . . .

V Values of the parameters used in the diagnostic schemes . . . . . . 49

VI A few commercially available diagnostic systems for air brakes . . . . 63

VII Error between the predicted and the measured steady state brake chamber pressure . . . . . . . . . . . .

VIII Comparison of the actual and the estimated push rod stroke . . . . . 91 


\section{LIST OF FIGURES}

FIGURE

Page

1 An on-board diagnostic system for air brakes . . . . . . . . . . . 9

2 Principle of operation of the train brake system . . . . . . . . . 13

3 A general layout of a tractor air brake system . . . . . . . . . . . . 14

4 The S-cam foundation brake . . . . . . . . . . . . . . . 15

$5 \quad$ A schematic of the drum brake . . . . . . . . . . . 16

6 A schematic of the experimental setup . . . . . . . . . . . . 24

$7 \quad$ A sectional view of the treadle valve . . . . . . . . . . . . . . 26

8 A layout of the treadle valve plunger position control system . . . . . 27

$9 \quad$ The air brake experimental facility at Texas A\&M University . . . . 29

10 The front axle of a typical commercial vehicle . . . . . . . . . . 30

11 The servo drive and the data acquisition system . . . . . . . . . . 31

12 The electromechanical actuator and the treadle valve . . . . . . . . 32

13 The pneumatic actuator and the treadle valve . . . . . . . . . . 33

14 Calibration curve of the rubber graduating spring . . . . . . . . . . . 40

15 The simplified pneumatic subsystem under consideration . . . . . . 43

16 The brake chamber as the control volume . . . . . . . . . . . . . 44

17 A sectional view of the brake chamber . . . . . . . . . . 45

18 Push rod stroke and brake chamber pressure at $653 \mathrm{kPa}$ (80 psig)

supply pressure . . . . . . . . . . . . . . . 46 
19 Calibration curve at $653 \mathrm{kPa}$ (80 psig) supply pressure . . . . . . . .

20 Pressure transients at $722 \mathrm{kPa}$ (90 psig) supply pressure . . . . . . 50

21 Treadle valve plunger displacement for the test run shown in Fig. $20 \quad 50$

22 Pressure and push rod stroke measurements for the test run shown in Fig. 20 . . . . . . . . . . . . . . . . . . . . . . . 51

23 The pneumatic subsystem of the air brake system modeled as a sequential hybrid system . . . . . . . . . . . . . . 55

24 A schematic representation of the control scheme . . . . . . . . 58

25 Controller response to a partial ramp to $446 \mathrm{kPa}$ (50 psig) at a supply pressure of $653 \mathrm{kPa}$ (80 psig) - repeated application . . . . . 59

26 Pressure transients at $653 \mathrm{kPa}$ (80 psig) supply pressure - partial application with leak . . . . . . . . . . . . . 67

27 Steady state treadle valve plunger displacement and brake chamber pressure at $653 \mathrm{kPa}(80 \mathrm{psig})$ supply pressure . . . . . . . . 68

28 Steady state treadle valve plunger displacement and brake chamber pressure at $722 \mathrm{kPa}$ (90 psig) supply pressure . . . . . . . . . . 68

29 Pressure transients at $653 \mathrm{kPa}$ (80 psig) supply pressure - partial application with leak . . . . . . . . . . . . . . 69

30 Pressure transients at $515 \mathrm{kPa}$ (60 psig) supply pressure - partial

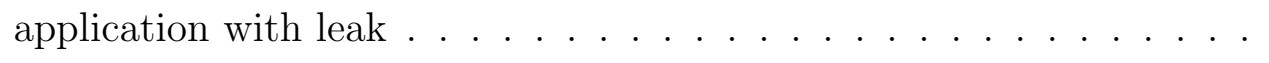

31 Pressure transients at $515 \mathrm{kPa}$ (60 psig) supply pressure - full application without leak . . . . . . . . . . . . 70

32 Pressure transients at $515 \mathrm{kPa}$ (60 psig) supply pressure - full application with leak . . . . . . . . . . . . .

33 Pressure transients at $584 \mathrm{kPa}$ (70 psig) supply pressure - full

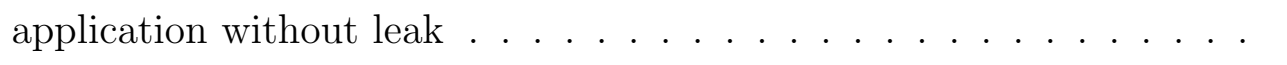


34 Pressure transients at $584 \mathrm{kPa}$ (70 psig) supply pressure - full application with leak . . . . . . . . . . . . . . . . . 72

35 Pressure transients at $653 \mathrm{kPa}$ (80 psig) supply pressure - full application without leak . . . . . . . . . . . . . . . . . 72

36 Pressure transients at $653 \mathrm{kPa}$ (80 psig) supply pressure - full application with leak . . . . . . . . . . . . . . . . . . . 73

37 Pressure transients at $722 \mathrm{kPa}$ (90 psig) supply pressure - full application without leak . . . . . . . . . . . . . . . . 73

38 Pressure transients at $722 \mathrm{kPa}$ (90 psig) supply pressure - full application with leak . . . . . . . . . . . . . 74

39 Comparison of test runs with and without leaks at $515 \mathrm{kPa}(60$ psig) supply pressure . . . . . . . . . . . . . . . . . . 76

40 Comparison of test runs with and without leaks at $584 \mathrm{kPa}(70$ psig) supply pressure . . . . . . . . . . . . . . . . . . . 77

41 Comparison of test runs with and without leaks at $653 \mathrm{kPa}(80$ psig) supply pressure . . . . . . . . . . . . . . . . . . . . . 77

42 Comparison of test runs with and without leaks at $722 \mathrm{kPa}(90$ psig) supply pressure . . . . . . . . . . . . . . . . . . . . . 78

43 Pressure transients at $515 \mathrm{kPa}$ (60 psig) supply pressure $-x_{1}=$ $0.016 \mathrm{~m}(0.63 \mathrm{in}), x_{2}=0.02398 \mathrm{~m}(0.944 \mathrm{in}) \ldots . . \ldots 81$

44 Pressure transients at $515 \mathrm{kPa}$ (60 psig) supply pressure $-x_{1}=$ $0.02324 \mathrm{~m}(0.915 \mathrm{in}), x_{2}=0.0237 \mathrm{~m}(0.933 \mathrm{in}) \ldots \ldots 2$

45 Pressure transients at $515 \mathrm{kPa}$ (60 psig) supply pressure $-x_{1}=$ $0.3505 \mathrm{~m}$ (1.38 in), $x_{2}=0.02385 \mathrm{~m}(0.939 \mathrm{in}) \ldots \ldots . . . . .$.

46 Pressure transients at $515 \mathrm{kPa}$ (60 psig) supply pressure $-x_{1}=$ $0.0479 \mathrm{~m}(1.886 \mathrm{in}), x_{2}=0.02393 \mathrm{~m}(0.942 \mathrm{in}) \ldots . . \ldots 83$

$47 \quad$ Normalized pressure residue at $653 \mathrm{kPa}$ (80 psig) supply pressure . . 
$48 \quad$ Normalized pressure residue at $722 \mathrm{kPa}$ (90 psig) supply pressure . . 89

49 Transition detection at $653 \mathrm{kPa}$ (80 psig) supply pressure . . . . . . . 92

50 Transition detection at $722 \mathrm{kPa}$ (90 psig) supply pressure . . . . . . . 92

51 Comparison of pressure transients with and without leaks at 653 $\mathrm{kPa}$ (80 psig) supply pressure . . . . . . . . . . . . 94

$52 \quad$ Plots of push rod stroke and brake chamber pressure with and without leaks at $653 \mathrm{kPa}(80 \mathrm{psig})$ supply pressure . . . . . . . . . 94

$53 \quad$ Comparison of pressure transients with and without leaks at 722 $\mathrm{kPa}(90 \mathrm{psig})$ supply pressure . . . . . . . . . . . . . . 95

54 Plots of push rod stroke and brake chamber pressure with and without leaks at $722 \mathrm{kPa}(90 \mathrm{psig})$ supply pressure . . . . . . . . . 95

55 The class of systems under study . . . . . . . . . . . . . 100

56 The proposed parameter estimation scheme . . . . . . . . . 103

57 Schematic of the system under study in Example 1 . . . . . . . 107

58 Example 1 - Estimates of the unknown parameters . . . . . . . . . 110

59 Example 1 - Plots of the output identification errors . . . . . . . . 110

60 Example 1 - Switching between the two modes . . . . . . . . . . 111

61 Example 2 - Estimates of the unknown parameters . . . . . . . 113

62 Example 2 - Plots of the output identification errors . . . . . . . 113

63 Example 3 - Estimate of the unknown parameter . . . . . . . . . 116

64 Example 3 - Plots of the output identification errors . . . . . . . 116

65 Example 4 - Estimate of the unknown parameter . . . . . . . . . 121

66 Example 4 - Plots of the output identification errors . . . . . . . . 121

67 Example 4 - Switching between the two modes . . . . . . . . . . 122 


\section{CHAPTER I}

\section{INTRODUCTION}

One of the most important systems in a vehicle that is critical for its safe operation is the brake system. A brake system must ensure the safe control of a vehicle during its normal operation and must bring the vehicle to a smooth stop within the shortest possible distance under emergency conditions [1]. It should also permit the safe operation of a vehicle while descending down a grade and also be able to hold a vehicle stationary once it comes to rest [2]. Based on these functions, brake systems are usually classified as service brakes (for normal operation), emergency brakes and parking brakes. The various components of a typical brake system are integrated such that they perform all the above mentioned functions.

An ideal brake system must be able to apply the necessary braking torque to the wheels to control the vehicle in a stable manner and at the same time dissipate the generated thermal energy efficiently. Braking action is usually achieved by the following two modes - (a). by mounting brakes on the wheels (called foundation brakes) that apply a braking torque directly on the wheels, and (b). by using brakes (called retarders) on the transmission shaft of the vehicle. The latter method has the advantage that it generates a higher braking force at the wheels when compared to the foundation brakes. But, a retarder can only provide very little braking torque at low vehicle speeds and hence they are usually used in conjunction with the foundation brakes [1].

A typical brake system can be broadly broken down into four subsystems [2]:

- a source that produces and stores the energy required for braking,

The journal model is IEEE Transactions on Automatic Control. 
- a subsystem that regulates the brake application process and thereby the amount of braking force,

- an energy transmission subsystem that transfers the energy required for braking to the brakes mounted on the axles, and

- foundation brakes mounted on the axles that apply the braking force on the wheels.

Existing brake systems typically use either brake fluid (hydraulic brakes) or compressed air (air brakes) as their energy transmitting medium. The force applied by the driver on the brake pedal regulates the brake application process and is transmitted through the energy transmitting medium to the foundation brake units mounted on the axles. Common types of foundation brakes include the disc brake and the drum brake. In this dissertation, the main focus will be restricted to air brake systems that use S-cam drum foundation brakes.

\section{A. Background and motivation}

The safety of vehicles operating on the road depends amongst other things, on a properly functioning brake system. In this dissertation, the focus will be on air brake systems which are widely used in commercial vehicles such as trucks, tractortrailer combinations and buses. ${ }^{1}$ In fact, most tractor-trailer vehicles with a Gross Vehicle Weight Rating (GVWR) ${ }^{2}$ over 19,000 lb, most single trucks with a GVWR of over 31,000 lb, most transit and inter-city buses, and about half of all school

\footnotetext{
${ }^{1}$ We shall follow the definition of a commercial vehicle as provided in the Federal Motor Carrier Safety Regulations (FMSCR) Part 390 [3] released by the Federal Motor Carrier Safety Administration (FMCSA).

${ }^{2}$ Refer to [3] for the definition of this term.
} 
buses are equipped with air brake systems [4]. It has been well established that one of the main factors that increases the risk of accidents involving commercial vehicles is an improperly maintained brake system. For example, a report published in 2002 [5] points out that brake problems have been observed in approximately $31.4 \%$ of the heavy trucks involved in fatal accidents in the state of Michigan. In roadside inspections performed between October 1996 and September 1999, 29.3 \% of all the vehicle-related violations among Intrastate carriers and $37.2 \%$ of those among Interstate carriers have resulted due to defects in the brake system [6]. As a result of its large size and mass, an accident involving a commercial vehicle is also very dangerous to the occupants of other vehicles on the road. In fact, it has been pointed out as early as in 1972 that approximately $63 \%$ of the fatalities in accidents involving interstate trucks were occupants of passenger cars [7]. It has been reported in [8] that nearly $77.5 \%$ of the fatalities in accidents involving trucks in 2002 were occupants of other vehicles.

The air brake system currently found in commercial vehicles is made up of two subsystems - the pneumatic subsystem and the mechanical subsystem. The pneumatic subsystem includes the compressor, storage reservoirs, treadle valve (or the brake application valve), brake lines, relay valves, quick release valve, brake chambers, etc. The mechanical subsystem starts from the brake chambers and includes push rods, slack adjusters, S-cams, brake pads and brake drums. Thus, the compressor serves as the source of energy in the air brake system by providing a supply of compressed air which is stored in the storage reservoirs. The treadle valve is used by the driver to regulate the brake application process and compressed air serves as the energy transmitting medium.

One of the most important differences between a hydraulic brake system (found in passenger cars) and an air brake system is in their mode of operation. In a hydraulic 
brake system, the force applied by the driver on the brake pedal is transmitted through the brake fluid to the wheel cylinders mounted on the axles. The driver obtains a sensory feedback in the form of a pressure on his / her foot. If there is a leak in the hydraulic brake system, this pressure will decrease and the driver can detect it through the relatively easy motion of the brake pedal. In an air brake system, the application of the brake pedal by the driver meters out compressed air from a supply reservoir to the brake chambers. The force applied by the driver on the brake pedal is utilized in opening certain ports in the treadle valve and is not used to pressurize air in the brake system. This leads to a lack of variation in the sensory feedback to the driver in the case of leaks, worn brake pads and other defects in the brake system. Another difference between the two braking systems is in the distribution of the braking force between the various axles. In passenger vehicles, the load distribution on the axles varies slightly whereas in commercial vehicles the distribution of the load on the various axles varies significantly depending on whether the vehicle is loaded or unloaded. Typically, commercial vehicle brakes are designed and balanced for the fully loaded condition and this results in excessive braking on some axles when the vehicle is not fully loaded [9]. This problem is compounded by the fact that the U.S. regulations, unlike the European standards, do not directly specify brake force distribution between the various axles [10].

Air brake systems found in commercial vehicles are very sensitive to maintenance. Their performance can degrade significantly in the absence of periodic inspection and maintenance [9]. As a result, periodic maintenance inspections are performed by fleet owners and roadside enforcement inspections are carried out by state and federal inspection teams. The performance of brakes in newly manufactured commercial vehicles in the United States is specified by the Federal Motor Vehicle Safety Standard (FMVSS) 121 [11]. The braking performance of "on-the-road" commercial 
vehicles is governed by the Federal Motor Carrier Safety Regulation (FMCSR) Part 393 [12]. These regulations specify the stopping distance, deceleration and brake force that should be achieved when the vehicle is braked from an initial speed of $20 \mathrm{mph}$. Due to the difficulty in carrying out such tests on the road, equivalent methods have been developed to inspect the brake system. A chronology of the development of the various commercial vehicle brake testing procedures used in the United States can be found in [13].

Inspection techniques that are currently used to monitor the air brake system can be broadly divided into two categories - "visual inspections" and "performance-based inspections" [14]. Visual inspections include observing the stroke of the push rod, thickness of the brake linings, checking for wear in other components and detecting leaks in the brake system through aural and tactile means. They are subjective, timeconsuming and difficult on vehicles with a low ground clearance since an inspector has to go underneath a vehicle to check the brake system. Performance-based inspections involve the measurement of the braking force / torque, stopping distance, brake pad temperature, etc. A description of two performance-based brake testers - the roller dynamometer brake tester and the flat plate brake tester, and the associated failure criteria when an air brake system is tested with them can be found in [15]. It is appropriate to point out that, in an appraisal of the future needs of the trucking industry [16], the authors, who represent a broad spectrum of the trucking industry, call for the development of improved methods of brake inspections. 


\section{B. Objectives}

In this dissertation, model-based diagnostic schemes for detecting leaks and "out-ofadjustment" 3 of push rods in the air brake system are presented. The presence of leaks and the push rods being out-of-adjustment are two prominent defects that cause a degradation in the performance of the brake system. Leaks in the brake system are caused due to the rupture of the brake chamber diaphragm, defects in the brake chamber clamps, hoses, couplings, valves, etc. The stroke of the push rod increases due to wear of the brake linings, heating of the brake drum, etc.

Detection of leaks is crucial to ensure the proper functioning of the air brake system. The response of the brake system will be slower in the presence of a leak (i.e., the "lag-time" will be increased) and also the resulting braking force generated will be lower. These will in turn lead to increased stopping distances. The presence of leaks will lead to an increased air consumption in the brake system. The compressor will be required to do more work than normal in order to maintain the supply pressure in the reservoirs in the presence of a leak and this will lead to faster wear of the compressor and related components. These considerations become important when the brakes are frequently applied, for example, when the vehicle is traveling down a grade, in city traffic, etc.

The stroke of the push rod has to be maintained within a certain limit for the proper operation of the brake system. The fact that the brake force / torque output, and hence the brake system performance, deteriorates rapidly when the push rod stroke exceeds a certain length (usually referred to as the "readjustment limit") has been well established and reported by many authors [15], [17], [18], [19], [20]. The

\footnotetext{
${ }^{3} \mathrm{~A}$ push rod is said to be in "out-of-adjustment" when its stroke exceeds a certain length.
} 
stroke of the push rod is one of the main performance criteria employed by the inspection teams to evaluate the condition of the brake system. Excessive push rod stroke has been found to be a major cause for brake-related violations and vehicles with their push rod strokes above the regulated limit will be placed out of service [14]. In fact, during roadside inspections carried out by the National Transportation Safety Board (NTSB) in 1990, $44 \%$ of the vehicles were placed out of service due to improper adjustment of the push rods [21]. In a safety study carried out by the NTSB in 1988 [22], it was determined that brakes being out-of-adjustment to be one of the most prevalent safety issues in accidents involving heavy trucks with brake problems. Thus, one can realize the importance of the push rod stroke as an indicator of the performance of the air brake system.

Motivated by these issues, preliminary model-based diagnostic schemes have been developed that detect leaks and push rod out-of-adjustment in a reliable manner. An experimentally corroborated "fault-free" model that predicts the pressure transients in the brake chamber of the air brake system has been developed and reported in [23]. This model relates the pressure transients in the brake chamber with the treadle valve plunger displacement and the pressure of air supplied to the treadle valve. The proposed diagnostic schemes utilize pressure measurements and predictions of this model in order to monitor the brake system for the defects mentioned above. The guideline issued by the Federal Motor Carrier Safety Administration (FMCSA) to check for the push rod stroke [24] states that "Stroke shall be measured with engine off and reservoir pressure of 80 to 90 psi with brakes fully applied." It also specifies the readjustment limits for various types of brake chambers. The diagnostic schemes have been developed to conform to these regulations. Such an inspection procedure is also recommended in air brake maintenance manuals [25].

The long-term objective of the research project that led to this dissertation is to 
integrate these diagnostic schemes into a portable diagnostic tool that can be used to monitor the performance of the air brake system and help in automating the brake inspection process. Such a diagnostic tool can be used for preventive maintenance inspections by fleet owners and drivers, and also for enforcement inspections by state and federal inspection teams. Current brake inspection methods require an inspector to get underneath the vehicle and check for push rod stroke, brake pad wear, leaks, etc. Such a diagnostic tool will speed up the brake inspection process since, according to [26], the average time required for a typical current roadside inspection of a commercial vehicle is 30 minutes, with approximately half of the time spent on brakes. A reduction in the inspection time will result in reduced lead times of the vehicles and also smaller lines at the roadside inspection stations. Also, the fleet operators can ensure that the brake system of their vehicles meet the required standards and thus reduce the risk of their vehicles being put out of service. Defects in the brake system can be identified and corrected immediately. An accident involving a commercial vehicle often results in the irreplaceable loss of life and is also monetarily expensive in terms of loss of property. It is reported in [8] that, between the years 1998-2002, an average of 5530 fatalities have occurred every year in the United States due to accidents involving commercial vehicles. In 2002, the average cost of an accident involving large trucks was reported to be approximately $\$ 59,153$ [27]. Also, commercial vehicle accidents will have a negative impact on the economy since they constitute the single largest mode (in terms of monetary value) for transporting commodities in the United States [28]. If the commercial vehicle involved in an accident is transporting hazardous materials the environmental impact would be tremendous and there will be huge clean-up costs associated with it. A well maintained and diagnosed brake system will reduce the chances of occurrence of such accidents. Given the rapid improvements in the field of communication technology it can be envisioned that, in 
the near future an on-board diagnostic system may be used to remotely communicate the status of the brake system to inspection stations in addition to providing the same information to the driver, thereby facilitating real-time monitoring of vehicles on roadways (see Fig. 1).

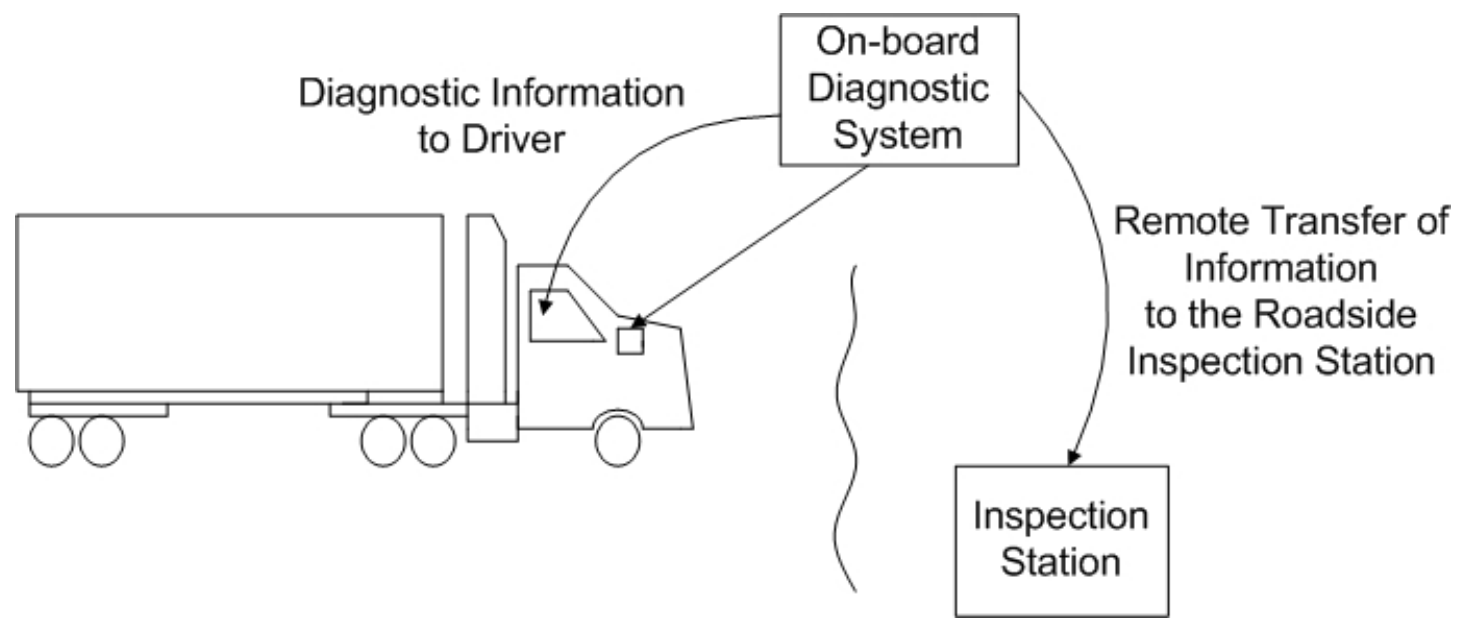

Fig. 1. An on-board diagnostic system for air brakes

\section{Organization of this dissertation}

A brief description of the air brake system currently used in commercial vehicles in the United States will be provided in chapter II. The experimental facility constructed at Texas A\&M University for testing air brake systems will be presented in chapter III. The details of the equipment used in the experimental setup will be provided in this chapter. A model for predicting the pressure transients in a brake chamber during the brake application process using the measurements of the treadle valve plunger displacement and the supply pressure to the treadle valve will be derived in chapter IV. In chapter V, a brief review of existing diagnostic tools for air brakes will be presented and a scheme for automatically detecting leaks in the brake system 
will be outlined. This scheme will be corroborated with experimental data and a preliminary method for selecting thresholds for leak detection will be presented. Two schemes for estimating the stroke of the push rod using the model for the pressure transients in the brake chamber will be described in chapter VI. These schemes will be corroborated with experimental data. Parameter estimation schemes for a class of sequential hybrid systems will be developed in chapter VII and their performance will be illustrated with examples. Chapter VIII presents concluding remarks and possible scope for future work. 


\section{CHAPTER II}

\section{A BRIEF DESCRIPTION OF THE AIR BRAKE SYSTEM}

Many mechanical systems have used and are using compressed air as their energy transmitting medium. Compressed air is being employed in a wide spectrum of applications including - machine shop tools (such as drills, impact wrenches, grinders, screwdrivers, tappers, nut runners, riveters, sand rammers, etc.), contractors' tools ${ }^{1}$ (such as road / pavement breakers and rock drills), mining and quarrying equipment, air motors, material handling equipment (such as hoists, wrenches, cranes, conveyors, agitators, etc.), paint spraying, marine applications, pneumatic actuators, etc. [29]. One of the major applications of compressed air in the field of transportation has been in the development of the air brake system.

In the United States railway industry, air brake systems were initially introduced during the nineteenth century. Before the introduction of the air brake system, railway cars were retarded mainly by mechanical means (for example, by levers, chains and other linkages) and were hand-operated by brakemen usually through the rotation of a handwheel [30]. A variety of alternate braking systems were developed by many individuals, but the first practically applicable air brake system was developed by George Westinghouse when he introduced his "Straight Air Brake" in 1869 [31], [32]. Interesting accounts of this invention of Westinghouse and his further improvements and additions to the air brake system can be found in [33] and [34]. A detailed description of the evolution of the air brake system including the early mechanical brakes, vacuum brakes and finally the air brake system can be found in [35]. A review of various issues with these early train air brake systems can be found in [36].

\footnotetext{
${ }^{1}$ usually refers to equipments used in construction sites that are powered by compressed air.
} 
A discussion of the development of different types of brakes including air brakes can be found in [37].

Before providing a detailed description of the air brake system that is currently used in commercial vehicles, a brief description of the air brake system used in trains is presented.

\section{A. The train air brake system}

The basic principle of operation of the air brake system used in trains in the United States is as follows (refer to Fig 2). When the locomotive is started, air is compressed and stored in storage reservoirs. Compressed air is also transferred through air hoses to the reservoirs located in each car. A valve referred to as the triple valve is mounted in each car and acts a relay valve in actuating the foundation brakes when the brake is applied. The main brake line is also filled with compressed air. When the driver applies the brake, he / she essentially decreases the pressure of air in the main brake line and this action opens a port in the triple valve. Then, air flows from the car's reservoir to the brake cylinder through this port. The amount of pressure in the foundation brake unit (and consequently the braking force) depends on the amount of pressure reduction in the main brake line. When the brake is released by the driver, the pressure of air in the main brake line is increased to its original value. This action opens up the exhaust port in the triple valve and the air from the brake cylinder is vented to the atmosphere. A detailed discussion of the air brake system used in trains can be found in [38]. 


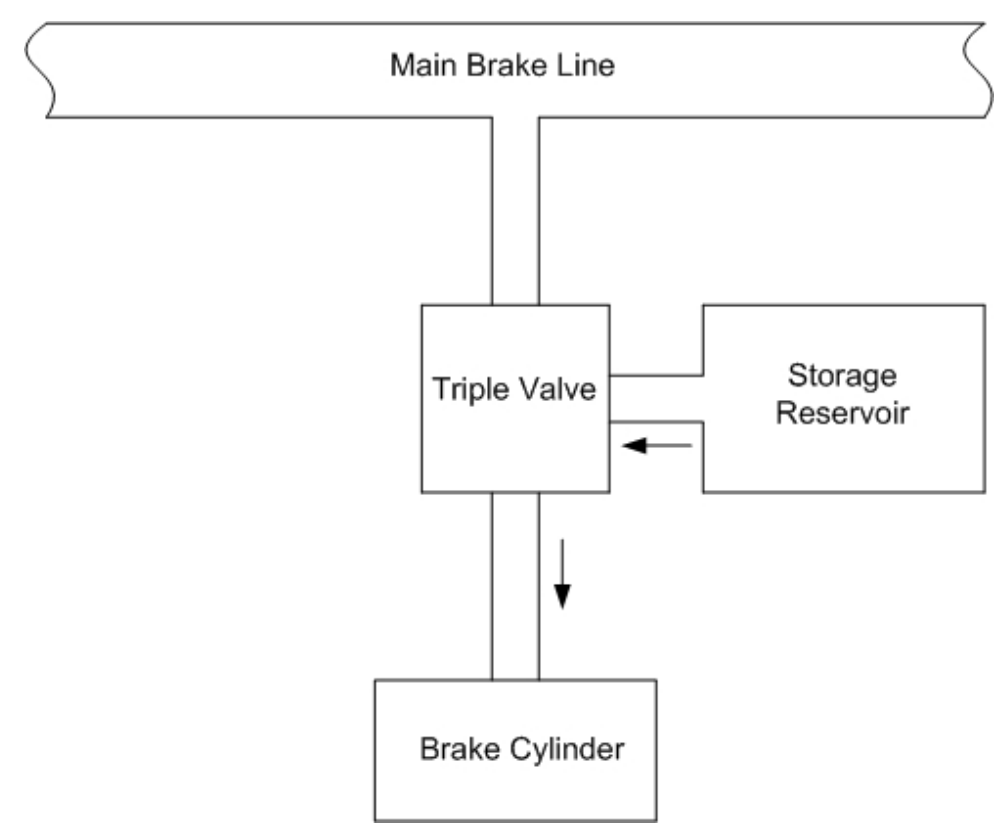

Fig. 2. Principle of operation of the train brake system

B. The air brake system used in commercial vehicles

The wide use of air brake systems in commercial vehicles started mainly in the early twentieth century. One of the earliest air brake systems for trucks was developed by George Lane in 1919 [39]. The initial air brake system consisted of storage reservoirs, control valves and brake chambers. As time progressed, the design of the air brake system underwent modifications to include several features such as foot-operated treadle valves, relay valves, spring brake chambers, tractor protection valves and many more [39], [40]. A description of the modern air brake system including its various components and their functioning can be found in [39].

A layout of the air brake system currently found in a typical tractor of a tractortrailer combination is presented in Fig. 3. Compressed air is provided by an enginedriven compressor and is collected in storage reservoirs. A governor serves to control the pressure of the compressed air stored in the reservoirs. The pressure of air in 
the storage reservoirs is typically maintained between $790.9 \mathrm{kPa}(100 \mathrm{psig})$ and 997.7 $\mathrm{kPa}$ (130 psig). Compressed air is supplied from these reservoirs to the treadle and relay valves. The driver applies the brake by pressing the brake pedal mounted on the treadle valve. This action meters the compressed air from the supply ports of the treadle valve to its delivery ports from where it travels through hoses to the brake chambers mounted on the axles.

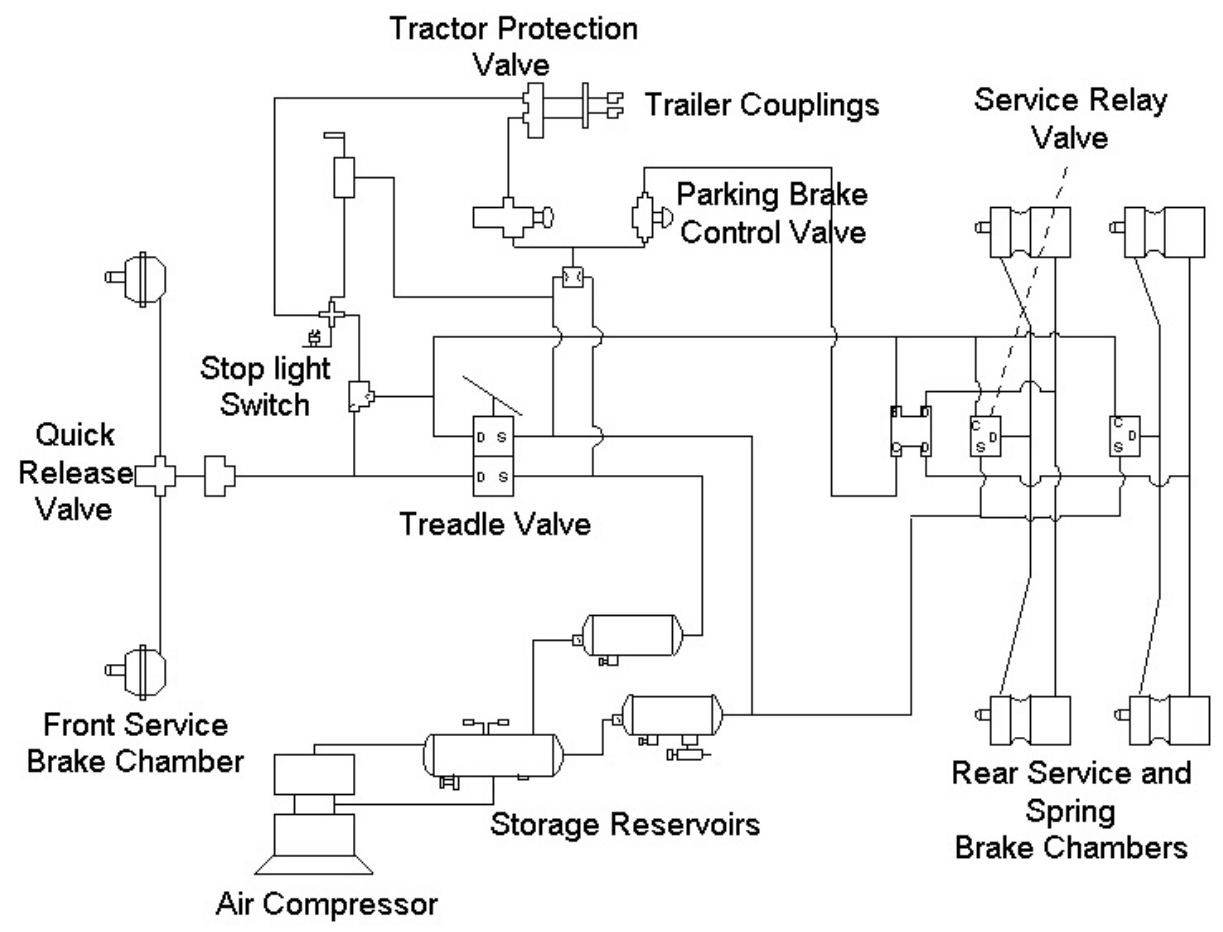

Fig. 3. A general layout of a tractor air brake system

The S-cam foundation brake, found in more than $85 \%$ of the air-braked vehicles in the United States [4], is shown in Fig. 4. Compressed air from the treadle valve enters the brake chamber and acts against the diaphragm generating a force resulting in the motion of the push rod. The motion of the push rod serves to rotate, through the slack adjuster, a splined shaft on which a cam in the shape of an ' $\mathrm{S}$ ' is mounted. 
The ends of two brake shoes rest on the profile of the S-cam and the rotation of the S-cam pushes the brake shoes outwards so that the brake pads make contact with the rotating drum. This action results in the deceleration of the rotating drum. When the brake pedal is released by the driver, air is exhausted from the brake chamber to the atmosphere causing the push rod to stroke back into the brake chamber and the S-cam now rotates in the opposite direction. The contact between the brake pads and the drum is now broken and the brake is thus released. A schematic of a drum brake is presented in Fig. 5 .

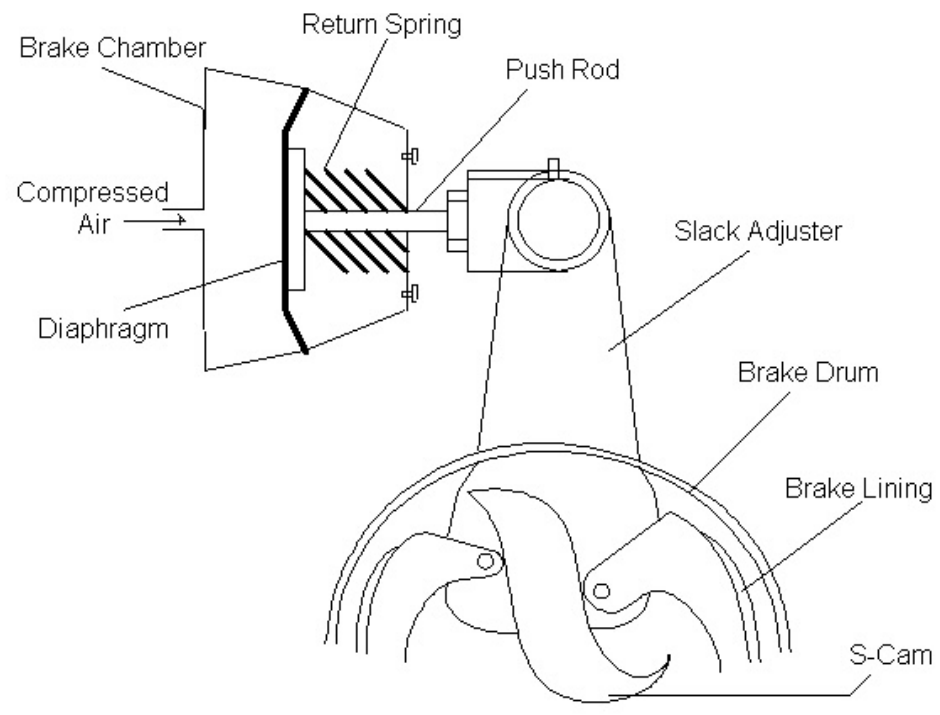

Fig. 4. The S-cam foundation brake

Some of the components of the typical air brake system used in commercial vehicles are briefly described below:

1. Compressor and storage reservoirs: The compressor is the energy source for the air brake system. Pressurized air from the compressor is stored in the storage reservoirs. The air from the compressor is allowed to cool down in 


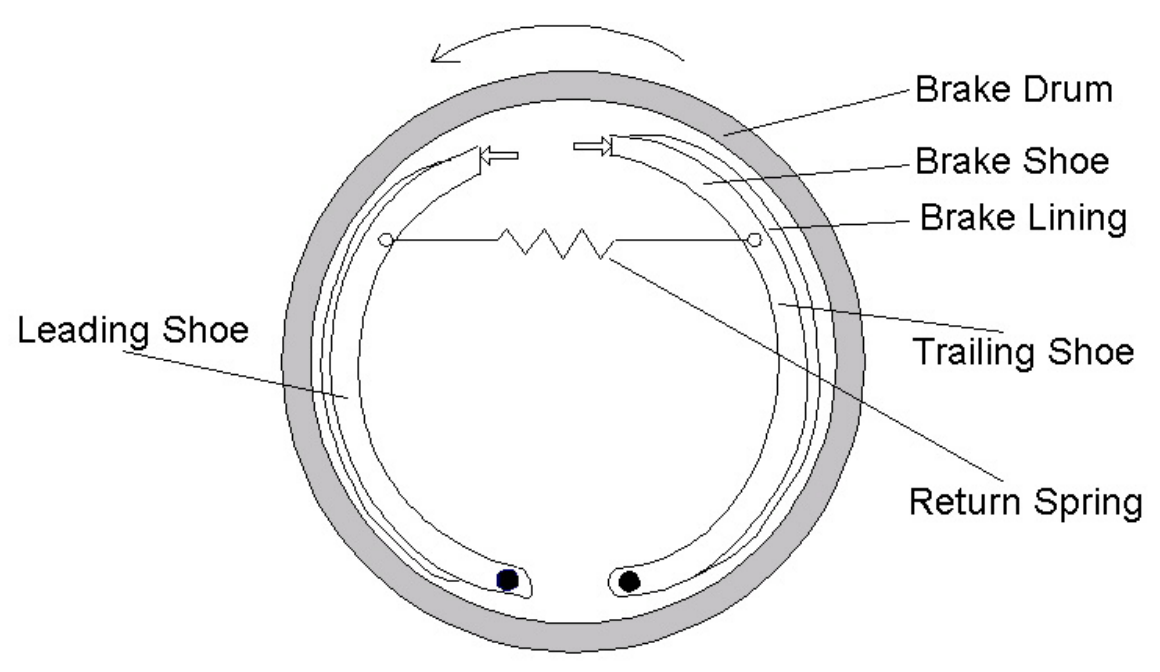

Fig. 5. A schematic of the drum brake

the storage reservoirs. The pressurized air also might have some moisture and contaminants (such as oil and dust) and these are collected at the bottom of the storage reservoirs as it cools down. They are expunged from the reservoirs by the automatic drain valve. The storage reservoirs also have safety valves that exhaust air from them in the event of an uncontrolled pressure build-up (for example, the pressure may increase to dangerous limits when the governor fails to operate). A low pressure air switch warns the driver when the pressure in the reservoirs falls to around $549.5 \mathrm{kPa}$ (65 psig).

2. Treadle valve: The treadle valve (brake application valve) modulates the amount of air supplied to the brake chambers from the storage reservoirs. Since the mid 1970's, federal regulations require the use of dual circuit application valves for all heavy commercial vehicles. The advantage of a dual circuit treadle valve is that partial braking is still possible in the event of failure of one of the two circuits. The typical treadle valve used in air brake systems has a primary circuit and a secondary circuit. The primary circuit is actuated via pedal force 
and it provides compressed air to the brakes mounted on the rear axles of a tractor and the secondary circuit acts like a relay valve in the sense that the air delivered by the primary circuit is used to actuate it. The secondary circuit provides air to the brake chambers on the front axle and in the event of failure of the primary circuit, it is actuated directly by pedal force.

3. Quick release valve and relay valve: A quick release valve is mounted on the front axle of the tractor and the air from the secondary circuit of the treadle valve passes through it en route to the two front brake chambers. It facilitates the quick exhaust of the air from the front brake chambers when the brake pedal is released by the driver. A relay valve (referred to as a service relay valve in Fig. 3) is mounted on the rear axles and obtains compressed air supply from the storage reservoirs. The air from the primary circuit of the treadle valve enters the control port of the relay valve and this action meters out compressed air to the rear brake chambers. The relay valve also helps in the quick exhaust of air from the rear brake chambers when the brake pedal is released by the driver.

4. Brake chambers: The brake chambers convert the energy from the pressurized air into a mechanical force that displaces the push rod which in turn actuates the foundation brakes. The push rod is used to rotate the S-cam (through the slack adjuster) which in turn pushes the brake pads against the rotating drum. A combination service brake / spring brake chamber mounted on the rear axles functions as a service / emergency / parking brake. It has two chambers - one of which acts as a normal service brake chamber and the other chamber is always filled with pressurized air to hold back a power spring in a compressed state. In the case of brake system failure or when the parking brakes are applied, this chamber is drained out and the compressed power spring then pushes the 
push rod thereby applying the brake. The specification of the brake chamber is usually given in terms of its effective cross-sectional area. For example, a "Type 20" brake chamber has a cross-sectional area of $20 \mathrm{in}^{2}$. Type 20 brake chambers are usually used on the front axle and "Type 30" brake chambers are usually used on the rear axles of a commercial vehicle.

5. Automatic slack adjuster: A slack adjuster converts a translational motion of the push rod into a rotation of the S-cam shaft. The output force from the brake chambers decreases rapidly when the push rod stroke exceeds the re-adjustment limit. Also, all the brakes in a tractor-trailer combination vehicle have to be in proper adjustment relative to each other so that the net braking effort is shared proportionally between all of them. Before the advent of automatic slack adjusters, the brakes had to be manually adjusted by rotating an adjusting nut which in turn rotated the S-cam through a worm shaft. During the late 1970's the use of automatic slack adjusters started and today their use is mandatory in all commercial vehicles. An automatic slack adjuster transmits the braking force from the push rod to the S-cam and also adjusts the brakes when the linings wear out and / or the drum expands (which results in an increased clearance between the brake pads and the brake drum).

6. Foundation brakes: These units are mounted on the axles and they act on the rotating wheels thereby retarding the motion of the vehicle. Commercial vehicles in the United States commonly use S-cam drum foundation brakes, whereas in Europe disc brakes are slowly replacing drum brakes [39]. Disc brakes offer lower sensitivity of the brake torque to the brake pad friction coefficient, better fade resistance and improved brake efficiency when compared to drum brakes. Their main limitation is the absence of "self-energization" [39] (this term 
refers to the augmentation of the moment due to the actuation force acting on the brake pad by the moment due to the friction force acting on the brake pad) available in drum brakes resulting in the need for higher actuation air pressures when compared to drum brakes. Comparisons between the performance of drum and disc brakes can be found in [41], [42] and [43].

The above discussion presented a brief description of a few critical components of the air brake system currently used in commercial vehicles. For a more detailed description, the interested reader is referred to [39], [44] and [45]. A list of components of the pneumatic subsystem and the mechanical subsystem is presented in Table I and Table II respectively.

C. Improvements to the basic air brake system and emerging technologies

A description of the various components of the basic air brake system was presented in the previous section. One of the most important improvements made to the air brake system is the introduction of the Antilock Brake System (ABS). As the name suggests this system prevents the wheels of a commercial vehicle from locking up (a wheel is said to have locked up if it has stopped rotating when the vehicle is still in motion) during the process of braking and thus improving the stability of the braking process. The locking up of wheels on the front axle of a tractor-trailer combination will result in the loss of steering control; the locking up of wheels on the rear axles of a tractor may result in jackknifing; and the locking up of the wheels on the trailer axles will result in trailer swing [39], [46]. Every single unit truck manufactured on or after March 1, 1998 and every tractor manufactured after March 1, 1997 must have an antilock brake system installed on them [11].

A typical ABS utilizes the measurement of wheel speeds and decreases the pres- 
Table I. Components of the pneumatic subsystem of the air brake system

\begin{tabular}{|c|c|}
\hline Component & Description \\
\hline Compressor & Acts as the energy source providing compressed air. \\
\hline $\begin{array}{l}\text { Storage reser- } \\
\text { voirs }\end{array}$ & $\begin{array}{l}\text { Store the compressed air and supply it to the treadle and relay } \\
\text { valves. }\end{array}$ \\
\hline Safety valve & Prevents an excessive pressure build-up in the storage reservoirs. \\
\hline Drain valve & $\begin{array}{l}\text { Removes moisture and contaminants from the air stored in the } \\
\text { reservoirs. }\end{array}$ \\
\hline $\begin{array}{l}\text { Low air pres- } \\
\text { sure switch }\end{array}$ & $\begin{array}{l}\text { Warns the driver when the pressure in the reservoirs falls to } \\
\text { around } 65 \text { psig. }\end{array}$ \\
\hline Treadle valve & $\begin{array}{l}\text { Modulates the amount of air being supplied to the brake cham- } \\
\text { bers. }\end{array}$ \\
\hline $\begin{array}{l}\text { Quick release } \\
\text { valve }\end{array}$ & Releases the front brakes quickly. \\
\hline Relay valve & Regulates the brakes on the rear axles. \\
\hline $\begin{array}{l}\text { Parking brake } \\
\text { control valve }\end{array}$ & $\begin{array}{l}\text { Located in the driver's cab and is used to apply the parking } \\
\text { brakes. }\end{array}$ \\
\hline $\begin{array}{l}\text { Tractor pro- } \\
\text { tection valve }\end{array}$ & $\begin{array}{l}\text { Protects the tractor brake system in the case of trailer break- } \\
\text { away and / or when there are severe leakages in the brake sys- } \\
\text { tem. }\end{array}$ \\
\hline $\begin{array}{l}\text { Trailer brake } \\
\text { control valve }\end{array}$ & $\begin{array}{l}\text { Actuates the trailer brakes independent of the tractor brakes } \\
\text { and is applied by the driver. }\end{array}$ \\
\hline
\end{tabular}


Table II. Components of the mechanical subsystem of the air brake system

\begin{tabular}{|l|l|}
\hline Component & Description \\
\hline Brake chamber & $\begin{array}{l}\text { Converts the energy provided by the compressed air into } \\
\text { a mechanical force. }\end{array}$ \\
\hline Push rod & $\begin{array}{l}\text { Connected to the brake chamber diaphragm and trans- } \\
\text { mits the force to the slack adjuster. }\end{array}$ \\
\hline $\begin{array}{l}\text { Automatic slack ad- } \\
\text { juster }\end{array}$ & $\begin{array}{l}\text { Converts the translational motion of the push rod into a } \\
\text { rotation of the S-cam. }\end{array}$ \\
\hline S-cam & $\begin{array}{l}\text { Moves the brake pads during brake application and } \\
\text { presses them against the brake drum. }\end{array}$ \\
\hline
\end{tabular}

sure of air in the brake chambers if it senses an impending wheel lock up. The main components of an ABS used in commercial vehicle include wheel speed sensors, an electronic control unit to process the information from these sensors and modulator valves that regulate the pressure in the brake chamber in the event of an impending wheel lock up [39]. Detailed descriptions of ABS and various layouts of the same can be found in [39], [44], [47], [48].

One of the emerging technologies for air brake systems is the Electronic Braking System (EBS). An EBS generates an electric signal when the driver presses the brake pedal and this electric signal is then provided to electro-pneumatic actuators that are mounted near the foundation brakes. These actuators regulate the pressure of air in the brake chambers in proportion to the magnitude of the electric signal received by them [39]. It should be noted that the foundation brakes are still actuated by compressed air. But the control signal to the relay valve is now an electric signal and this leads to a reduction in both the number of pneumatic components and the time 
lag between the brake pedal motion and the build up of pressure in the brake chamber that exist in current air brake systems. This would lead to faster response times and shorter stopping distances when compared with existing air brake systems [49], [50]. Also, an EBS results in an improved compatibility between the brakes on a tractor and trailer since an electric signal is used to modulate the pressure in all the brake chambers [49], [51]. If EBS is to be provided on existing commercial vehicles, it has to be installed as a "redundant" system on top of the existing air brake system since current regulations still require the existence of a complete air brake system [39]. 


\section{CHAPTER III}

\section{THE EXPERIMENTAL SETUP}

An experimental setup has been constructed at Texas A\&M University that mirrors the actual air brake system currently used in commercial vehicles. A schematic of this experimental setup is presented in Fig. 6. The various components of the experimental setup can be broadly classified under three categories - brake system components, actuation and motion control components and sensing and data acquisition components. A brief description of each of these three categories is provided in this chapter.

\section{A. Brake system components}

Two "Type-20" brake chambers (having an effective cross-sectional area of $20 \mathrm{in}^{2}$ ) are mounted on a front axle of a tractor and two "Type-30" brake chambers (having an effective cross-sectional area of $30 \mathrm{in}^{2}$ ) are mounted on a fixture designed to simulate the rear axle of a tractor. The air supply to the two circuits of the brake system is provided by means of two compressors and storage reservoirs. The reservoirs are chosen such that their volume is more than twelve times the volume of the brake chambers that they provide to, as required by FMVSS 121 [11], [52]. Pressure regulators are mounted at the delivery ports of the reservoirs to control the supply pressure to the treadle valve.

A cross-sectional view of the treadle valve used in the experiments is illustrated in Fig. 7. The treadle valve consists of two circuits - the primary circuit and the secondary circuit. The primary circuit is actuated by the force applied by the driver on the brake pedal and the secondary circuit acts essentially as a relay valve. Under normal operating conditions, pressurized air delivered by the primary circuit is used 


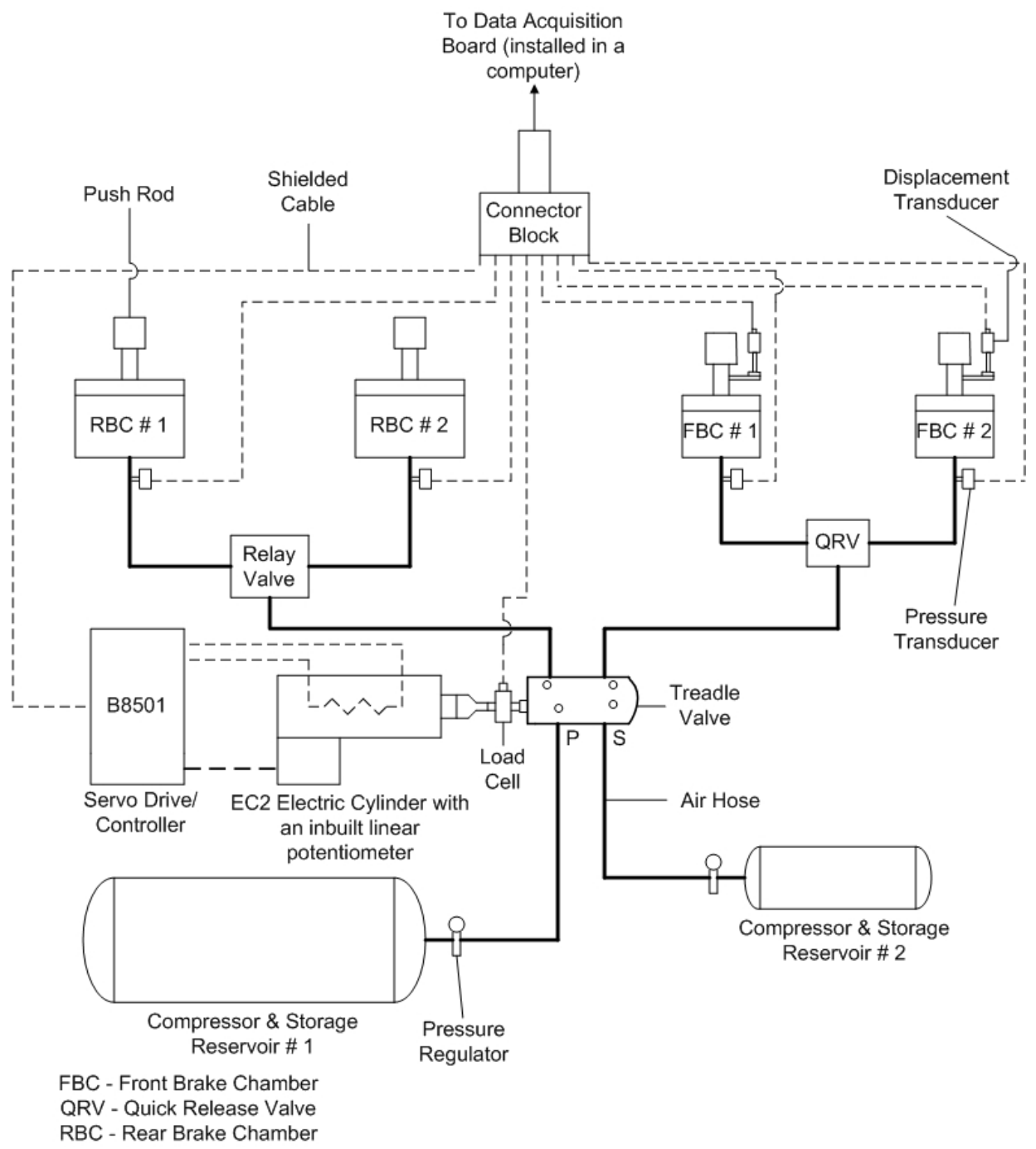

Fig. 6. A schematic of the experimental setup 
to actuate a relay piston which in turn actuates the secondary circuit. When the primary circuit fails, the secondary circuit is actuated directly by pedal force. When the brake pedal is applied, the primary piston first closes the primary exhaust port and then opens the primary inlet valve (when $x_{p p}>x_{p t}$ ). This phase is called the "apply phase". When the pressure of air at the primary delivery port increases to a level where it balances the pedal input force, the primary inlet valve is closed with the primary exhaust port also remaining closed (when $x_{p p}=x_{p t}$ ). This phase is called the "balance or the hold phase". When the pedal is released, so is the balancing force on the primary piston, which causes the primary piston to lift off from the primary exhaust seat and the air in the primary delivery circuit is exhausted to the atmosphere thereby releasing the brakes (when $x_{p p}<x_{p t}$ ). This phase is referred to as the "exhaust phase". The secondary circuit functions in a similar manner except for the fact that the relay piston is actuated by the pressurized air from the primary circuit under normal operating conditions.

The delivery port of the primary circuit is connected to the control port of the relay valve and the delivery ports of the relay valve are connected to the two rear brake chambers. The relay valve has a separate port for obtaining compressed air supply from the reservoir. The delivery port of the secondary circuit is connected to the Quick Release Valve (QRV) and the delivery ports of the QRV are connected to the two front brake chambers. It is interesting to note that prior to the 1980's, drivers used to disconnect the front wheel brakes of their vehicle in order to obtain better control during braking. But subsequently tremendous improvements have been made in the design of the vehicle and a federal law passed in January 1987 requires that the brakes be operational on all the wheels of a commercial vehicle [53]. 


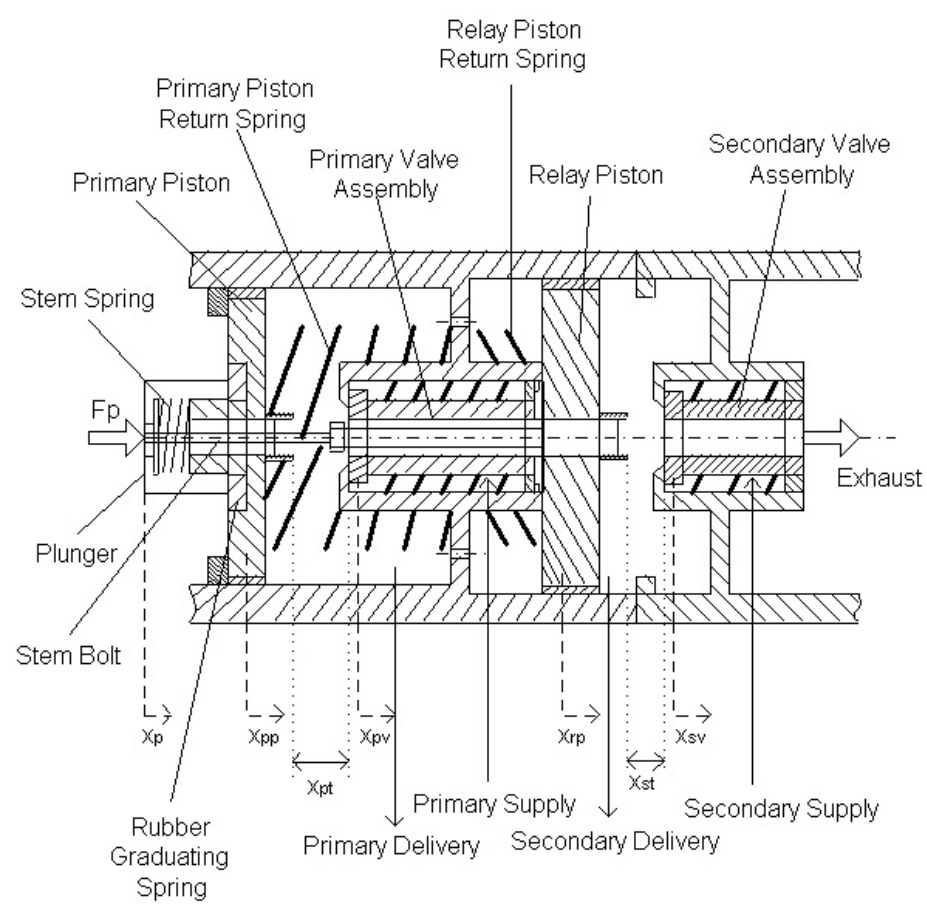

Fig. 7. A sectional view of the treadle valve

B. Actuation and motion control components

The treadle valve in the brake system is actuated by displacing the treadle valve plunger. During the initial phases of developing the experimental setup, this actuation was carried out by means of a pneumatic actuator. The pneumatic actuator received compressed air supply from one of the storage reservoirs and the pressure of air provided to the pneumatic actuator was regulated by means of a separate pressure regulator. In the current experimental setup, the actuation of the treadle valve plunger is carried out by means of an electromechanical actuator that is part of a custom designed automated position control system. A layout of this system is presented in Fig. 8.

This closed loop position feedback control system is used to regulate the displacement of the treadle valve plunger. An EC2 electric cylinder (mounted with a 


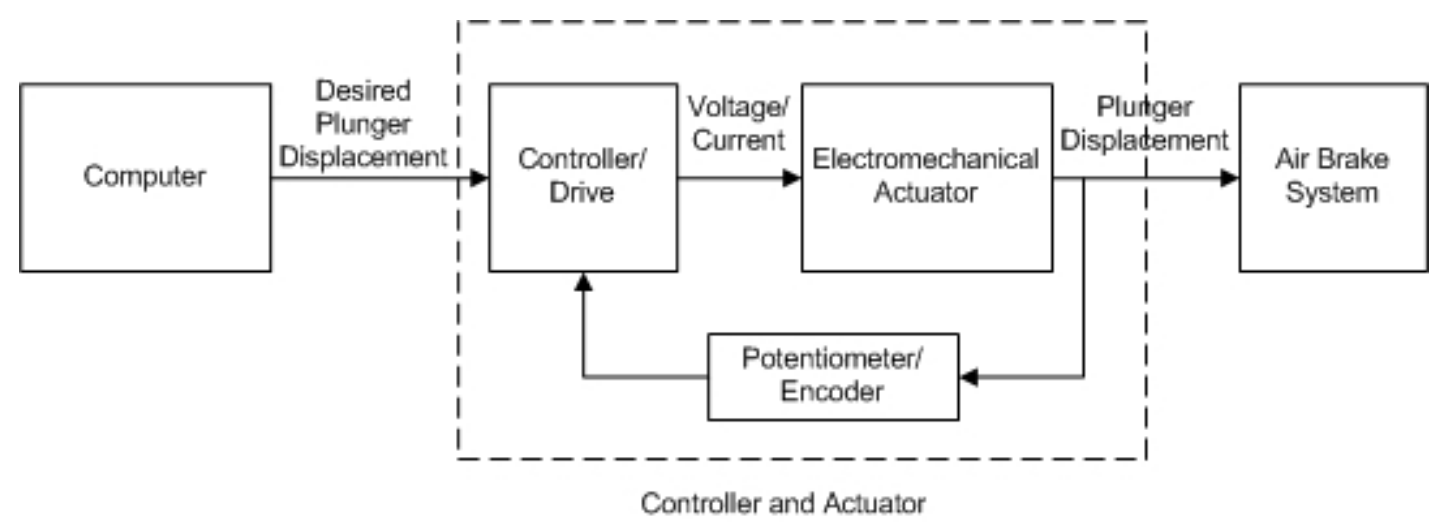

Fig. 8. A layout of the treadle valve plunger position control system

B23 brushless servo motor) manufactured by Industrial Devices Corporation (IDC) / Danaher Motion is used for actuation [54]. The actuator shaft is interfaced with the servo motor through a belt drive and lead screw assembly. The actuator is controlled by a B8501 Servo Drive / Controller [55], [56]. A linear potentiometer is inbuilt in the electric cylinder and its output is provided to the servo drive. The servo drive also receives a feedback signal from an encoder mounted on the motor shaft to regulate the torque input to the motor. The desired plunger motion trajectory is provided from the computer to the servo drive through the analog output channel of a Data Acquisition (DAQ) board. The servo drive compares the difference between the desired displacement and the measurement from the linear potentiometer at each instant in time and provides the suitable control input to the actuator. The position control system is tuned to obtain the desired performance using IDC's Servo Tuner software program [57]. A general overview of the processes of design and implementation of motion control systems can be found in [58]. 


\section{Sensing and data acquisition components}

A pressure transducer is mounted at the entrance of each of the four brake chambers by means of a custom designed and fabricated pitot tube fixture. A displacement transducer is mounted on each of the two front brake chamber push rods through appropriately fabricated fixtures in order to measure the push rod stroke. All the transducers are interfaced with a connector block through shielded cables. The connector block is connected to a PCI-MIO-16E-4 DAQ board [59] (mounted on a PCI slot inside a desktop computer) that collects the data during experimental test runs. This DAQ board can measure eight analog input signals in the differential mode and can provide two analog output signals. The DAQ board discretizes the analog input signals using an analog-to-digital (A/D) converter and the resulting digital signals are stored in the computer. An application program written in MATLAB / Simulink is used to collect and store the data in the computer. A discussion of various aspects of data acquisition in general can be found in [60].

The specifications of the various brake system components used in the experimental setup are summarized in Table III. The specifications of the various sensing and actuation components used in the experimental setup are summarized in Table IV. A few photographs of the experimental setup are presented in Figs. 9 to 13. 


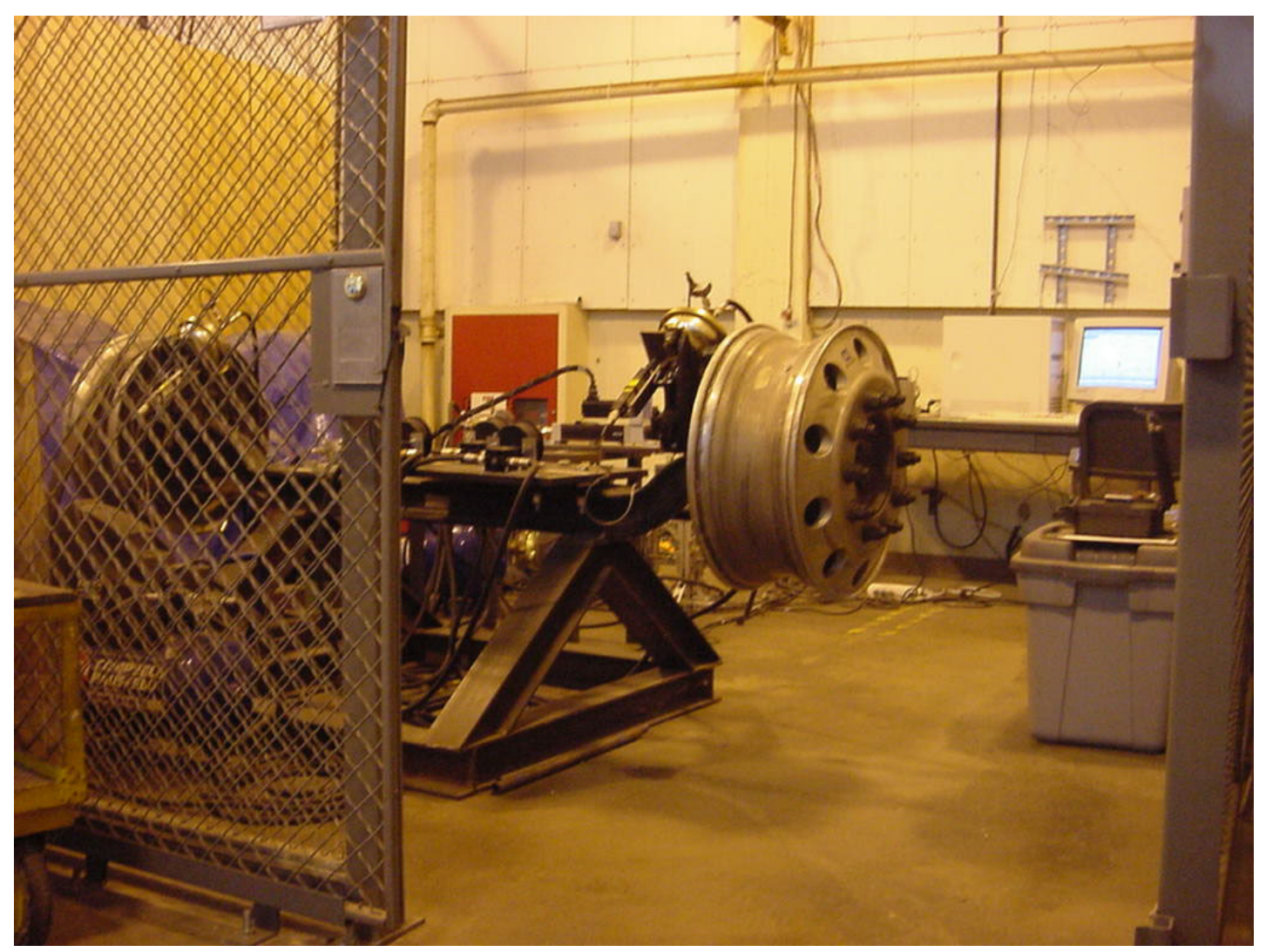

Fig. 9. The air brake experimental facility at Texas A\&M University 




Fig. 10. The front axle of a typical commercial vehicle 




Fig. 11. The servo drive and the data acquisition system 


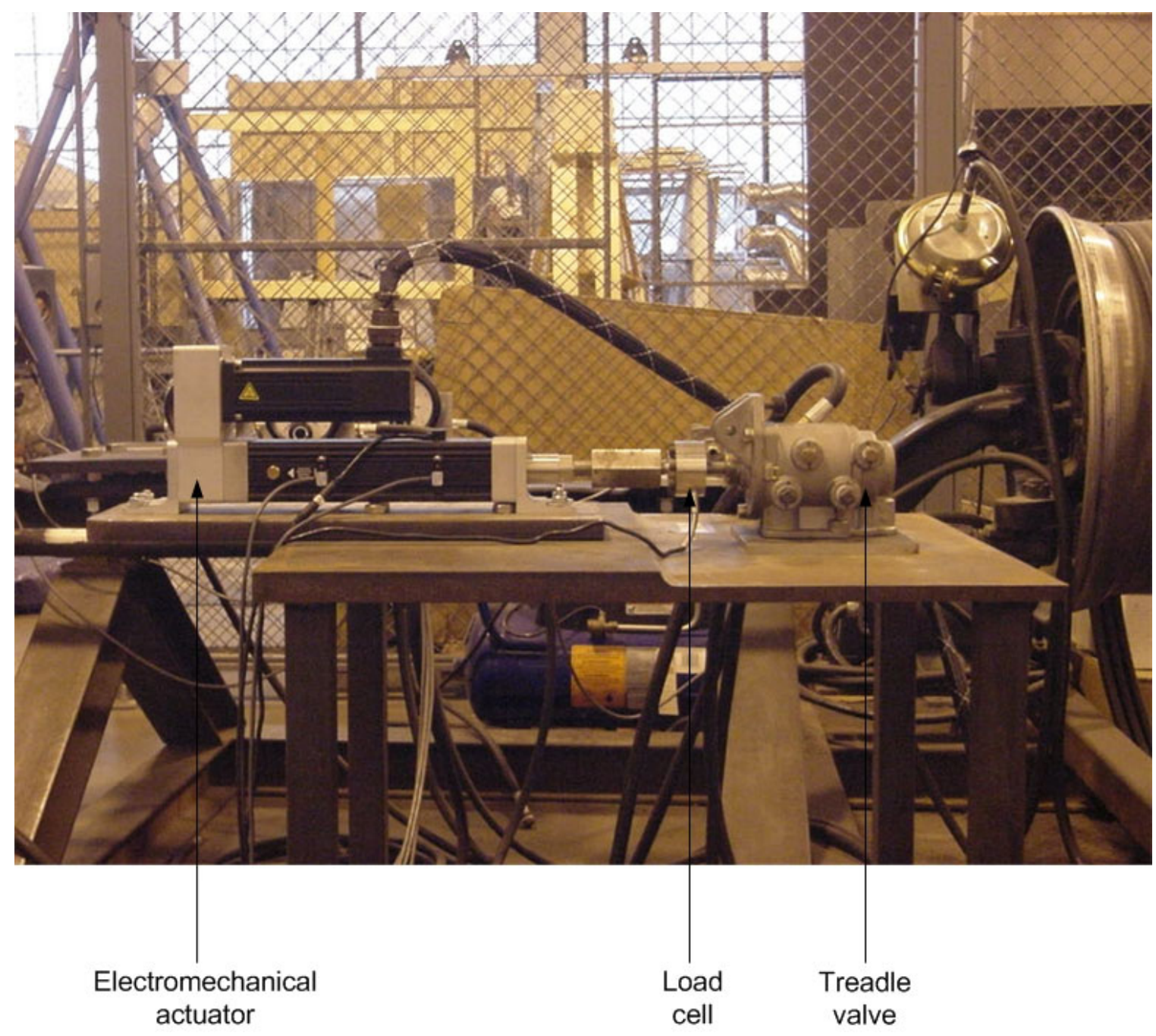

Fig. 12. The electromechanical actuator and the treadle valve 




Fig. 13. The pneumatic actuator and the treadle valve 
Table III. Details of the brake system components used in the experimental setup at Texas A\&M University

\begin{tabular}{|l|l|l|l|}
\hline Title & Manufacturer & $\begin{array}{l}\text { Model } \\
\text { number }\end{array}$ & Description \\
\hline $\begin{array}{l}\text { Compressor } \\
\text { and storage } \\
\text { reservoir } \\
\text { - Primary } \\
\text { circuit }\end{array}$ & $\begin{array}{l}\text { Campbell } \\
\text { Hausfeld }\end{array}$ & WL651300AJ & $\begin{array}{l}\text { The storage reservoir has a twelve gal- } \\
\text { lon capacity. }\end{array}$ \\
\hline $\begin{array}{l}\text { Compressor } \\
\text { and storage } \\
\text { reservoir } \\
\begin{array}{l}\text { Secondary } \\
\text { circuit }\end{array}\end{array}$ & Hausfeld & FP200200AV & $\begin{array}{l}\text { The storage reservoir has a six gallon } \\
\text { capacity. }\end{array}$ \\
\hline $\begin{array}{l}\text { Pressure } \\
\text { regulator }\end{array}$ & Omega Engi- & $\begin{array}{l}\text { PRG501- } \\
120\end{array}$ & $\begin{array}{l}\text { It has a regulation range of 115.1-928.8 } \\
\text { kPa }(2-120 \text { psig). }\end{array}$ \\
\hline $\begin{array}{l}\text { Treadle } \\
\text { valve }\end{array}$ & Bendix & E-7 & $\begin{array}{l}\text { Regulates the air pressure in the brake } \\
\text { chambers. }\end{array}$ \\
\hline $\begin{array}{l}\text { Quick re- } \\
\text { lease valve }\end{array}$ & Bendix & QR1 & $\begin{array}{l}\text { Distributes pressurized air to the front } \\
\text { brake chambers. }\end{array}$ \\
\hline $\begin{array}{l}\text { Relay valve } \\
\text { Brake }\end{array}$ & Bendix & R-12 & $\begin{array}{l}\text { Meters compressed air to the rear brake } \\
\text { chambers. }\end{array}$ \\
\hline $\begin{array}{l}\text { Brake } \\
\text { chambers }\end{array}$ & Bendix & $\begin{array}{l}\text { Type 20 and } \\
\text { Type } 30\end{array}$ & $\begin{array}{l}\text { Receives pressurized air and converts } \\
\text { that energy into a mechanical force. }\end{array}$ \\
\hline
\end{tabular}


Table IV. Details of the transducers and actuators used in the experimental setup at Texas A\&M University

\begin{tabular}{|c|c|c|c|}
\hline Title & Manufacturer & $\begin{array}{l}\text { Model } \\
\text { number }\end{array}$ & Description \\
\hline $\begin{array}{l}\text { Linear po- } \\
\text { tentiometer }\end{array}$ & $\begin{array}{l}\text { Omega Engi- } \\
\text { neering }\end{array}$ & LP802-75 & It has a maximum stroke of 3 in. \\
\hline $\begin{array}{l}\text { Linear po- } \\
\text { tentiometer }\end{array}$ & $\begin{array}{l}\text { Omega Engi- } \\
\text { neering }\end{array}$ & LP802-100 & It has a maximum stroke of 4 in. \\
\hline Load cell & $\begin{array}{l}\text { Omega Engi- } \\
\text { neering }\end{array}$ & LC203-1K & It has a capacity of $1000 \mathrm{lb}$. \\
\hline $\begin{array}{l}\text { Pressure } \\
\text { transducer }\end{array}$ & $\begin{array}{l}\text { Omega Engi- } \\
\text { neering }\end{array}$ & $\begin{array}{l}\text { PX181- } \\
\text { 100G5V }\end{array}$ & It has a range of 0-100 psig. \\
\hline $\begin{array}{l}\text { Power sup- } \\
\text { ply }\end{array}$ & $\begin{array}{ll}\text { Omega } & \text { Engi- } \\
\text { neering }\end{array}$ & PSS-5A & $\begin{array}{l}\text { It provides a } 5 \mathrm{~V} \text { d.c. power supply to } \\
\text { the linear potentiometers. }\end{array}$ \\
\hline $\begin{array}{l}\text { Power sup- } \\
\text { ply and am- } \\
\text { plifier }\end{array}$ & $\begin{array}{l}\text { Omega Engi- } \\
\text { neering }\end{array}$ & $\begin{array}{l}\text { DMD- } \\
465 W B\end{array}$ & $\begin{array}{l}\text { It provides a } 10 \mathrm{~V} \text { d.c. excitation to the } \\
\text { load cell and also amplifies the output } \\
\text { from the load cell. }\end{array}$ \\
\hline $\begin{array}{l}\text { Power sup- } \\
\text { ply }\end{array}$ & $\begin{array}{ll}\text { Omega } & \text { Engi- } \\
\text { neering }\end{array}$ & U24Y101 & $\begin{array}{l}\text { It provides a } 24 \mathrm{~V} \text { d.c. power supply to } \\
\text { the pressure transducers. }\end{array}$ \\
\hline $\begin{array}{l}\text { Data acqui- } \\
\text { sition board }\end{array}$ & $\begin{array}{l}\text { National } \\
\text { Instruments }\end{array}$ & $\begin{array}{l}\text { PCI-MIO- } \\
16 \mathrm{E}-4\end{array}$ & $\begin{array}{l}\text { It has } 8 \text { differential analog input chan- } \\
\text { nels and } 2 \text { analog output channels. }\end{array}$ \\
\hline $\begin{array}{l}\text { Electro me- } \\
\text { chanical ac- } \\
\text { tuator }\end{array}$ & IDC & $\begin{array}{l}\text { EC2-B23- } \\
\text { 20-05B-50- } \\
\text { MSI/MS6E- } \\
\text { MT1E-L }\end{array}$ & $\begin{array}{l}\text { Actuates the treadle valve plunger and } \\
\text { has a stroke range of } 100 \mathrm{~mm} \text {. }\end{array}$ \\
\hline Servo drive & IDC & $\mathrm{B} 8501$ & $\begin{array}{l}\text { Controls the actuator in order to ob- } \\
\text { tain the desired treadle valve plunger } \\
\text { displacement. }\end{array}$ \\
\hline
\end{tabular}




\section{CHAPTER IV}

\section{A MODEL FOR PREDICTING THE PRESSURE TRANSIENTS IN THE AIR BRAKE SYSTEM}

The first step in developing reliable model-based diagnostic schemes for air brake systems is to develop a "fault-free" model (one that describes the response of the system under the absence of faults in the system) for the same. It has been found out from experiments that observing the pressure transients in the brake chambers of the air brake system during the brake application process will help in monitoring the brake system for leaks and out-of-adjustment. Hence, a model for predicting the pressure transients in a brake chamber of the air brake system has been developed and presented in [23]. This model correlates the pressure in the brake chamber with the treadle valve plunger displacement and the supply pressure to the treadle valve. In this chapter, a brief description of the model is provided and the governing equations of the model are summarized. Improvements have been made to this model and these are also presented.

\section{A. Existing models for air brake systems}

The hydraulic brake system has been extensively studied and models for the same have been developed by many authors. Gerdes et al. [61] developed a model for a hydraulic brake system with a vacuum booster. They combined a static valve model with equations of air flow within the booster. Khan et al. [62] used bond graph techniques to develop models for the booster, the master cylinder and the wheel cylinder. In both cases, the authors measured the wheel cylinder chamber pressure as a function of time and attempted to predict the pressure transients with their models. In [63], the author has developed an overall model for the hydraulic brake system by 
presenting individual models for each major component of the brake system.

A large number of published works on models for air brake systems relate quantities such as brake force, vehicle deceleration, brake pad temperature and brake torque with the brake chamber pressure and the push rod stroke [64], [65], [66], [15]. Such models essentially characterize the mechanical subsystem of the air brake system. It is also important to develop models that predict the pressure transients in the brake system since such models can check the brake "rise times" and compare them with the values specified by FMVSS 121 to ensure the proper operation of the brake system. The maximum brake force developed in a given brake application depends on the steady state brake chamber pressure and a model for the pneumatic subsystem is necessary to predict the same. Also, the estimation of stopping distances from measurements of brake force requires the values of air pressure buildup / rise times which can be obtained from a model of the pressure transients.

It has been observed in experiments that the occurrence of leaks and out-ofadjustment of push rods are reflected on the pressure transients in the brake chamber. Hence, a model for the pressure transients provides a way to develop diagnostic schemes for the air brake system. Acarman et al. [67] presented a model for the pressure transients in air brakes with an Antilock Braking System (ABS). Dunn et al. [68] modeled the pressure transients using a first order linear ordinary differential equation with the associated "time constants" obtained from experimental data. A similar model has been developed by Kandt et al. [69] for the pressure transients during brake release. These models do not explicitly take into account the mechanics of operation of the treadle valve. 
B. A model for predicting the pressure transients in the brake chamber

The model presented in [23] takes into account the mechanics of operation of the treadle valve and the flow of air in the brake system. A lumped parameter approach has been adopted to model the pneumatic subsystem of the air brake system. The configuration of the air brake system considered in this dissertation is the one where the delivery port of the primary circuit is directly connected to one of the two front brake chambers. This configuration will be considered for this first study of developing model-based diagnostic schemes for air brakes based on the pressure transients in the brake chamber.

1. Equations governing the mechanics of operation of the treadle valve

In this sub-section, the equations governing the motion of the components in the primary circuit of the treadle valve (refer to Fig. 7) are presented. The operation of the treadle valve has been described in section A of chapter III. The primary inlet valve opening in the treadle valve has been modeled as a nozzle. The friction at the sliding surfaces of the treadle valve is assumed to be negligible since these surfaces are well lubricated. The springs in the treadle valve have been tested and found to be linear in the region of their operation (except the rubber graduating spring). Geometric parameters such as areas, initial deflections, etc., were also measured and used in the following equations. The force applied by the driver on the brake pedal is transmitted through the rubber graduating spring to the primary piston which then opens the primary inlet valve. The governing equation of the primary piston during the apply and hold phases of the brake application process is given by

$$
\begin{array}{r}
\left(M_{p p}+M_{p v}\right)\left(\frac{d^{2} x_{p p}(t)}{d t^{2}}\right)+K_{2} x_{p p}(t)=K_{s s} x_{p}(t)+F_{g s}(t)+F_{1} \\
-P_{p d}(t)\left(A_{p p}-A_{p v}\right)-P_{p s} A_{p v 1}+P_{a t m} A_{p p}
\end{array}
$$




$$
F_{1}=K_{p v} x_{p t}+F_{k s s i}-F_{k p p i}-F_{k p v i}
$$

and

$$
K_{2}=K_{s s}+K_{p p}+K_{p v}
$$

where $M_{p p}$ and $M_{p v}$ denote respectively the mass of the primary piston and the primary valve assembly gasket, $x_{p}$ and $x_{p p}$ denote respectively the displacement of the treadle valve plunger and the primary piston from their respective initial positions, $x_{p t}$ is the distance traveled by the primary piston before it closes the primary exhaust port, $K_{s s}, K_{p p}$ and $K_{p v}$ denote respectively the spring constants of the stem spring, the primary piston return spring and the primary valve assembly return spring, $F_{k s s i}$, $F_{k p p i}$ and $F_{k p v i}$ denote respectively the pre-loads on the same, $A_{p p}$ is the net area of the primary piston exposed to the pressurized air at the primary delivery port, $A_{p v}$ is the net cross-sectional area of the primary valve assembly gasket exposed to the pressurized air at the primary delivery port, $A_{p v 1}$ is the net cross-sectional area of the primary valve assembly gasket exposed to the pressurized air at the primary supply port, $F_{g s}$ is the force transmitted from the treadle valve plunger to the primary piston by the rubber graduating spring, $P_{p s}$ is the pressure of air being supplied to the primary circuit, $P_{p d}$ is the pressure of air at the primary delivery port and $P_{a t m}$ is the atmospheric pressure. For convenience, time $(t)$ in the parenthesis following a variable shall be suppressed after its first appearance.

The mechanical response (the load-deflection curve) of the rubber graduating spring is nonlinear. It has been tested to obtain the calibration curve illustrated in Fig. 14 .

The deflection of the rubber graduating spring is denoted by $x_{p d}(t)$ which is equal to $\left(x_{p}(t)-x_{p p}(t)\right)$. From the calibration curve, the following relationship is obtained 


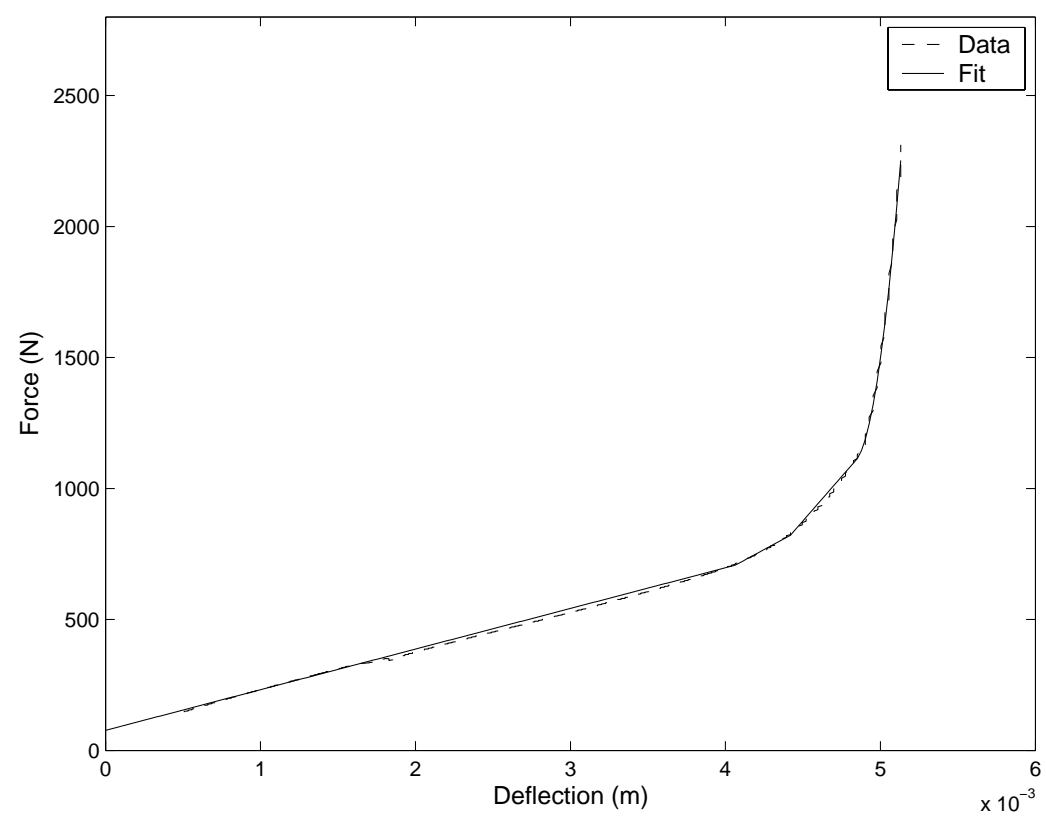

Fig. 14. Calibration curve of the rubber graduating spring

between $F_{g s}$ and $x_{p d}$ :

$$
F_{g s}= \begin{cases}m_{1} x_{p d}+n_{1} & \text { if } x_{p d} \leq l_{1} \\ m_{2} x_{p d}+n_{2} & \text { if } l_{1}<x_{p d} \leq l_{2} \\ m_{3} x_{p d}+n_{3} & \text { if } l_{2}<x_{p d} \leq l_{3} \\ a_{1} x_{p d}^{2}+a_{2} x_{p d}+a_{3} & \text { if } x_{p d}>l_{3},\end{cases}
$$

where the calibration constants are obtained from Fig. 14 . In the above equation, $l_{1}$ is the value of the deflection of the rubber graduating spring until which its response is described by the first sub-equation. The second sub-equation describes the response of the rubber graduating spring when its deflection lies between $l_{1}$ and $l_{2}$, the third sub-equation describes its response when its deflection lies between $l_{2}$ and $l_{3}$, and the fourth sub-equation describes its response when its deflection is greater than $l_{3}$.

The mass of the primary piston was found out to be approximately $0.16 \mathrm{~kg}$ and the magnitude of the spring and pressure forces was found to be in the order of $10^{2} \mathrm{~N}$. 
Thus, the acceleration required for the inertial forces to be comparable with the spring force and the pressure force terms has to be in the order of $10^{2}-10^{3} \mathrm{~m} / \mathrm{s}^{2}$, which is not the case. Hence the inertial forces are neglected and Eq. (4.1) reduces to

$$
\begin{aligned}
K_{2} x_{p p}=K_{s s} x_{p}+F_{g s}+ & F_{1}-P_{p d}\left(A_{p p}-A_{p v}\right) \\
& -P_{p s} A_{p v 1}+P_{a t m} A_{p p} .
\end{aligned}
$$

During the exhaust phase, the equation of motion of the primary piston can be written as

$$
\begin{array}{r}
M_{p p}\left(\frac{d^{2} x_{p p}}{d t^{2}}\right)=F_{g s}+F_{k s s i}+K_{s s}\left(x_{p}-x_{p p}\right)-\left(P_{p d}-P_{a t m}\right) A_{p p} \\
-K_{p p} x_{p p}-F_{k p p i} .
\end{array}
$$

It should be noted that at the start of the exhaust phase $x_{p p}$ is equal to $x_{p t}$ and decreases as the exhaust phase progresses. Neglecting the inertia of the primary piston the above equation can be simplified to

$$
K_{3} x_{p p}=K_{s s} x_{p}+F_{g s}+F_{2}-P_{p d} A_{p p}+P_{a t m} A_{p p}
$$

where

$$
\begin{gathered}
F_{2}=F_{k s s i}-F_{k p p i}, \\
K_{3}=K_{s s}+K_{p p} .
\end{gathered}
$$

A detailed derivation of the model is presented in [23]. The equations of motion governing the operation of the secondary circuit of the treadle valve have been similarly derived and presented in [23]. 
2. Equations governing the flow of air in the pneumatic subsystem of the brake system

The primary inlet opening in the treadle valve serves as a channel through which compressed air from the storage reservoirs flows to the brake chambers connected to the delivery port of the primary circuit. This opening has been modeled as a nozzle. For the flow through a restriction, if the ratio of the cross-sectional area of the upstream section to the cross-sectional area of the restriction is 4.4 or higher, the approach velocity to this restriction can be neglected and the upstream properties (such as pressure, enthalpy, temperature, etc.) can be taken to be the upstream total or stagnation properties [70]. In this application, the minimum ratio of the crosssectional area of the supply chamber of the treadle valve to the cross-sectional area of the primary inlet opening (the restriction in this case) was found out to be around 15.4. Also, the cross-sectional area of the valve opening decreases monotonically to a minimum value. Hence, the valve opening can be considered as a nozzle and the properties in the supply chamber of the treadle valve can be taken as the stagnation properties at the inlet section of the nozzle. It is assumed that the flow through this valve opening is one-dimensional and isentropic. Further, it is assumed that the fluid properties are uniform at all sections in the nozzle and air is assumed to behave like an ideal gas with constant specific heats.

Under the above assumptions, the part of the pneumatic subsystem under consideration can be visualized as illustrated in Fig. 15. It should be noted that when the primary delivery port is connected directly to a front brake chamber, the term $P_{p d}$ in the above equations is taken to be the same as the pressure in the brake chamber (denoted by $P_{b}$ ). For this configuration, the supply pressure term, denoted by $P_{p s}$ in the above equations, is denoted by $P_{o}$ in the equations that follow. 


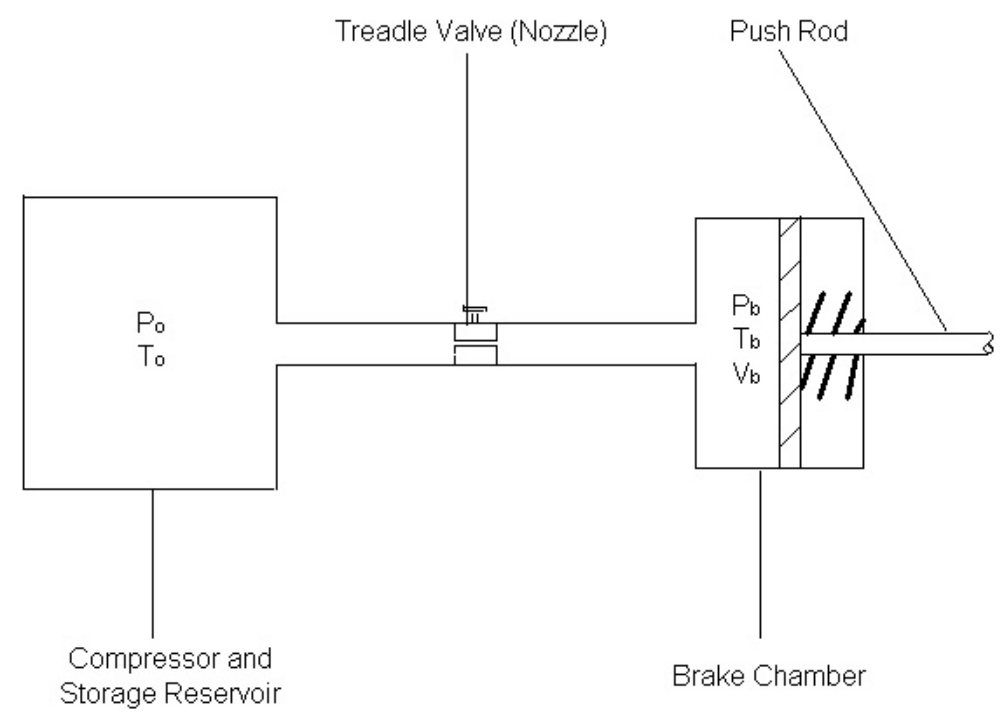

Fig. 15. The simplified pneumatic subsystem under consideration

The brake chamber and the hose connecting the delivery port of the primary circuit to it are lumped together and taken as the control volume under consideration (see Fig. 16). The assumption that air can be modeled as an ideal gas provides the following relationship [23]:

$$
\dot{m}_{b}(t)=\left(\frac{1}{\gamma}\right) \frac{\dot{P}_{b}(t) V_{b}(t)}{R T_{b}(t)}+\frac{P_{b}(t) \dot{V}_{b}(t)}{R T_{b}(t)},
$$

where $m_{b}$ is the mass of air in the control volume at any instant of time, $V_{b}$ is the volume of air in the control volume at that instant of time, $T_{b}$ is the temperature of air in the control volume at that instant of time and $R$ is the gas constant of air. The dot in the above equation represents the derivative with respect to time.

During the brake application process, the volume of air in the brake chamber (refer to Fig. 17 for a cross-sectional view of the same) varies due to the fact that the push rod strokes out of the brake chamber. In [23], the following relationship was 




Fig. 16. The brake chamber as the control volume

assumed between the push rod stroke $\left(x_{b}\right)$ and the brake chamber pressure $\left(P_{b}\right)$ :

$$
x_{b}=\frac{\left(P_{b}-P_{a t m}\right) A_{b}-F_{k b i}}{K_{b}},
$$

where $A_{b}$ is the effective cross-sectional area of the brake chamber, $F_{k b i}$ is the preload on the brake chamber return spring and $K_{b}$ is the spring constant of the brake chamber return spring. Displacement transducers were not installed on the brake chamber push rods when the model was initially developed and corroborated.

Subsequently, the experimental setup was upgraded and new brake chambers and slack adjusters were obtained and this facilitated the installation of displacement transducers on the brake chamber push rods. From experiments performed in the past one year, it has been found out that the evolution of the push rod stroke with the brake chamber pressure can be divided into three phases (refer to Fig. 18). The push rod starts to move only after a "threshold pressure" $\left(P_{t h}\right)$ is reached in the brake chamber. This is the first phase and $P_{t h}$ represents the amount of pressure needed to overcome the pre-load on the brake chamber diaphragm. In the second phase, the push rod moves and rotates the S-cam such that the clearance between the brake pads and the brake drum decreases. The brake pads contact the brake drum at a 




Fig. 17. A sectional view of the brake chamber

certain pressure in the brake chamber. This pressure shall be referred to as "contact pressure" and denoted by $P_{c t}$. In the third phase, further stroke of the push rod with increasing brake chamber pressure is caused due to the deformation of the mechanical components of the brake system. Thus, the total stroke of the push rod is made up of two components - one that is required to overcome the clearance between the brake pads and the brake drum and another that is due to the deformation of the mechanical components after the brake pads make contact with the brake drum. Thus, the total stroke of the push rod depends both on the clearance between the brake pads and the brake drum and the steady state pressure in the brake chamber. These effects have been included in the model and the corresponding regions are approximated with linear models (see Fig. 19) to obtain a calibration curve relating the push rod stroke to the brake chamber pressure. In Fig. 18, the arrows represent the steady state condition in each of the three sets of data presented. It can be observed that the steady state push rod stroke in each case depends on the corresponding steady 
state brake chamber pressure. The calibration curve relating the push rod stroke and the brake chamber pressure in Test 3 (of Fig. 18) is shown in Fig. 19. The calibration constants are obtained from this curve and used for all the subsequent test runs. It should be noted that the value of $P_{c t}$ depends on the clearance between the brake pads and the brake drum. This clearance will increase during the operation of the vehicle due to the wear of the brake pads and the brake drum and also due to the expansion of the brake drum due to heating.

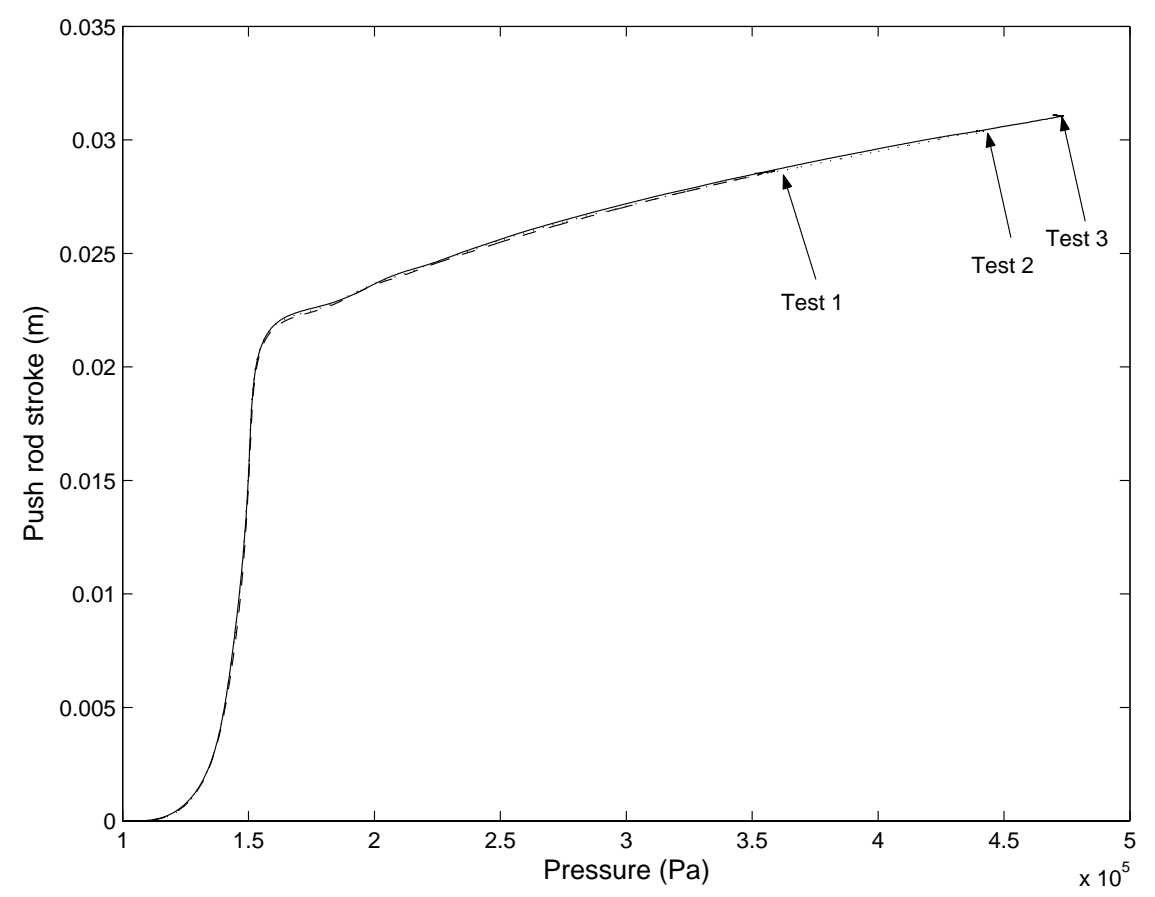

Fig. 18. Push rod stroke and brake chamber pressure at $653 \mathrm{kPa}$ (80 psig) supply pressure

From the calibration curve illustrated in Fig. 19, the following relationship between the push rod stroke $\left(x_{b}\right)$ and the brake chamber pressure $\left(P_{b}\right)$ is obtained:

$$
x_{b}= \begin{cases}M_{1} P_{b}+N_{1} & \text { if } P_{t h} \leq P_{b}<P_{c t} \\ M_{2}\left(P_{b}-P_{c t}\right)+M_{1} P_{c t}+N_{1} & \text { if } P_{b} \geq P_{c t},\end{cases}
$$




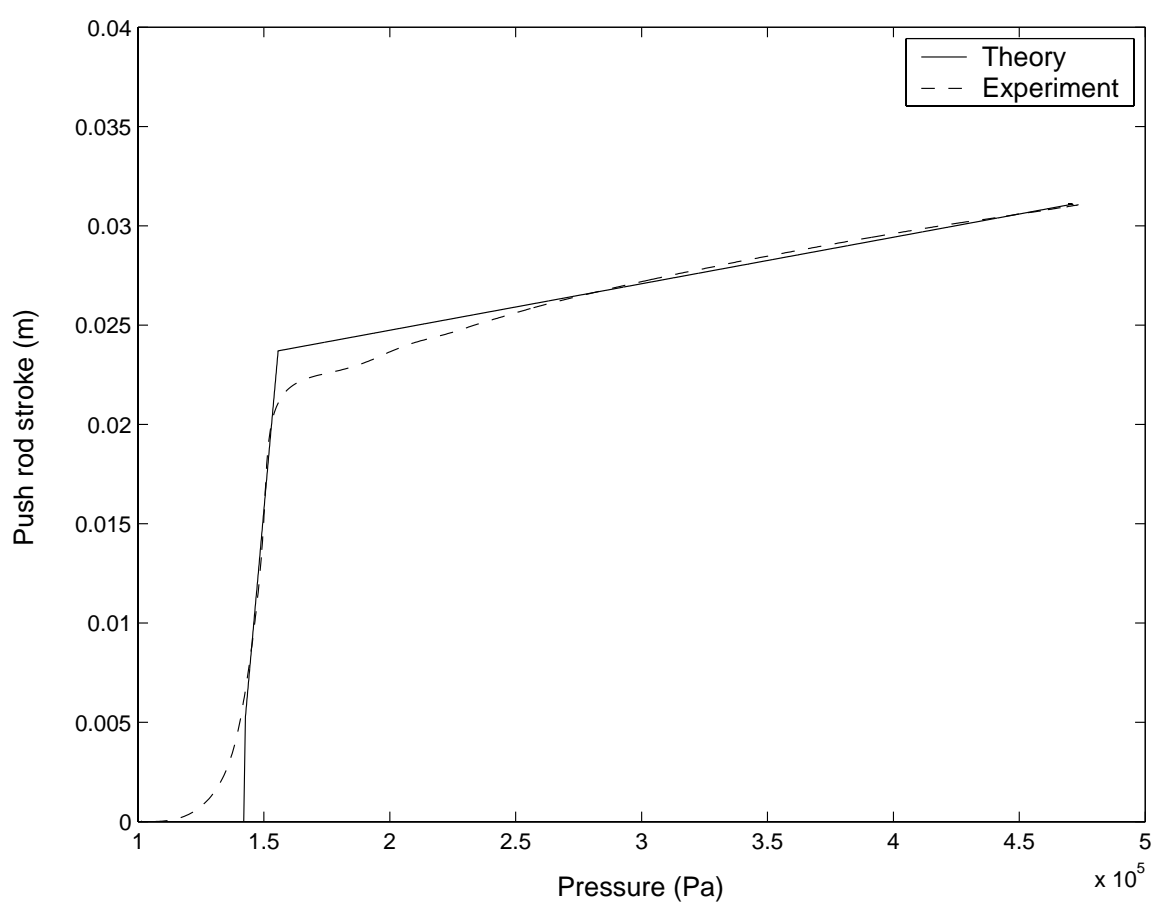

Fig. 19. Calibration curve at $653 \mathrm{kPa}(80 \mathrm{psig})$ supply pressure

where the constants $M_{1}, M_{2}$ and $N_{1}$ are obtained from Fig. 19 .

Thus, the volume of air in the control volume (denoted by $V_{b}$ ) at any instant of time is given by

$$
V_{b}= \begin{cases}V_{o 1} & \text { if } P_{b}<P_{t h} \\ V_{o 1}+A_{b}\left(M_{1} P_{b}+N_{1}\right) & \text { if } P_{t h} \leq P_{b}<P_{c t} \\ V_{o 1}+A_{b}\left(M_{2}\left(P_{b}-P_{c t}\right)+M_{1} P_{c t}+N_{1}\right) & \text { if } P_{b} \geq P_{c t},\end{cases}
$$

where $V_{o 1}$ is the initial volume of air in the control volume.

The application of the balance of mass and balance of energy to the control volume under study provides the following equations describing the flow of air in the brake system during the apply and hold phases (refer to [23] for a detailed derivation): 


$$
\begin{aligned}
& \left(\left(\frac{2 \gamma}{\gamma-1}\right) \frac{1}{R T_{o}}\left|\left[\left(\frac{P_{b}}{P_{o}}\right)^{\left(\frac{2}{\gamma}\right)}-\left(\frac{P_{b}}{P_{o}}\right)^{\left(\frac{\gamma+1}{\gamma}\right)}\right]\right|\right)^{\frac{1}{2}} \\
& A_{p} C_{D} P_{o} \operatorname{sgn}\left(P_{o}-P_{b}\right)= \\
& \left\{\begin{array}{l}
\left(\frac{V_{o 1} P_{o}^{\left(\frac{\gamma-1}{\gamma}\right)}}{\gamma R T_{o} P_{b}^{\left(\frac{\gamma-1}{\gamma}\right)}}\right) \dot{P}_{b} \\
\text { if } P_{b}<P_{t h}, \\
\left(\frac{V_{b} P_{o}^{\left(\frac{\gamma-1}{\gamma}\right)}}{\gamma R T_{o} P_{b}^{\left(\frac{\gamma-1}{\gamma}\right)}}+\frac{P_{b}^{\frac{1}{\gamma}} A_{b} M_{1} P_{o}^{\left(\frac{\gamma-1}{\gamma}\right)}}{R T_{o}}\right) \dot{P}_{b} \\
\text { if } P_{t h} \leq P_{b}<P_{c t}, \\
\left.\left(\begin{array}{l}
V_{b} P_{o}^{\left(\frac{\gamma-1}{\gamma}\right)} \\
\gamma R T_{o} P_{b}^{\left(\frac{\gamma-1}{\gamma}\right)}
\end{array}\right) \frac{P_{b}^{\frac{1}{\gamma}} A_{b} M_{2} P_{o}^{\left(\frac{\gamma-1}{\gamma}\right)}}{R T_{o}}\right) \dot{P}_{b} \\
\text { if } P_{b} \geq P_{c t},
\end{array}\right.
\end{aligned}
$$

where

$$
A_{p}=2 \pi r_{p v}\left(x_{p p}-x_{p t}\right)
$$

where $r_{p v}$ is the external radius of the primary valve inlet section.

The above equations are solved numerically using the fourth order Runge-Kutta method to obtain the pressure transients in the brake chamber during the apply phase of a brake application cycle. The input data to the numerical scheme is the displacement of the treadle valve plunger $\left(x_{p}\right)$. This model has been corroborated for various test runs and the results have been presented in [23]. Here, the prediction of the model is compared with the experimental data for one of the recent test runs for illustration. The numerical values of the various parameters (related to the compo- 
nents used in the experimental setup) used in the model and the diagnostic schemes are presented in Table V. For example, the cross-sectional areas were calculated by taking measurements with a vernier caliper (having a resolution of $0.001 \mathrm{in}$ ) and then converting the values from in ${ }^{2}$ to $\mathrm{m}^{2}$.

Table V. Values of the parameters used in the diagnostic schemes

\begin{tabular}{|c|c|c|c|}
\hline Parameter & Value & Parameter & Value \\
\hline$A_{p v}$ & $0.0002032 \mathrm{~m}^{2}$ & $A_{p v 1}$ & $0.0002026 \mathrm{~m}^{2}$ \\
$A_{p p}$ & $0.002371 \mathrm{~m}^{2}$ & $C_{D}$ & 0.82 \\
$F_{1}$ & $-151.196 \mathrm{~N}$ & $K_{2}$ & $9832.181 \mathrm{~N} / \mathrm{m}$ \\
$x_{p t}$ & $0.001575 \mathrm{~m}$ & $P_{a t m}$ & $101.356 \mathrm{kPa}$ \\
$K_{s s}$ & $2846.545 \mathrm{~N} / \mathrm{m}$ & $V_{o 1}$ & $0.0001639 \mathrm{~m}$ \\
$r_{p v}$ & $0.01283 \mathrm{~m}$ & $A_{b}$ & $0.0129 \mathrm{~m}$ \\
$m_{1}$ & $155138.175 \mathrm{~N} / \mathrm{m}$ & $n_{1}$ & $76.68 \mathrm{~N}$ \\
$m_{2}$ & $321320.874 \mathrm{~N} / \mathrm{m}$ & $n_{2}$ & $-598.686 \mathrm{~N}$ \\
$m_{3}$ & $678364.265 \mathrm{~N} / \mathrm{m}$ & $n_{3}$ & $-2176.675 \mathrm{~N}$ \\
$a_{1}$ & $11536836074.281 \mathrm{~N} / \mathrm{m}^{2}$ & $l_{1}$ & $0.004064 \mathrm{~m}$ \\
$a_{2}$ & $-111089651.687 \mathrm{~N} / \mathrm{m}$ & $l_{2}$ & $0.00442 \mathrm{~m}$ \\
$a_{3}$ & $268522.758 \mathrm{~N}$ & $l_{3}$ & $0.004851 \mathrm{~m}$ \\
$P_{t h}$ & $142.726 \mathrm{kPa}$ & $M_{1}$ & $0.000001419 \mathrm{~m} / \mathrm{Pa}$ \\
$N_{1}$ & $-0.1972 \mathrm{~m}$ & $M_{2}$ & $0.00000002341 \mathrm{~m} / \mathrm{Pa}$ \\
\hline
\end{tabular}

It can be observed from Fig. 20 that the model predicts the start of the pressure rise and the steady state value well. It should be pointed out that for the particular 


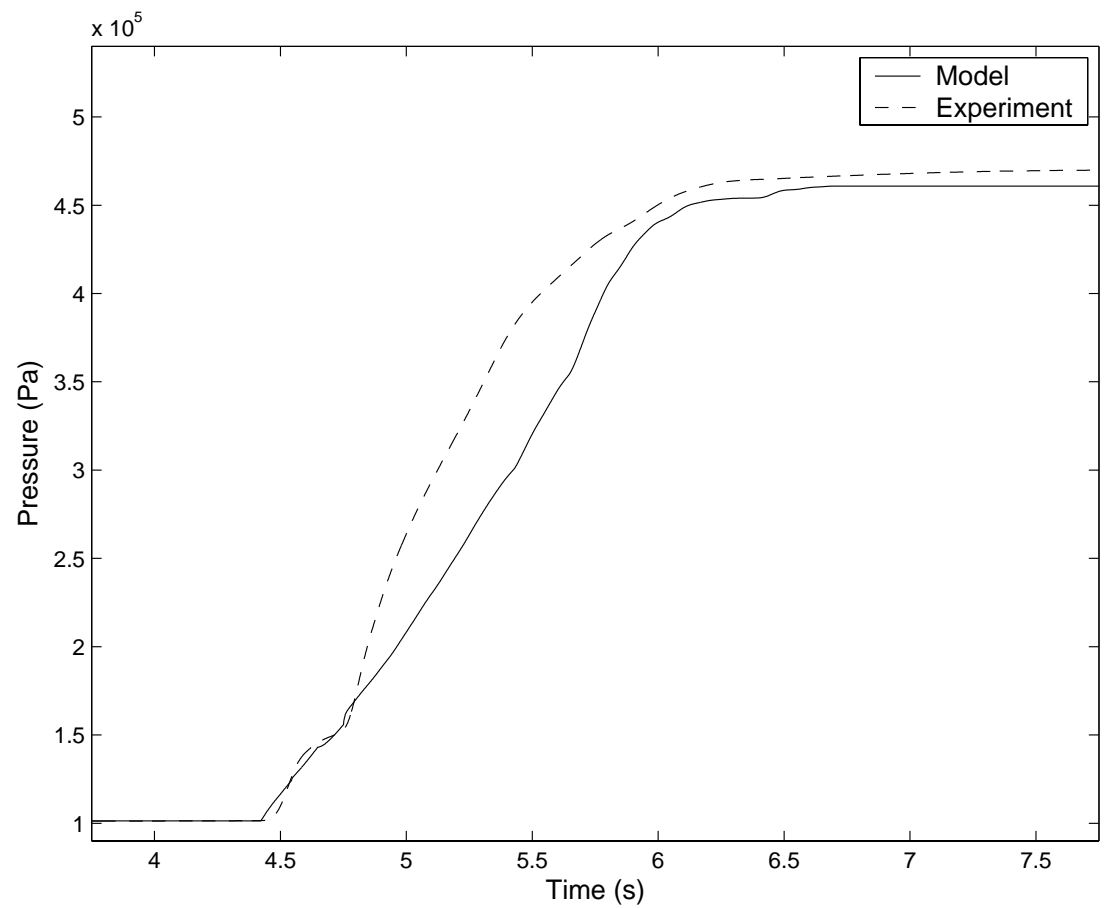

Fig. 20. Pressure transients at $722 \mathrm{kPa}$ (90 psig) supply pressure



Fig. 21. Treadle valve plunger displacement for the test run shown in Fig. 20 


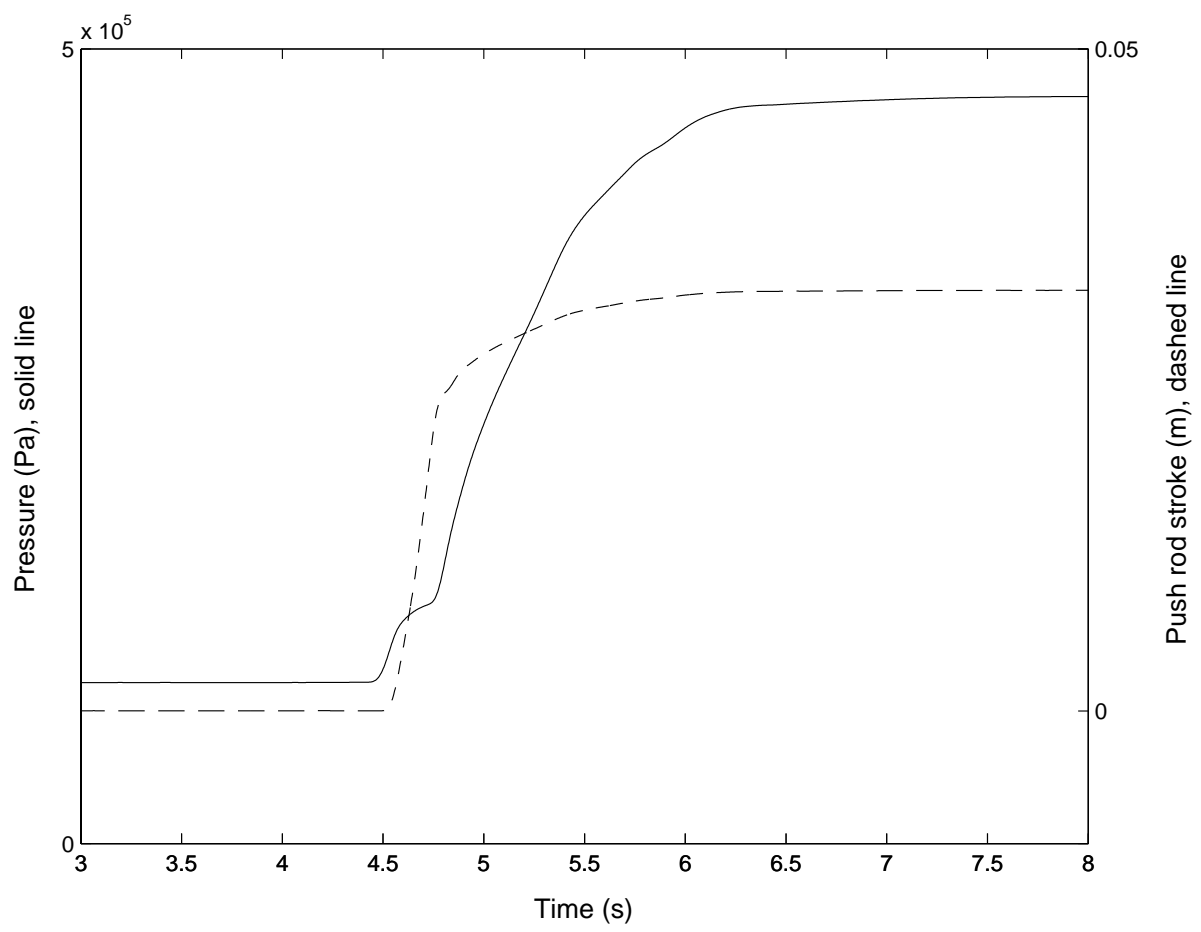

Fig. 22. Pressure and push rod stroke measurements for the test run shown in Fig. 20 test run illustrated in this figure, the brake application is started at approximately $t=4.1 s$ (refer to Fig. 21). The value $t=0 s$ corresponds to the instant of time at which the computer program for collecting the data is started. Also, note that the second phase of the pressure transients (where there is a decrease in the slope of the pressure growth curve) is also captured. One of the assumptions that was made in deriving the model is that the second phase of the pressure transients is caused by the increase in the volume of the brake chamber due to the stroke of the push rod. This assumption is supported with the data presented in Fig. 22. Here, the measured brake chamber pressure and push rod stroke have been plotted for the test run illustrated in Fig. 20. It can be observed that the majority of the push rod stroke falls in the second phase of the pressure growth curve. The latter part of the push rod stroke is due to the deformation of the brake pads and other mechanical components 
as the brake lining contacts the brake drum and is pressed against it.

This model will be the basis for the diagnostic schemes developed in this dissertation. To summarize, the main features of this model include the following:

1. This model considers both the mechanics of operation of the treadle valve and the flow of air in the brake system to predict the pressure transients in the brake chamber.

2. There is a time lag between the start of brake pedal application and the inception of pressure increase in the brake chamber. This effect is captured well by this model through the equations governing the mechanics of operation of the treadle valve.

3. The steady state brake chamber pressure depends on the supply pressure and the steady state plunger displacement. This is also predicted reasonably well by the model for a wide range of supply pressures and brake applications.

4. There are three modes / phases in the evolution of the brake chamber pressure during the brake application process. In the first mode, due to pre-loads on the push rod, it is stationary until the pressure increases to a threshold value. Once this happens, a transition occurs to the second mode where the push rod strokes out and the clearance between the brake pads and the brake drum starts to decrease. During this mode the volume of the brake chamber increases and the time rate of pressure increase falls down when compared with that of the first mode. Once the brake pads contact the brake drum a transition is made to the third mode and the pressure then increases to the steady state value. These physically observed effects are included in the model and are captured by the same. 
C. The air brake system as an example of a sequential hybrid system

The response of the pneumatic subsystem of the air brake system is such that it can be classified as what is usually referred to as an "Sequential Hybrid System". In this dissertation, the term "hybrid systems" is used to denote those systems whose mathematical representation involves a finite set of governing ordinary differential equations corresponding to a finite set of modes of operation. The mathematical representation of a hybrid system is referred to as its "hybrid model". The governing equation in each mode is different and the transition / switch from one mode to another occurs when some conditions involving one or more of the following - system's states, inputs, outputs, system parameters, etc., are satisfied. These conditions are referred to as "transition / switch conditions". These conditions may be known a priori or unknown. In a sequential hybrid system, the possible modes are ordered in a specific sequence. From a given mode, there can be only one forward transition to the next mode in this ordered set or one backward transition to the previous mode. Thus, the system can switch from a given mode to either the previous mode or the following mode. Some examples of physical systems that exhibit this behavior include the automatic transmission system in vehicles [1], multi-stage valves [71], [72], air brake system, etc.

Many automotive systems have recently been described by hybrid models. Balluchi et al. [73] have proposed a hybrid model for the automotive engine and powertrain that takes into account the four strokes of the pistons in the engine cylinders. They use this hybrid model to develop a variety of engine controllers. Borrelli et al. [74] have used a linearized hybrid vehicle model to develop traction control systems. Traction control systems improve the driver's ability to control the vehicle under wet and / or icy road conditions. Altafini et al. [75] have developed a lin- 
earized hybrid model for the motion of a miniature tractor-trailer combination along straight line and circular arc trajectories. In [76], the authors have developed a hybrid model for the drive-line of an automotive power-train and designed observers based on this model.

There are three modes of operation in the pneumatic subsystem of the air brake system (refer to Eq.(4.14)) when the brake is applied. In 'Mode 1', the pressure in the brake chamber $\left(P_{b}\right)$ increases to $P_{t h}$. In 'Mode 2', the push rod starts to move with further increase in pressure and the clearance between the brake pads and the brake drum starts to decrease. When the brake chamber pressure is equal to $P_{c t}$, the brake pads touch the brake drum and 'Mode 3' begins with further increase in pressure. In this mode, the stroke of the push rod increases with pressure due to the deformation of the mechanical components of the brake system. These three modes are illustrated in Fig. 23.

The following features of the model should be noted:

1. The governing equation in each mode for each brake chamber is a nonlinear first order ordinary differential equation in $P_{b}$ and also it is different in each mode.

2. The transition conditions from one mode to another are linear equalities / inequalities involving the state $\left(P_{b}\right)$, a known parameter $\left(P_{t h}\right)$ and an unknown parameter $\left(P_{c t}\right)$. Thus, the transition condition between Mode 2 and Mode 3 is not known. But the range of values of $P_{c t}$ is known from the possible range of values of the push rod stroke.

3. Hence, a transition detection problem and a parameter estimation problem have to be solved simultaneously. Also, the governing equations in Mode 3 involve the unknown parameter $\left(P_{c t}\right)$.

This hybrid model for predicting the pressure transients in the air brake system 


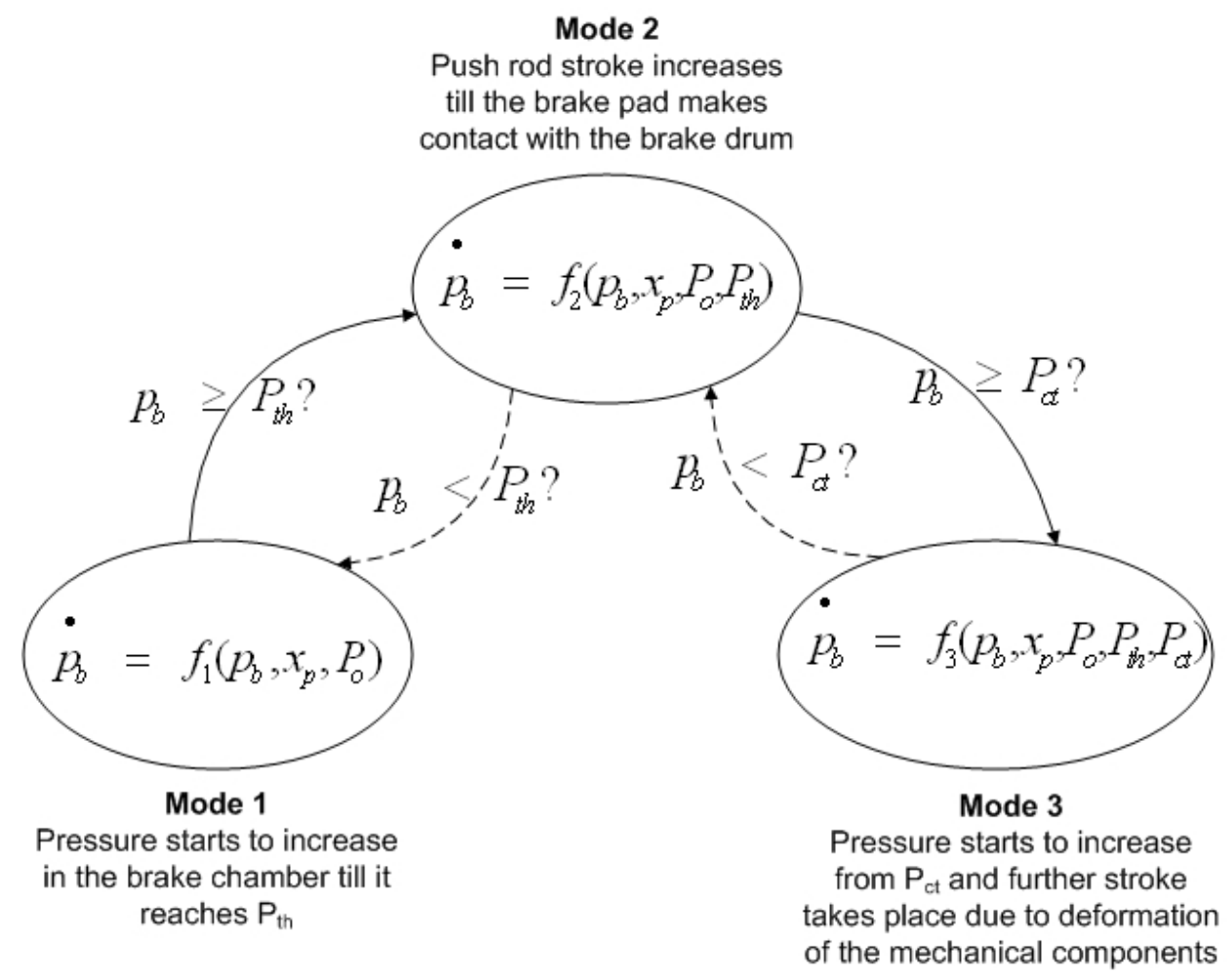

Fig. 23. The pneumatic subsystem of the air brake system modeled as a sequential hybrid system 
will be used to develop schemes for estimating the push rod stroke. It shall be observed shortly that the problem of estimating the push rod stroke can be posed as a parameter estimation problem and a transition detection problem involving the hybrid model presented in this section. The problems of transition detection and parameter estimation in such classes of nonlinear sequential hybrid systems are currently open.

D. A brief discussion concerning controlling the pressure in the air brake system

A cruise control system is a standard feature in most of the automobiles on the road today. It maintains the vehicle speed to the value set by the driver by automatically regulating the engine throttle [77], [78]. A sensor that measures the vehicle speed is used to provide the feedback signal to this system. A cruise control system is usually activated by the driver when the vehicle is traveling at medium / high speeds in smoothly flowing traffic. A conventional cruise control system utilizes a ProportionalIntegral-Derivative (PID) controller to minimize the error between the desired and the measured vehicle speed [79].

In recent years, studies have been carried out to develop "Adaptive Cruise Control" (ACC) systems or "Autonomous Intelligent Cruise Control" (AICC) systems. The objective of these systems is to maintain a constant distance between two consecutive vehicles by controlling the engine throttle and the brake system. These systems obtain the spacing between vehicles from sensors such as a radar mounted on the vehicle [80]. They are being developed so that they can be engaged at low speeds in moderate to heavy traffic conditions to automatically control the motion of the vehicle in a safe manner. Studies have been recently carried out to evaluate and implement these systems on vehicles [81], [82], [83].

While most of the research on ACC has focused on passenger cars, the benefits 
of implementing this system on heavy trucks have far reaching consequences [84]. A typical ACC system for heavy trucks controls the engine throttle, the transmission and the brake system and will be interfaced with existing systems like the Antilock Braking System (ABS), Traction Control System (TCS), etc. A typical truck ABS monitors the speed of the wheels and modulates the brake system pressure in the event of an impending wheel lock up [85]. The ABS consists of an Electronic Control Unit (ECU) that receives signals from the wheel speed sensors and processes this information to regulate the brake system pressure through modulator valves. It should be noted that $\mathrm{ABS}$ does not control the treadle valve to regulate the pressure in the brake system. It reduces the brake system pressure that is "commanded" by the driver when it senses an impending wheel lock up. It cannot provide a higher pressure than that corresponding to the pedal input from the driver.

It is important to note that the ABS modulates the brake system pressure only under conditions when a wheel lock up is impending. The ABS is disengaged during "normal" braking operations. In fact, it has been pointed out in [39] that ABS is "passive during the vast majority of braking operations". During such braking operations, the pressure of air in the brake system is the level that is commanded by the driver through the motion of the brake pedal (and consequently the motion of the treadle valve plunger). Hence, in order to implement ACC systems on commercial vehicles it is necessary to develop control schemes that will automatically regulate the brake system pressure during all braking operations.

The model for the pressure transients presented in this chapter has been used to develop a control scheme for regulating the pressure in the brake chamber. This scheme has been implemented on the experimental setup to track a variety of desired pressure trajectories and the results are presented in [86]. A schematic representation of this control scheme is provided in Fig. 24. This control scheme measures the brake 
chamber pressure at each instant of time and compares it to the desired brake chamber pressure at that instant of time. It then utilizes the model to calculate the treadle valve plunger displacement required to decrease this difference. Then, the control scheme provides a command signal corresponding to this value of the treadle valve plunger displacement to the servo drive that moves the treadle valve plunger to the corresponding position through the electromechanical actuator. The performance of the controller in tracking a repeated trapezoidal desired pressure trajectory is illustrated in Fig. 25. In this figure, the dotted line represents the desired pressure trajectory and $C$ represents a controller parameter. It is hoped that this modelbased control scheme can be used as part of emerging technologies such as ACC for commercial vehicles.



Fig. 24. A schematic representation of the control scheme 




Fig. 25. Controller response to a partial ramp to $446 \mathrm{kPa}$ (50 psig) at a supply pressure of $653 \mathrm{kPa}$ (80 psig) - repeated application 


\section{CHAPTER V}

\section{DETECTION OF LEAKS IN THE AIR BRAKE SYSTEM}

In this chapter, a scheme will be presented for monitoring the air brake system for leaks. In the following chapter, schemes will be presented to estimate the stroke of the push rod and thus can be used for monitoring the brake system for out-of-adjustment of push rods. All these schemes will use the model presented in chapter IV and the measurement of the pressure in the brake chamber. These schemes have been corroborated with experimental data and the corresponding results will be presented.

Designing a Fault Detection and Isolation (FDI) scheme for a physical system involves the tasks of residual generation and residual processing. Exhaustive surveys of various FDI schemes have been provided by Willsky [87], Gertler [88], [89], Basseville [90], Isermann [91] and Frank [92]. Economic constraints require that a reliable diagnostic tool be obtained with the least number of sensors. For the proposed diagnostic system, a pressure transducer is required at each brake chamber and a displacement transducer is required to measure the treadle valve plunger displacement. The investment on these sensors will be justified by the availability of a fast, reliable and automatic diagnostic system. For a given brake application, the governing equations of the model will be solved numerically to obtain the solution for the brake chamber pressure. This will be compared with the experimental data to generate the values of the residuals. The diagnostic schemes will generate the pressure residuals and process them to detect leaks and estimate the push rod stroke. The features of the diagnostic schemes proposed in this dissertation include:

1. The presence of a leak will be determined from measurements of the steady state brake chamber pressure and the supply pressure taken during a full brake application. The difference between these two values serves as an indicator for 
the absence or the presence of leaks.

2. The stroke of the push rod will be estimated from the parameter estimation and transition detection schemes developed using the hybrid model for the pressure transients in the brake chamber.

Currently in commercial vehicles, leaks can be detected only by manual inspection. The only available indicator is in the form of a low-pressure warning signal which is activated when the air pressure in the storage reservoirs falls below around 65 psig ${ }^{1}$. But such an indicator will be activated only when the compressor fails to operate properly and thus is a "worst-case" indicator of leakage. Visual push rod adjustment indicators are required on all commercial vehicles manufactured from 1994 [11], [12]. But the use of these indicators also involves manual inspection. The diagnostic schemes presented in this dissertation will use the measurement of the pressure in the brake chamber along with the model presented in chapter IV to automatically monitor the brake system for leaks and out-of-adjustment of push rods. Before presenting the scheme for detecting leaks in the air brake system, a brief review of diagnostic tools that are currently available for monitoring air brake systems is presented.

A. A brief review of existing diagnostic tools for air brake systems

In this section some of the tools that are currently available to monitor the performance of the air brake system are listed. A few patents that have been awarded with respect to developing diagnostic tools for the air brake system are also presented.

Some of the current on-board diagnostic tools give a warning when the push rod stroke exceeds the re-adjustment limit. Transducers measure or infer the push rod

\footnotetext{
${ }^{1}$ The normal range of pressure in the storage reservoirs is $100-130$ psig.
} 
stroke and transmit the signals to a decision module that illuminates a warning light when the stroke exceeds the point of re-adjustment. Also, stroke indicators can be mounted on the push rod to facilitate visual inspections. Brake pad wear indicators are also available to help the inspector to check the level of the brake lining wear.

On August 9, 2002, the Federal Motor Carrier Safety Administration (FMCSA) established a rule to allow for the inspection of commercial vehicles using Performance Based Brake Testers (PBBTs) [93]. Flat plate testers and roller dynamometers are two examples of PBBTs. They measure / infer the brake force generated during a brake application. A few diagnostic systems for air brakes that are commercially available are listed in Table VI.

In a flat plate tester, brakes are applied on a vehicle in motion and the brake forces generated on each axle are measured. In a roller dynamometer, the vehicle is stationary while the wheels of an axle are being rotated on rollers. During a brake application, the resistance offered by the wheels to the rotation of the rollers is an indication of the brake forces generated on that axle.

Next, a list of a few recent patents with regards to diagnostic tools for air brake systems is presented. A more comprehensive list can be found at the website of the United States Patent and Trademark Office (USPTO) [94]. This list of patents is as follows:

1. Patent No. 6,754,568 - Brake response analysis system [June 22, 2004]: This system measures the service brake application and release times and the parking brake application time and checks for compliance with the requirements of FMVSS 121. A data acquisition and recording system is provided to record the pressure in the brake chamber during brake application and release. 
Table VI. A few commercially available diagnostic systems for air brakes

\begin{tabular}{|l|l|l|}
\hline Company Name & Product & Function \\
\hline Hicklin Engg., Inc. & Roller Dynamome- & Measure brake force \\
ters & torque \\
\hline Hunter Engg., Inc. & Flat Plate Testers & Measure brake force \\
\hline $\begin{array}{l}\text { Vehicle Inspection } \\
\text { Systems }\end{array}$ & Roller dynamometers & Measure brake force \\
\hline Radlinski \& Asso- & Roller Brake Testers & Measure brake force \\
ciates & E-Stroke & Measures push rod stroke \\
\hline MGM Brakes & Brake Safe & Visual push rod stroke \\
\hline Spectra Inc. & Brake Inspector & Measures push rod stroke \\
\hline Spectra Inc. & Brake Wear Indica- & $\begin{array}{l}\text { Visual brake pad wear } \\
\text { indicator }\end{array}$ \\
\hline Spectra Inc. & tor & \\
\hline
\end{tabular}


2. Patent No. 6,215,394 - Air brake stroke adjustment monitoring apparatus and method [April 10, 2001]: This apparatus monitors the stroke of the push rod by means of an electrical circuit. Two switches are mounted on the brake chamber and the push rod such that they remain in contact when the push rod stroke is within acceptable limits. When the stroke crosses the readjustment limit, the contact between the switches is broken and the electrical circuit becomes open which serves as an indicator of out-of-adjustment of the push rod.

3. Patent No. 6,019,197 - Air brake stroke gage and seal [February 1, 2000]: It is a visual push rod stroke indicator. An "elastomeric-like" grommet is mounted on the push rod and acts like a seal to the brake chamber when the brakes are not applied. A reference rod is mounted parallel to the push rod and the stroke adjustment is determined by the position of the grommet relative to this reference rod when the push rod strokes out.

4. Patent No. 5,892,437 - On-board brake warning device for air brake equipped vehicles [April 6, 1999]: This tool measures certain parameters in the brake system and compares them with pre-determined values and a fault is indicated once a pre-determined threshold in the difference is crossed. Some of the parameters measured include brake line pressure, time lag between pressurizing a control brake line from the treadle valve and the application of the brake, vehicle speed, etc.

5. Patent No. 5,320,198 - Air brake stroke length adjustment gauge [June 14, 1994]: Reference markers are mounted on the clevis of the push rod and on the arm of the slack adjuster. The state of adjustment of the push rod is inferred visually by the relative motion of these two indicators when the brake 
is applied.

Some other patents for monitoring the push rod stroke include Patent No.s 5,358,076, $5,244,061$ and 4,879,964.

It can be noted that most of the tools listed above mainly monitor the push rod stroke. But leakage in the air brake system too affects the performance of the brake system by increasing the time lag in the brake system and reducing the brake torque generated. Also, it is possible that the stroke of the push rod is within the prescribed limits even in the presence of a big leak in the hoses; but the force transmitted to the drum through the linkages and correspondingly the brake torque will be diminished due to the leakage. Hence, it is equally important to develop a diagnostic tool that can detect leaks in the air brake system in addition to estimating the push rod stroke. It is hoped that the diagnostic schemes presented in this dissertation can be ultimately incorporated into an on-board / portable diagnostic tool for air brakes that achieves both of these objectives.

B. A scheme for detecting leaks in air brake systems

In this section, a procedure for detecting leaks in the air brake system from the measurement of the brake chamber pressure is presented. In the experimental setup, a leak is introduced in the brake system by loosening the hose couplings at the entrance of the brake chamber. Brake applications are made at different supply pressures and the prediction of the model is compared with the corresponding brake chamber pressure measurement in each case.

During "partial" brake applications (a "partial" application refers to a brake application where, in the absence of any leaks and other faults, the steady state brake chamber pressure is less than the supply pressure to the treadle valve) made 
in the absence of a leak, the inlet port of the primary circuit of the treadle valve will close at some point during the brake application process (which is determined in the simulations from the force balance equation, Eq. (4.5)), and there is no further flow of air in the system until the brakes are applied further or released. It is observed that at partial brake applications made in the presence of a leak, the brake system tends to make up for the loss of air due to leakage by continuously bleeding air from the reservoir until the brakes are released. This effect was observed in the experimental setup where the air could be heard flowing through the pressure regulator and other components as long as the brake was kept applied in the presence of a leak. This was not the case when there were no leaks in the system.

The above observation is illustrated in Fig. 26 where one can hardly notice any difference between the steady state pressure predicted by the "fault-free" model and that from the experimental data for a partial brake application test run despite the presence of a leak in the system. Also, the response of the treadle valve is such that the full range of brake chamber pressure is realized in a very narrow range of the plunger displacement. This is illustrated in Figs. 27 and 28 where the steady state values of the brake chamber pressure and the treadle valve plunger displacement have been plotted for a wide range of test runs performed at a supply pressure of $653 \mathrm{kPa}(80 \mathrm{psig})$ and $722 \mathrm{kPa}$ (90 psig) respectively. It can be observed that the majority of the pressure range is achieved within a span of $0.002 \mathrm{~m}$ of the plunger displacement. Thus, the prediction of the steady state brake chamber pressure by the model at partial applications is sensitive to measurements from the treadle valve displacement transducer. External factors such as noise, temperature, etc., affect these measurements and there is invariably some error between the prediction of the model and the measured steady state brake chamber pressure. This is illustrated in Figs. 29 and 30 where the steady state brake chamber pressure predicted by the 
model is lower than the measured value during a partial brake application carried out in the presence of a leak. These are the issues that have posed a challenge in developing reliable leak detection schemes while making partial brake applications.

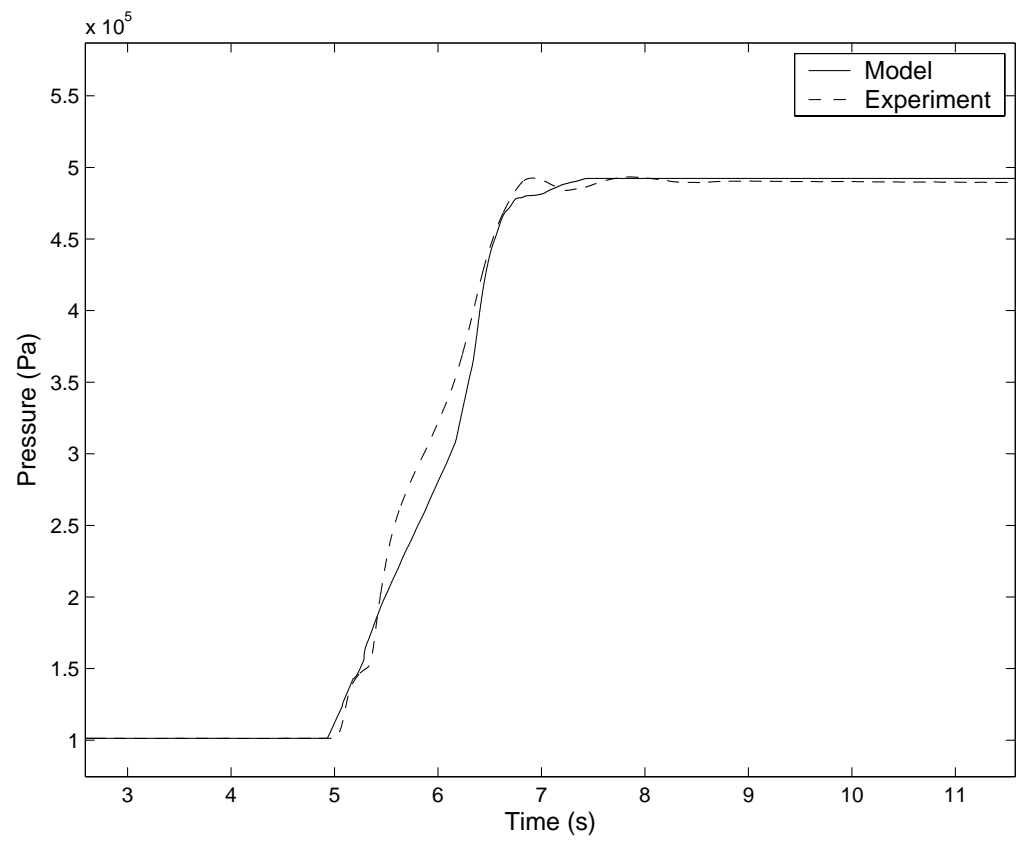

Fig. 26. Pressure transients at $653 \mathrm{kPa}(80 \mathrm{psig})$ supply pressure - partial application with leak

It has been found that a reliable and repeatable manner of detecting leaks in the current configuration of the air brake system is to make a "full" brake application (a "full" application refers to a brake application where, in the absence of any leaks and other faults, the steady state brake chamber pressure is almost equal to the supply pressure to the treadle valve). In such an application made in the presence of a leak, it has been observed that the air still keeps flowing through the system as long as the brake is applied. But, it should be noted that the maximum steady state brake chamber pressure that can be reached during a brake application is the supply pressure to the treadle valve. This can happen only during full brake applications 


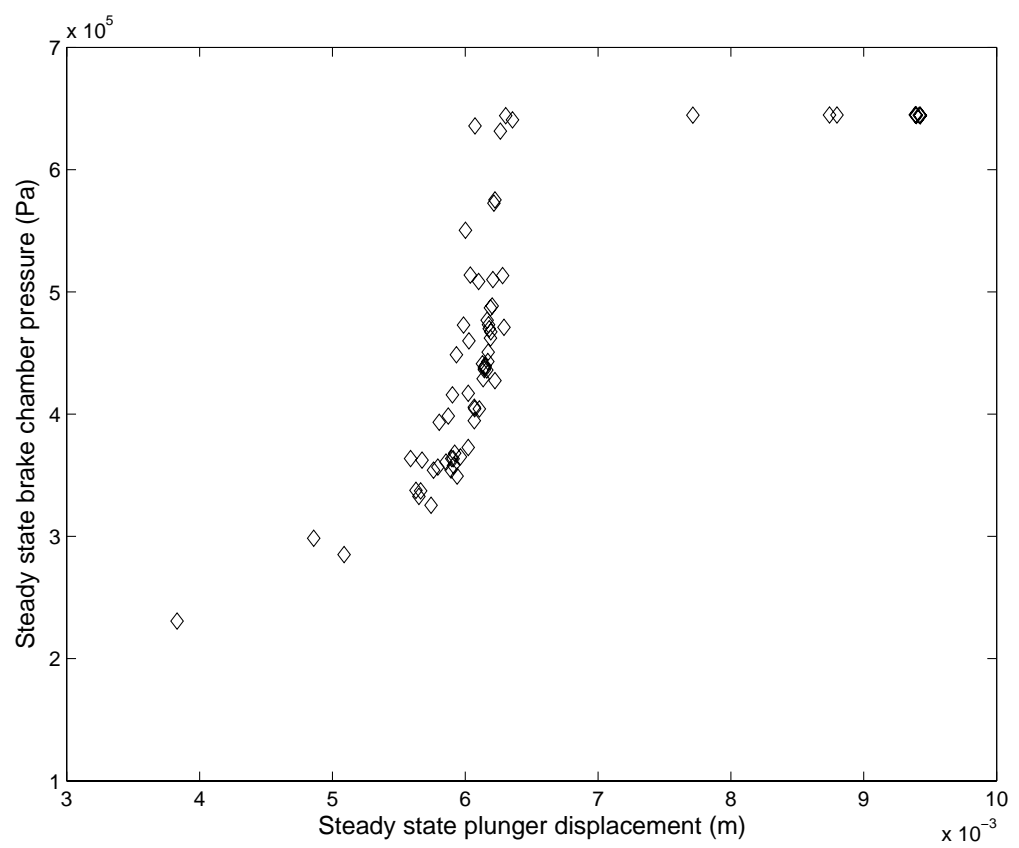

Fig. 27. Steady state treadle valve plunger displacement and brake chamber pressure at $653 \mathrm{kPa}$ (80 psig) supply pressure

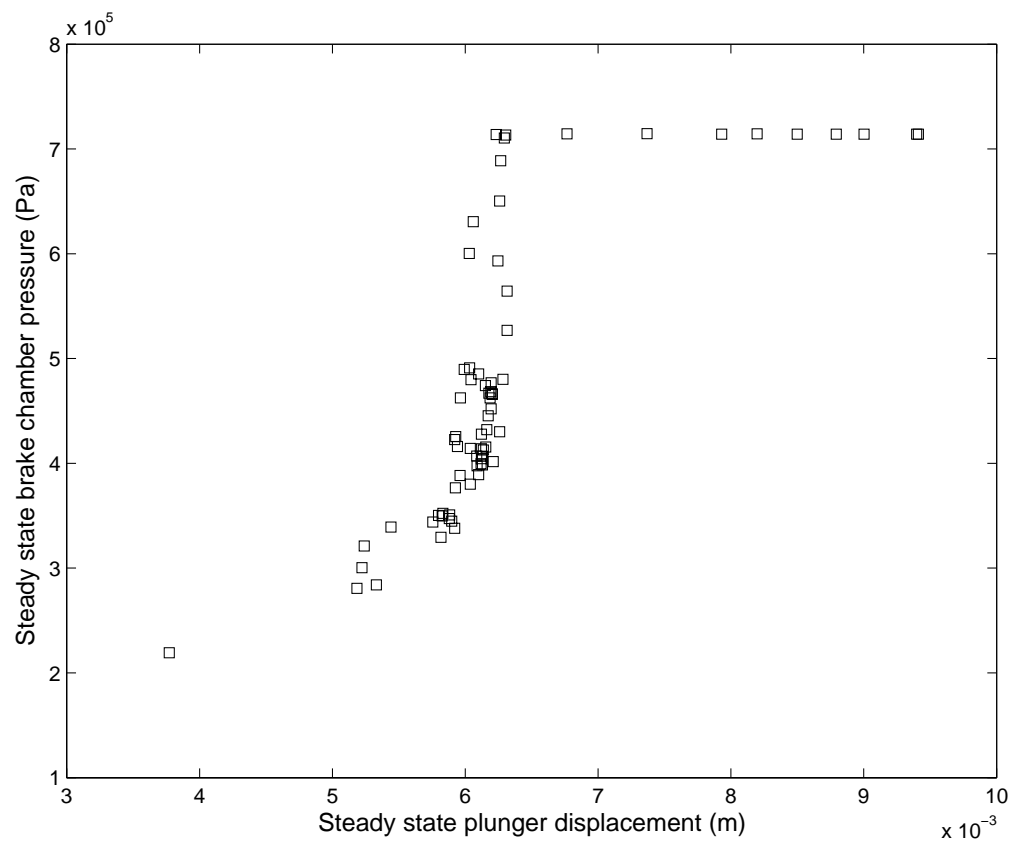

Fig. 28. Steady state treadle valve plunger displacement and brake chamber pressure at $722 \mathrm{kPa}$ (90 psig) supply pressure 




Fig. 29. Pressure transients at $653 \mathrm{kPa}$ (80 psig) supply pressure - partial application with leak

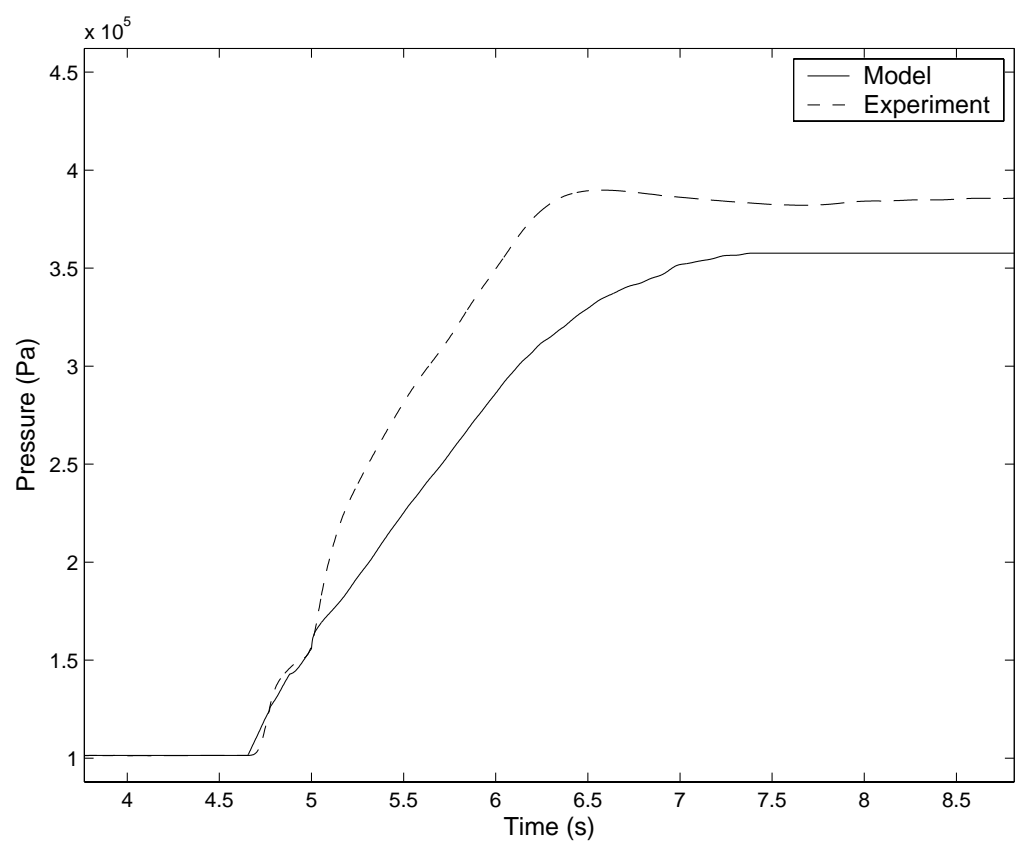

Fig. 30. Pressure transients at $515 \mathrm{kPa}$ (60 psig) supply pressure - partial application with leak 
with no leaks in the system. The "fault-free" model developed in chapter IV reliably predicts that during full brake applications, the steady state brake chamber pressure is the supply pressure to the treadle valve. It has been observed from experiments that, during a full brake application made in the presence of a leak, the measured steady state brake chamber pressure is always lower than that predicted by the fault-free model. This behavior is illustrated in Figs. 31 to 38 for various full brake applications carried out over a range of supply pressures.

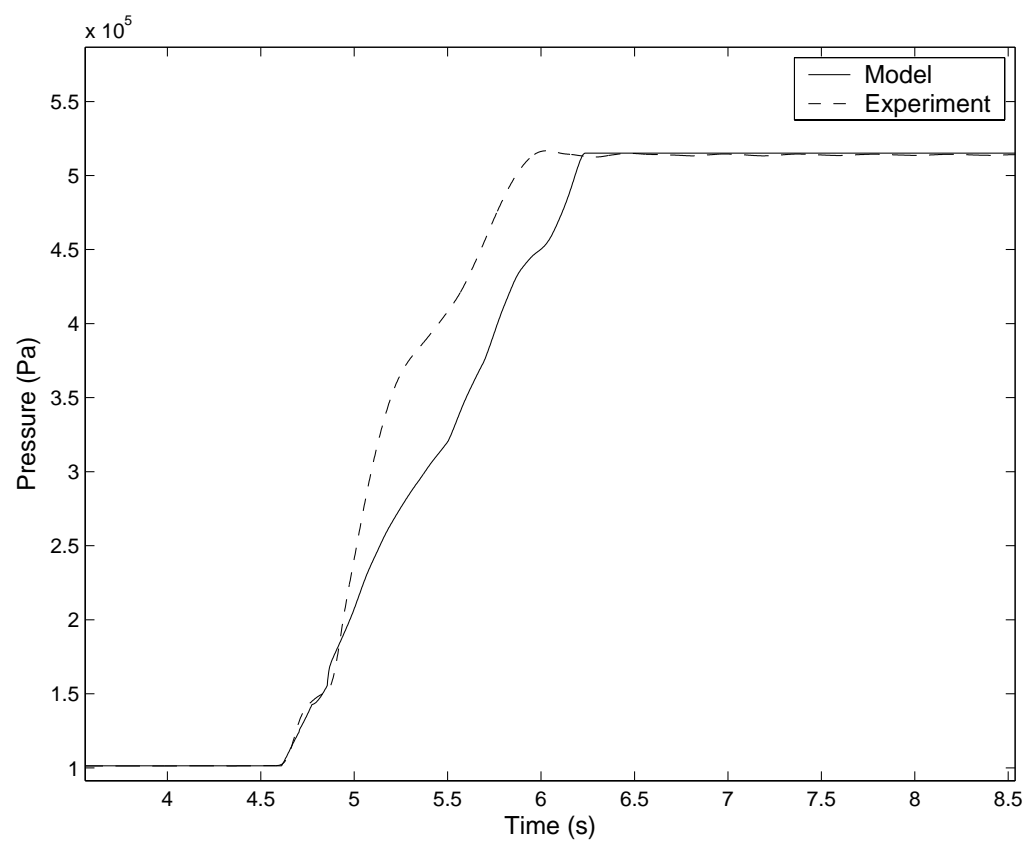

Fig. 31. Pressure transients at $515 \mathrm{kPa}(60 \mathrm{psig})$ supply pressure - full application without leak

It can be inferred from Figs. 31, 33, 35 and 37 that in the absence of leaks, the steady state brake chamber pressure predicted by the model and the actual measurement are in good agreement. A marked difference is observed between these two values when a leak is introduced in the system as can be seen from Figs. 32, 34, 36 and 38. Also, the pressure rise (observed from the measured data) becomes "sluggish" 


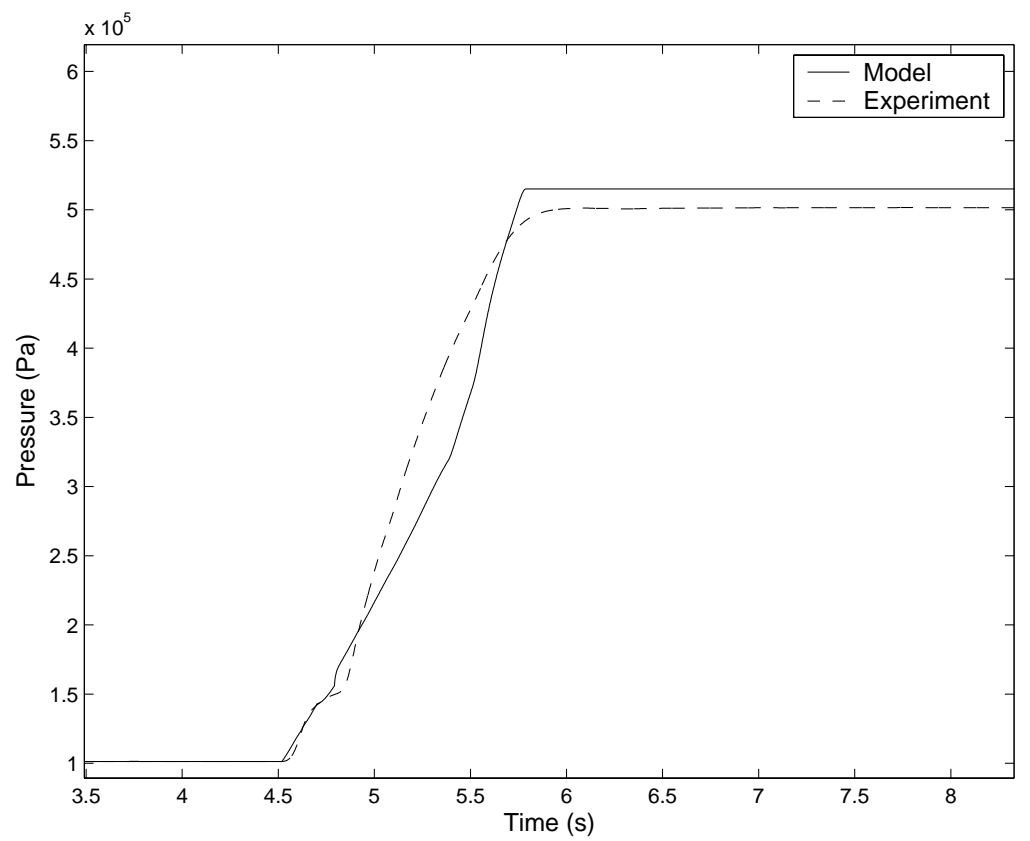

Fig. 32. Pressure transients at $515 \mathrm{kPa}$ (60 psig) supply pressure - full application with leak

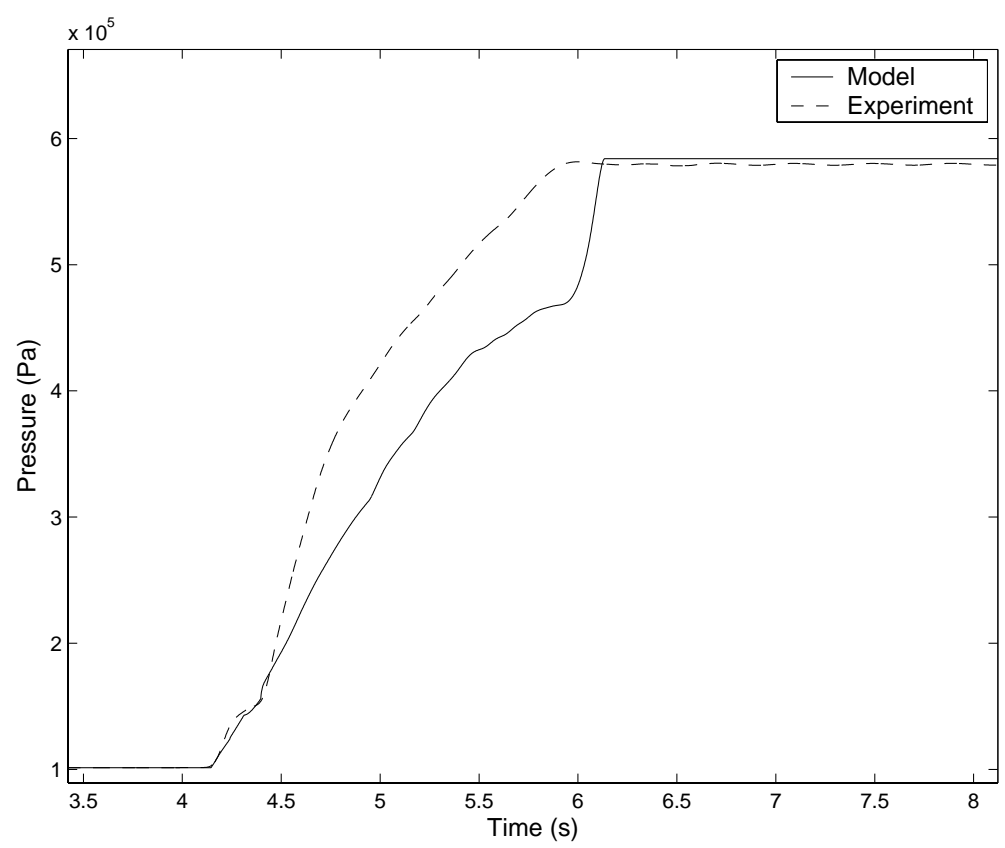

Fig. 33. Pressure transients at $584 \mathrm{kPa}$ (70 psig) supply pressure - full application without leak 




Fig. 34. Pressure transients at $584 \mathrm{kPa}$ (70 psig) supply pressure - full application with leak

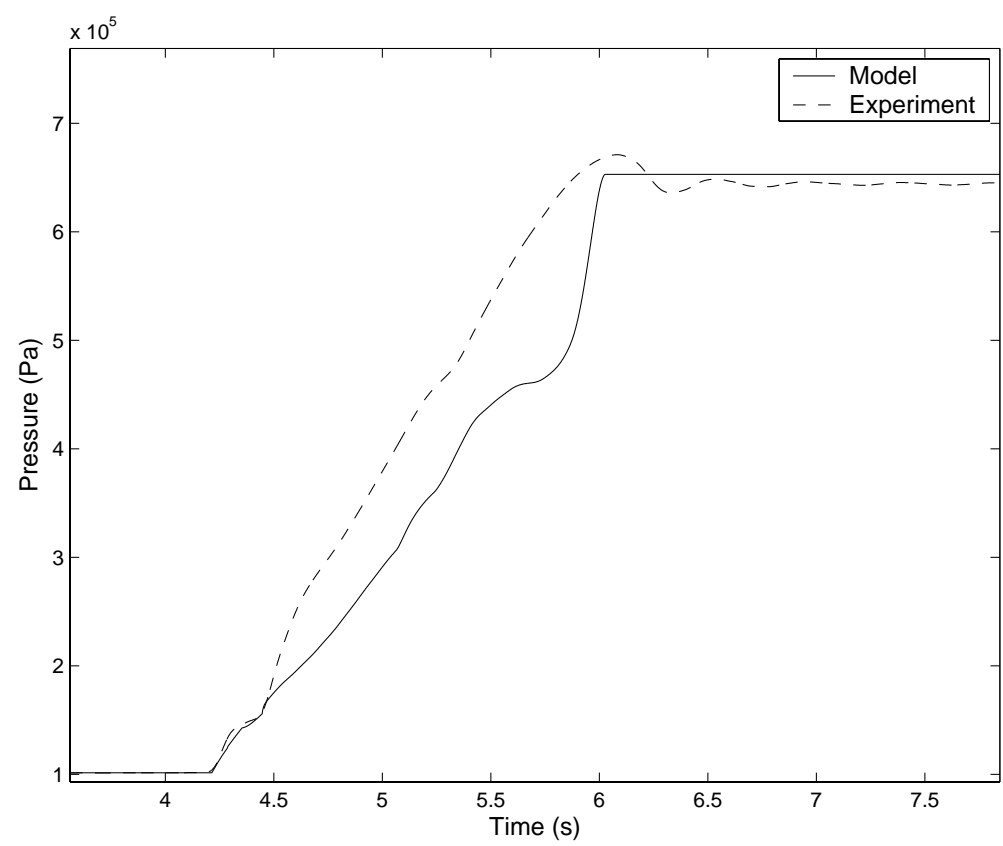

Fig. 35. Pressure transients at $653 \mathrm{kPa}$ (80 psig) supply pressure - full application without leak 


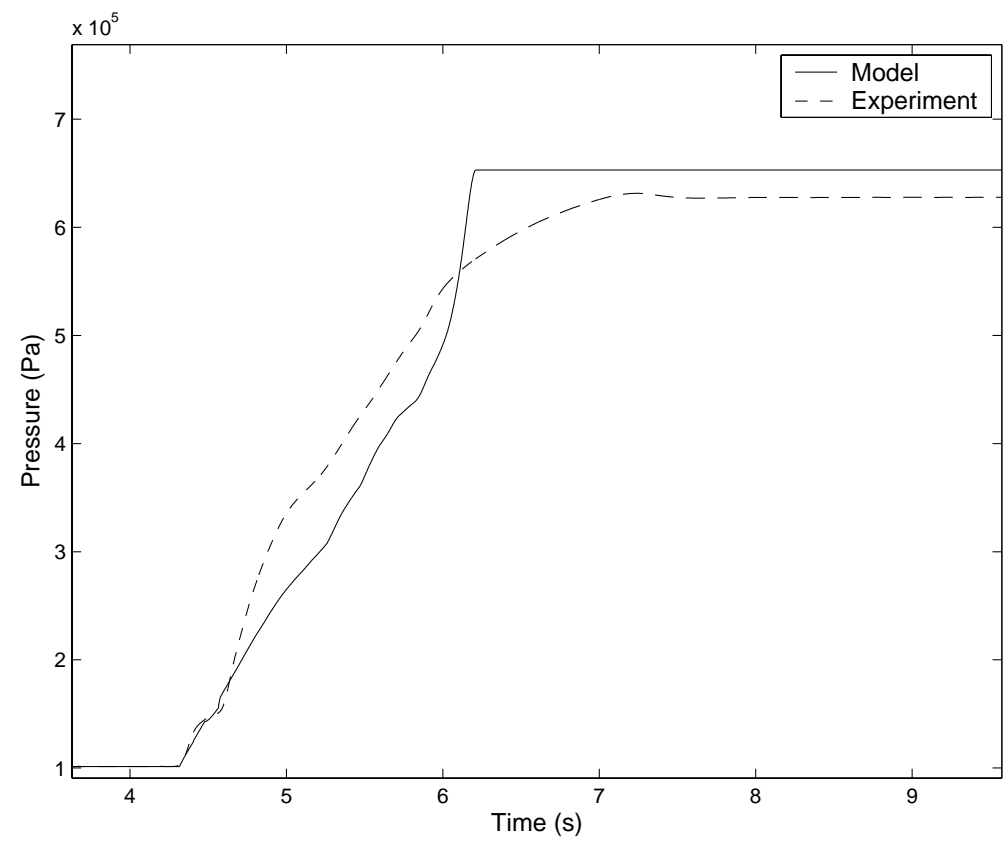

Fig. 36. Pressure transients at $653 \mathrm{kPa}$ (80 psig) supply pressure - full application with leak

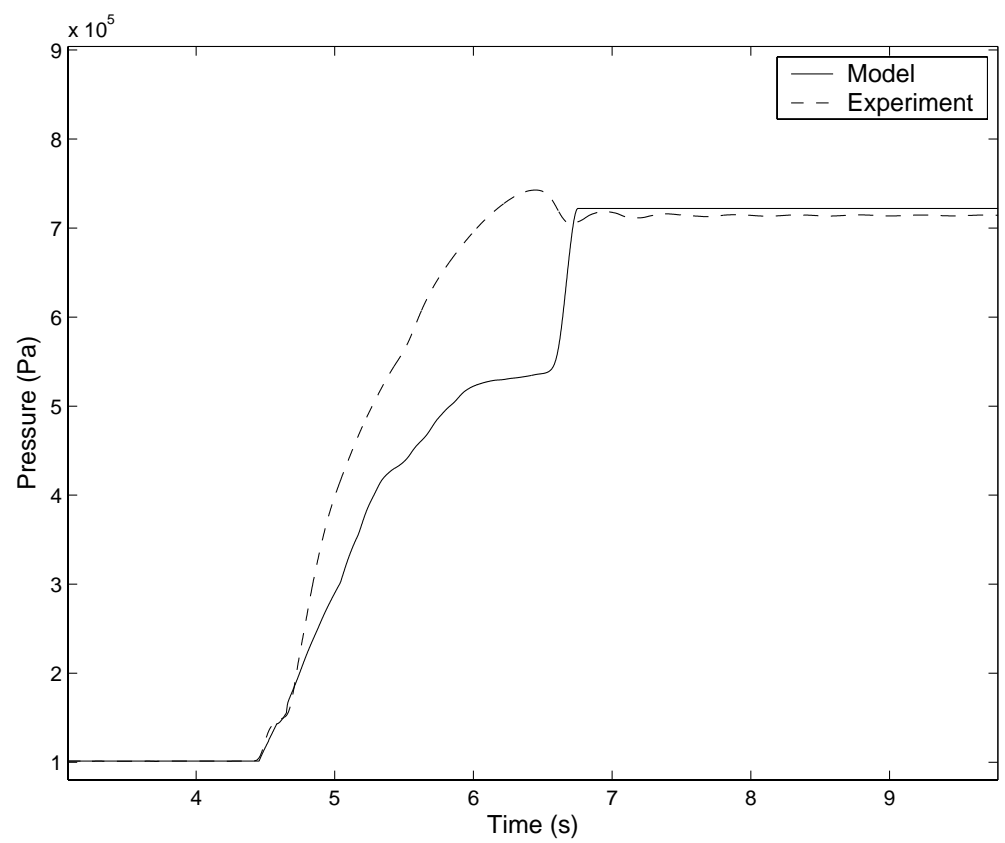

Fig. 37. Pressure transients at $722 \mathrm{kPa}$ (90 psig) supply pressure - full application without leak 


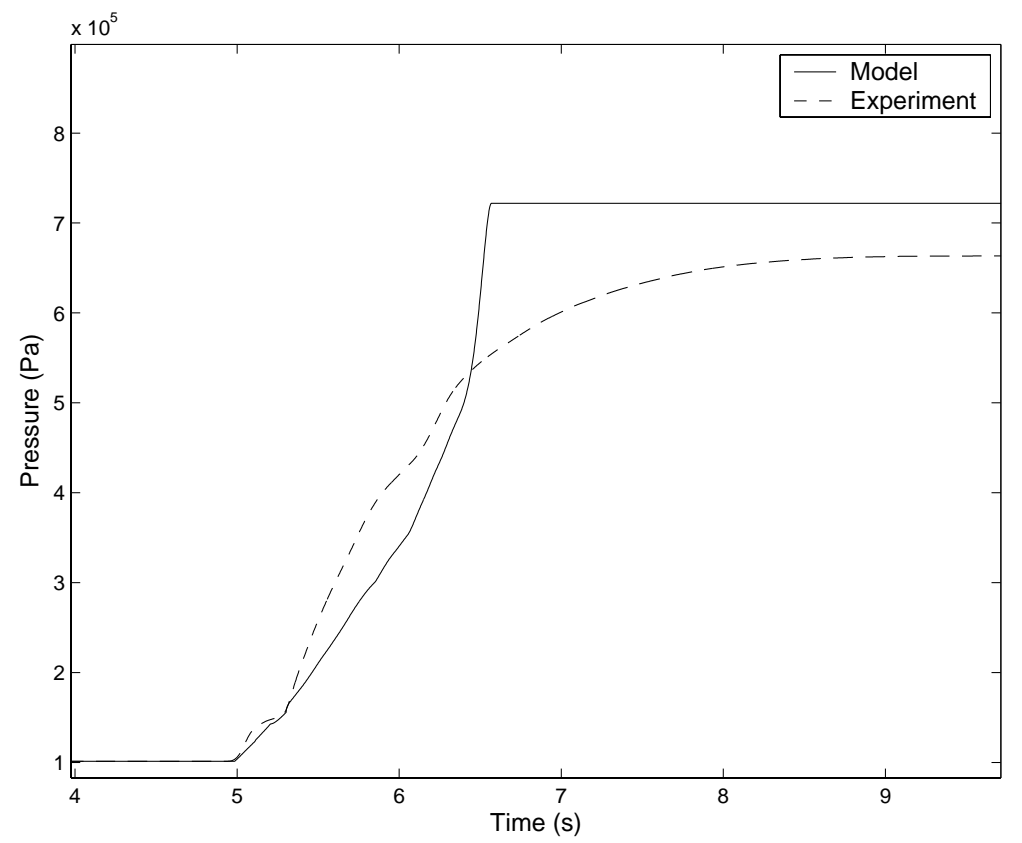

Fig. 38. Pressure transients at $722 \mathrm{kPa}$ (90 psig) supply pressure - full application with leak

when there is a leak in the system compared to cases without a leak. This effect is very pronounced at $722 \mathrm{kPa}$ (90 psig) supply pressure when compared with the other test runs. It should be noted that the pressure capacity of the reservoir used in the experiments is between $756.4 \mathrm{kPa}(95 \mathrm{psig})$ and $825.3 \mathrm{kPa}(105 \mathrm{psig})$ and hence this behavior is more prominent as the supply pressure approaches the maximum pressure capacity of the reservoir. Also, it has already been mentioned that the model reliably predicts that the steady state brake chamber pressure in a full brake application is equal to the supply pressure. Thus, checking for leaks involves the measurement of the supply pressure and comparing it with the measured steady state brake chamber pressure while making a full brake application.

Next, a quantitative look at the differences between the steady state brake chamber pressure predicted by the model and the measured value for the various test runs illustrated in Figs. 31 to 38 is presented. The results are presented in Table VII. In 
Table VII. Error between the predicted and the measured steady state brake chamber pressure

\begin{tabular}{|c||c|c||c|c||c|c|}
\hline \multirow{2}{*}{ Supply Pressure $(\mathrm{kPa} / \mathrm{psig})$} & \multicolumn{2}{||}{$P_{\text {ssim }}(\mathrm{kPa})$} & \multicolumn{2}{|||}{$P_{\text {smeas }}(\mathrm{kPa})$} & \multicolumn{2}{c|}{$\%$ difference } \\
\cline { 2 - 7 } & No leak & Leak & No leak & Leak & No leak & Leak \\
\hline $515 / 60$ & 515 & 515 & 514.1 & 501.6 & 0.175 & 2.602 \\
$584 / 70$ & 584 & 584 & 579.7 & 565.1 & 0.736 & 3.236 \\
$653 / 80$ & 653 & 653 & 644.2 & 627.8 & 1.348 & 3.859 \\
$722 / 90$ & 722 & 722 & 714.1 & 658.4 & 1.094 & 8.809 \\
\hline
\end{tabular}

this table, $P_{\text {ssim }}$ refers to the steady state brake chamber pressure predicted by the model for a brake application and $P_{\text {smeas }}$ is the steady state brake chamber pressure measured for that brake application. The percentage difference is calculated by using the following formula:

$$
\% \quad \text { difference }=\frac{\left(P_{\text {ssim }}-P_{\text {smeas }}\right)}{P_{\text {ssim }}} * 100
$$

It can be observed from Table VII that there is an appreciable increase in the percentage error when a leak is introduced in the system when compared to the case when there is no leakage.

C. Determination of thresholds for the detection of leaks

The leak detection scheme presented in this dissertation relies on the introduction of a substantial difference between the steady state brake chamber pressure and the supply pressure during a full brake application. In order to implement this scheme in practice, it is important to establish a reliable threshold value such that the occurrence of a leak can be declared once this difference exceeds this threshold value. In this 
section, a preliminary determination of such a threshold value is presented on the basis of experimental data.

Test runs that involved the full application of the brake were carried out at different supply pressures both in the presence and the absence of a leak over a period of many days. The results from these experiments are presented in Figs. 39 to 42. In these figures, the term "Normalized steady state pressure" has been plotted on the ordinate. This is obtained by dividing the measured steady state pressure for a particular test run by the supply pressure for that test run. An appreciable difference can be observed between the test runs made in the presence of a leak and those made in the absence of a leak.

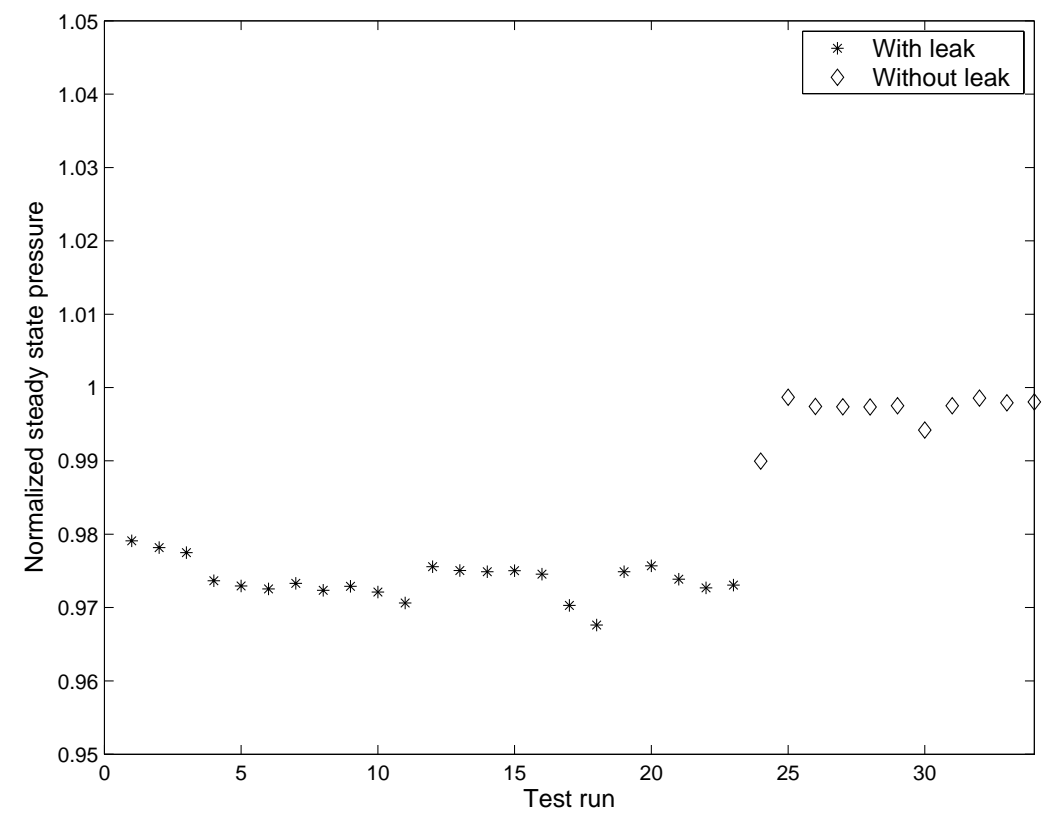

Fig. 39. Comparison of test runs with and without leaks at $515 \mathrm{kPa}$ (60 psig) supply pressure

For tests carried out at supply pressures of $515 \mathrm{kPa}(60 \mathrm{psig})$ and $584 \mathrm{kPa}(70$ psig), it can be observed that, the normalized steady state pressure is always below 


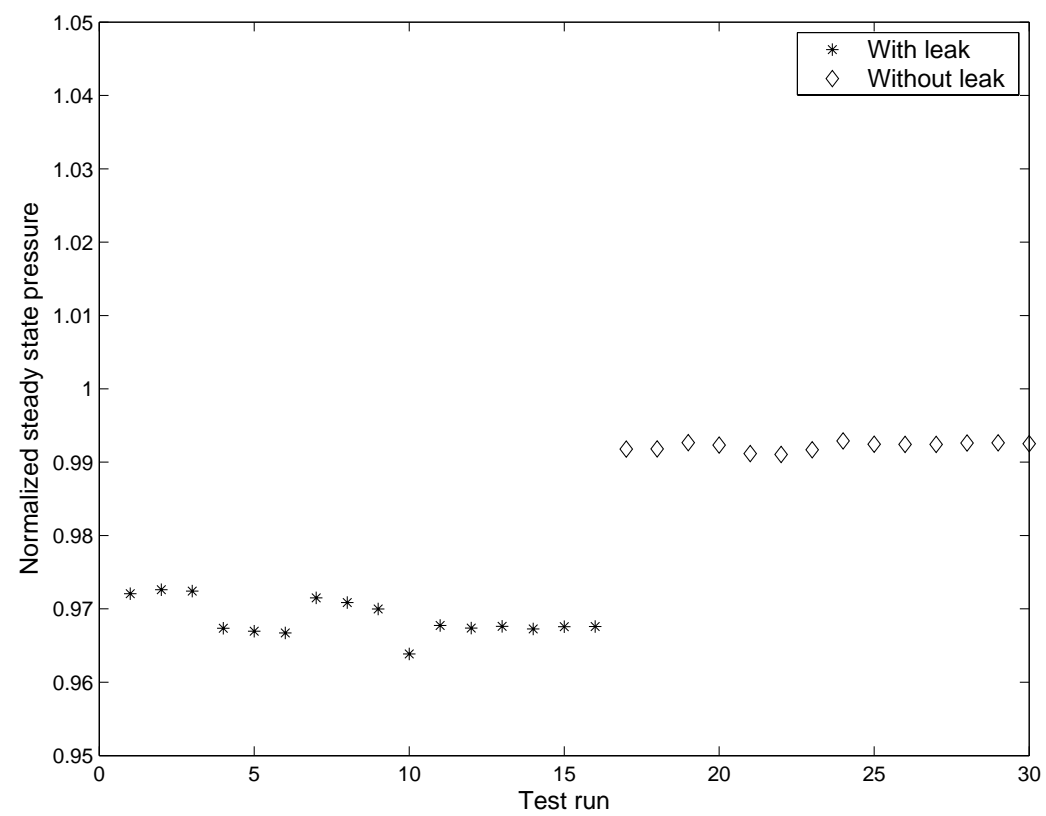

Fig. 40. Comparison of test runs with and without leaks at $584 \mathrm{kPa}$ (70 psig) supply pressure

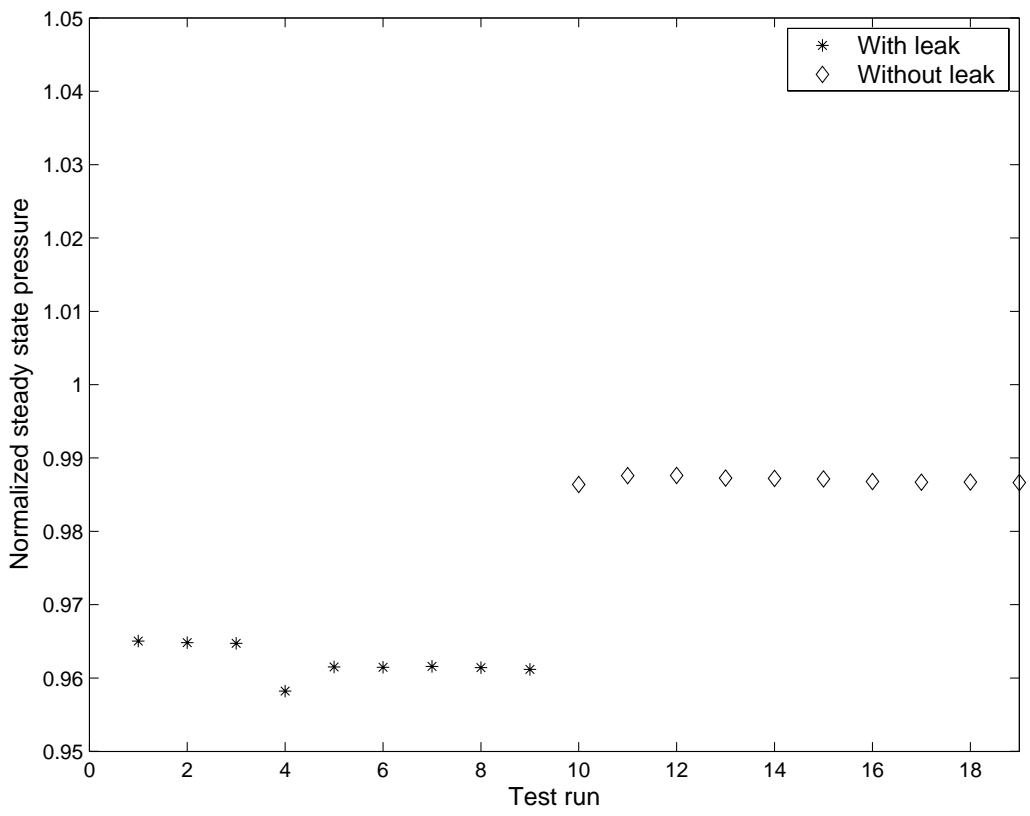

Fig. 41. Comparison of test runs with and without leaks at $653 \mathrm{kPa}$ (80 psig) supply pressure 




Fig. 42. Comparison of test runs with and without leaks at $722 \mathrm{kPa}$ (90 psig) supply pressure

0.98 in the presence of a leak and is always above 0.99 in the absence of a leak. With a supply pressure of $653 \mathrm{kPa}(80 \mathrm{psig})$, this value is always below 0.97 in the presence of a leak. When the supply pressure is $722 \mathrm{kPa}(90 \mathrm{psig})$, this value is always below 0.93 in the presence of a leak. At supply pressures of $653 \mathrm{kPa}(80 \mathrm{psig})$ and $722 \mathrm{kPa}$ (90 psig), this value is above 0.98 in the absence of a leak. Since the regulations for air brake testing prescribe a full brake application with a supply pressure of 80 to 90 psig, a suitable threshold for detecting leaks in the configuration of the brake system under consideration can be chosen to be 0.97 .

It should be recalled that the configuration of the brake system under consideration in this dissertation is one where the delivery port of the primary circuit is directly connected to one of the front brake chambers. The objective of this section is to illustrate a method for selecting thresholds for leak detection using the proposed leak detection scheme. The thresholds for the entire brake system should be deter- 
mined by carrying out experiments on the air brake system in an actual commercial vehicle. Many factors affect the selection of these threshold values. The accuracy of the pressure sensor plays a vital role in the determination of thresholds. Also, the air brake system contains check valves that will operate only when the difference between the pressure at the inlet port and the outlet port exceeds a certain minimum value (usually 2 to $3 \mathrm{psig}$ ). Due to the presence of such valves, the steady state pressure in the brake chamber might be less than the supply pressure even in the absence of a leak. Thus, the presence of such valves may also affect the selection of thresholds for leak detection. 


\section{CHAPTER VI}

\section{ESTIMATION OF THE PUSH ROD STROKE}

In this chapter, two schemes will be presented to obtain an estimate of the push rod stroke during the brake application process. These schemes will use the hybrid model for the pressure transients in the brake chamber and the measurement of the pressure to obtain an estimate of the push rod stroke. Thus, these schemes can be used to monitor the air brake system for out-of-adjustment of the push rods. These schemes have been corroborated with experimental data and the results are presented. Before presenting details of these schemes, the effect of variation of the push rod stroke on the pressure transients in the brake chamber will be illustrated with experimental data.

A. Effect of push rod stroke on the pressure transients

In this section, the effect of variation of the push rod stroke on the pressure transients in the brake chamber is presented. A set of experimental test runs are carried out by connecting the secondary delivery port of the treadle valve to the Quick Release Valve (QRV) and the delivery ports of the QRV are connected to each of the two front brake chambers (FBC). These two front brake chambers are labeled as FBC \# 1 and FBC \# 2 for convenience. The stroke of the push rod of each of these brake chambers is adjusted by rotating the manual adjustment nut on the corresponding automatic slack adjuster mounted on the S-cam shaft associated with that brake chamber. The rotation of this nut essentially varies the clearance between the brake pads and the brake drum and thus the push rod stroke. The automatic stroke adjustment feature of the automatic slack adjuster is disengaged when performing these experiments. In this set of experiments, the stroke of the push rod of FBC \# 2 is kept fixed and 
that of $\mathrm{FBC} \# 1$ varied over a wide range to observe the effects of the push rod stroke variation on the pressure transients. The measured pressure transients for these various test runs are presented in Figs 43 to 46 . In these figures, $x_{1}$ refers to the steady state stroke of the push rod of FBC \# 1 and $x_{2}$ refers to the steady state stroke of the push rod of FBC \# 2 .



Fig. 43. Pressure transients at $515 \mathrm{kPa}$ (60 psig) supply pressure $-x_{1}=0.016 \mathrm{~m}(0.63$ in), $x_{2}=0.02398 \mathrm{~m}(0.944 \mathrm{in})$

It can be observed from Figs. 43 to 46 that the pressure transients in both chambers start simultaneously. The steady state values are also equal in both brake chambers. The major difference can be observed in the second phase of the pressure growth curve which corresponds to the phase when the push rod strokes out. The stroke of the push rod of FBC \# 2 is kept fixed at around $0.02388 \mathrm{~m}$ (0.94 inches) and the stroke of the push rod of FBC \# 1 is varied. It can be observed from Fig. 43 that when $x_{1}$ is less than $x_{2}$ the second phase of the pressure transients in FBC \# 


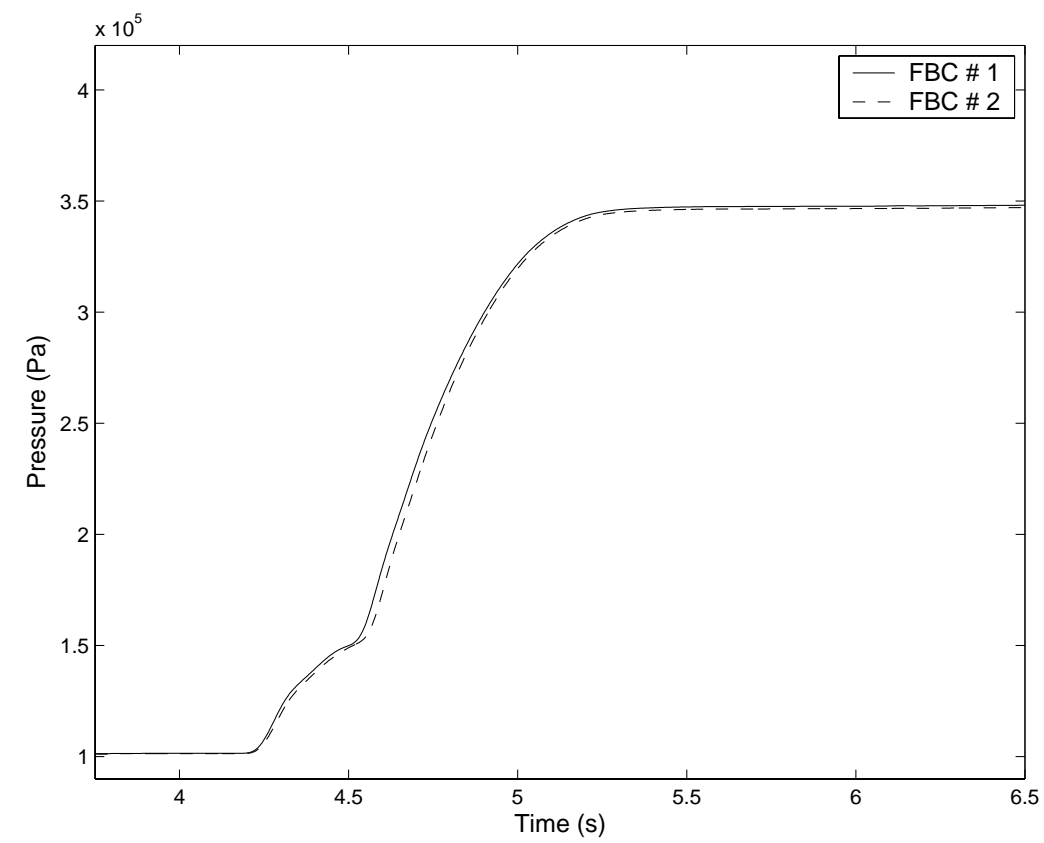

Fig. 44. Pressure transients at $515 \mathrm{kPa}(60 \mathrm{psig})$ supply pressure $-x_{1}=0.02324$ $\mathrm{m}(0.915 \mathrm{in}), x_{2}=0.0237 \mathrm{~m}(0.933 \mathrm{in})$

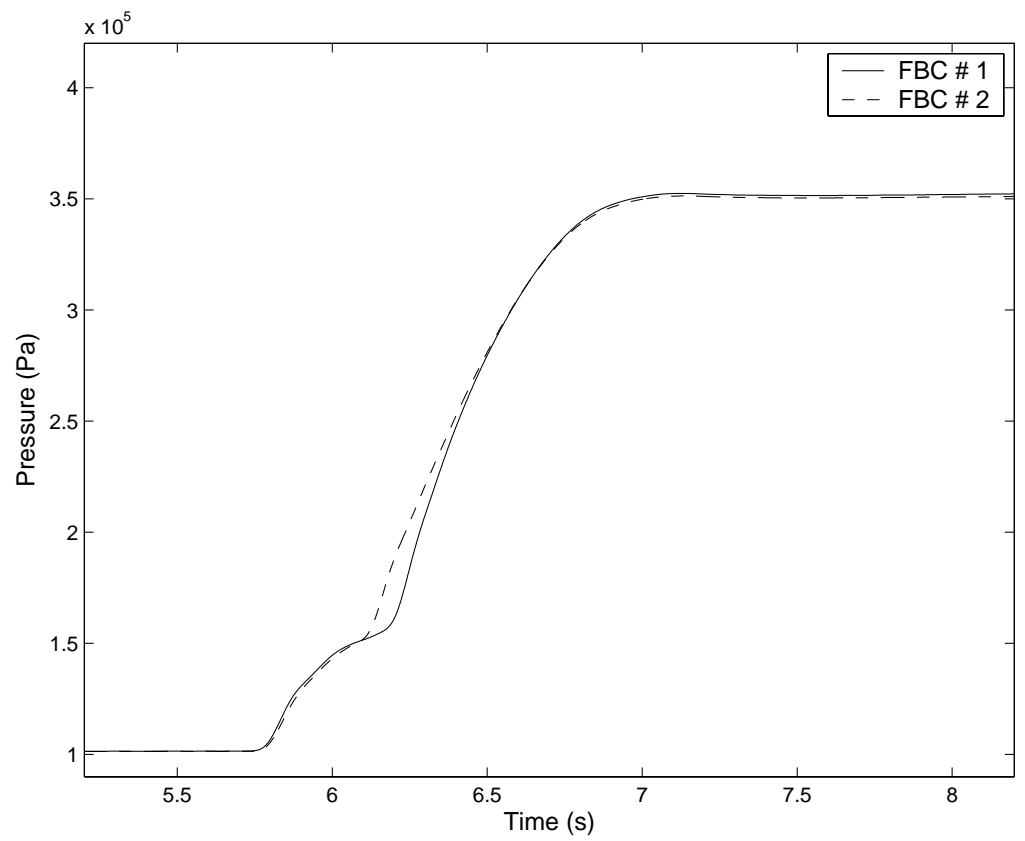

Fig. 45. Pressure transients at $515 \mathrm{kPa}$ (60 psig) supply pressure $-x_{1}=0.3505 \mathrm{~m}(1.38$ in), $x_{2}=0.02385 \mathrm{~m}(0.939 \mathrm{in})$ 


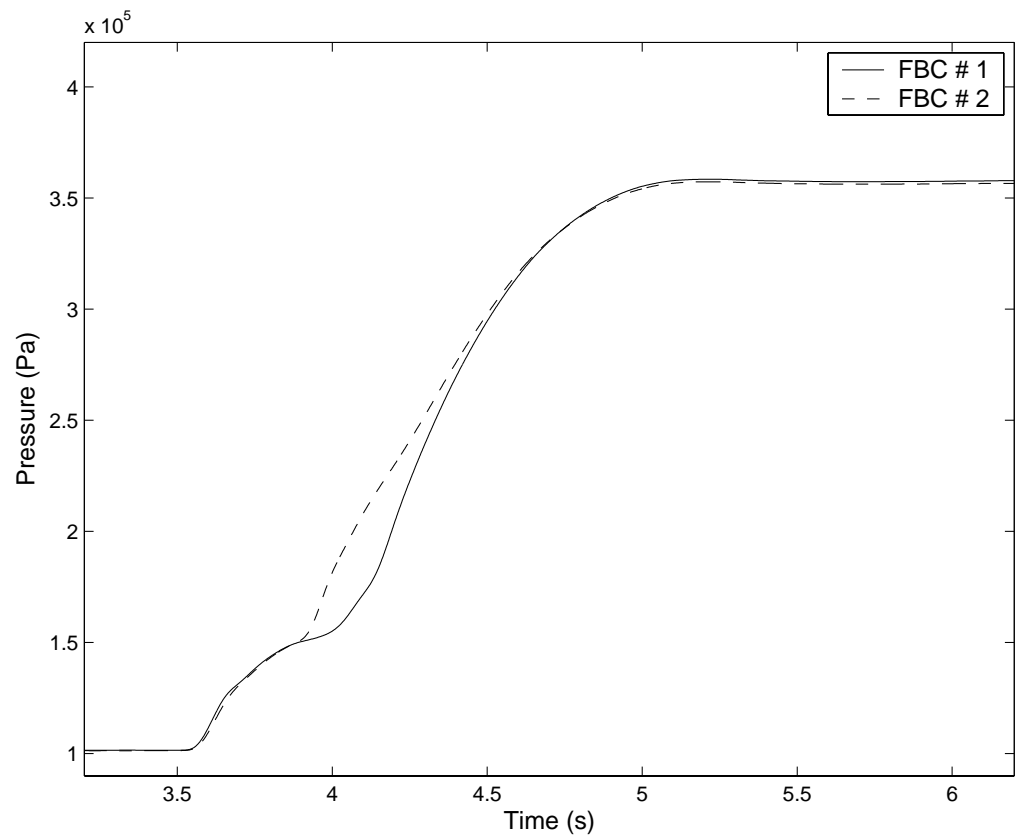

Fig. 46. Pressure transients at $515 \mathrm{kPa}$ (60 psig) supply pressure $-x_{1}=0.0479$ $\mathrm{m}$ (1.886 in), $x_{2}=0.02393 \mathrm{~m}(0.942 \mathrm{in})$

1 is shorter than that in FBC \# 2. Fig. 44 illustrates that when the strokes of both push rods are almost equal, the pressure transients in both chambers almost overlap one another. When $x_{1}$ is increased to a value greater than $x_{2}$, the second phase of the pressure transients in FBC \# 1 is longer than that in FBC \# 2. This is shown in Fig. 45. This difference becomes more pronounced when $x_{1}$ is increased even further as can be observed from Fig. 46. Thus, one can observe the effect of the variation of the push rod stroke on the second phase of the pressure transients in the brake chamber. This effect will be used to develop schemes for estimating the push rod stroke. 
B. Schemes for estimating the stroke of the push rod

In this section, two schemes for estimating the stroke of the push rod from the measurement of the brake chamber pressure are discussed. It was illustrated in chapter IV that the final stroke of the push rod is made up of two parts - the first part is for overcoming the clearance between the brake pads and the brake drum and the second part is due to the subsequent deformation of the mechanical components. Thus, from Eq. (4.12), the steady state stroke of the push rod $\left(x_{b s s}\right)$ can be written as

$$
x_{b s s}=M_{2}\left(P_{b s s}-P_{c t}\right)+M_{1} P_{c t}+N_{1},
$$

where $P_{b s s}$ is the steady state brake chamber pressure. The value of $P_{b s s}$ can be found from the measured pressure data. Thus, the problem of estimating the final stroke is equivalent to obtaining a good estimate of the parameter $P_{c t}$ (which is the brake chamber pressure at which the clearance between the brake pads and the brake drum is overcome).

Two schemes are now presented that provide an estimate of $P_{c t}$ and thus an estimate for the push rod stroke. In the first scheme, the range of possible values of $P_{c t}$ is discretized into sufficiently small intervals. Then, a pressure residue measure is calculated for each possible value of $P_{c t}$ and the one that minimizes this measure is taken to be the estimate of $P_{c t}$. In the second scheme, a method is proposed for detecting the transition from Mode 2 to Mode 3 and subsequently an estimate of $P_{c t}$ is obtained.

1. Scheme 1 - Estimation of the push rod stroke by discretization of the possible range of values

In this scheme, the following procedure is proposed to obtain an estimate of $P_{c t}$ [95]: 
1. From the physical limits on the stroke of the push rod, bounds on the value of $P_{c t}$ can be obtained. Let $P_{c t l}$ and $P_{c t u}$ denote respectively the lower bound and the upper bound on $P_{c t}$. It should be noted that the lower bound corresponds to zero clearance between the brake pad and the brake drum and the upper bound is obtained from the maximum possible push rod stroke. The maximum push rod stroke for the "Type-20" brake chamber that is being used in the experimental setup is $0.05715 \mathrm{~m}$ (2.25 in) [96]. The value of $P_{c t l}$ is found from experiments to be $142.73 \mathrm{kPa}(6 \mathrm{psig})$ and the value of $P_{c t u}$ is calculated to be $184.1 \mathrm{kPa}(12 \mathrm{psig})$.

2. The estimate of $P_{c t}$, denoted by $\hat{P}_{c t}$, will lie in the interval between $P_{c t l}$ and $P_{c t u}$. In order to obtain this value, the interval $\left[P_{c t l}, P_{c t u}\right]$ is discretized into finer intervals by using a step size $(\delta P)$ of $689.5 \mathrm{~Pa}(0.1 \mathrm{psi})$. Thus, a set $\mathcal{P}$ is obtained whose elements are equally spaced by a step size of $\delta P$ and whose first and last elements are $P_{c t l}$ and $P_{c t u}$ respectively. It was illustrated in chapter IV that, the push rod stroke needed to overcome the clearance between the brake pads and the brake drum is reflected in the second region (Mode 2) of the pressure growth curve. Hence, the focus is restricted to this region for obtaining $\hat{P}_{c t}$.

3. Next, the governing equations of the model (Eqs. (4.5), (4.14) and (4.15)) are solved numerically for each element in the set $\mathcal{P}$ to obtain the corresponding solution of the brake chamber pressure. Then, the following pressure error / residue measure is calculated:

$$
e_{P}\left(P_{c t i}\right)=\sum_{j=0}^{k}\left|P_{\text {meas }}(j)-P_{b}\left(P_{c t i}\right)(j)\right|,
$$

where $P_{\text {meas }}(j)$ is the measured brake chamber pressure at the $j^{\text {th }}$ instant of 
time and $P_{b}\left(P_{c t i}\right)(j)$ is the solution of the model (at the same instant of time) corresponding to $P_{c t i}$ which is given by

$$
P_{c t i}=P_{c t l}+(\delta P) i, \quad i=0, \ldots, N
$$

where $\delta P=\frac{\left(P_{c t i}-P_{c t l}\right)}{N}$.

4. The choice of $k$ in Eq. (6.2) is determined by the maximum possible dwell time of the system in Mode 2. Depending on the brake pad to brake drum clearance this time interval will vary. But it has been observed from experiments that this time interval is usually not more than $0.3-0.35$ seconds. The sampling time used in the experiments is 2 milliseconds. Hence, the value of $\mathrm{k}$ is chosen to be 200 (which corresponds to a time interval of 0.4 seconds). It should be pointed out that $j=0$ corresponds to the time instant at which Mode 2 starts. Hence, one starts at the beginning of Mode 2 (which occurs when the brake chamber pressure reaches the threshold pressure $\left.\left(P_{t h}\right)\right)$ and calculates the quantity $e_{P}\left(P_{c t i}\right)$ given by Eq. (6.2). This procedure is repeated for each value of $P_{c t i}$ and finally an array of values representing the residue measure given by Eq. (6.2) is generated. Then, the estimate $\hat{P}_{c t}$ is obtained as

$$
\hat{P}_{c t}=\operatorname{argmin}_{P_{c t i} \in \mathcal{P}} e_{P}\left(P_{c t i}\right)
$$

The results obtained by using this scheme on two test runs are illustrated in Fig. 47 and Fig. 48. Before discussing the results a few practical issues involved in implementing the scheme are pointed out. Obtaining accurate measurements of the brake chamber pressure and the treadle valve plunger displacement is critical to the successful implementation of this scheme. In reality, measurements are corrupted by noise and environmental factors. Efforts have been made to minimize the effects of 
noise by using shielded twisted pair cables for transmitting electrical signals. Also, a shielded connector block has been used for interfacing the transducers with the DAQ board. Environmental effects such as temperature, humidity, etc., try to shift the initial reading ("zero reading") of the transducers and also affect their calibration curves. These effects are minimized by obtaining the initial readings at the start of each and every set of experiments and taking their variation into account while converting voltage signals into physical quantities (such as pressure, displacement, etc.). Also, a digital filter with a cut-off frequency of $10 \mathrm{~Hz}$. is used to further minimize the effect of noise.

In Fig. 47, the results obtained for a test run made at $653 \mathrm{kPa}$ (80 psig) supply pressure are plotted. The array of the pressure error / residue is calculated and the minimum value is located and the estimate $\hat{P}_{c t}$ is obtained from $\mathcal{P}$ as the value corresponding to this minimum residue. On the ordinate the term "Normalized pressure residue" has been plotted. The values corresponding to this term are obtained by dividing the array of the residues by its minimum value (thus the minimum residue will always be given a value of 1 ). Once the value of $\hat{P}_{c t}$ is determined an estimate of the final push rod stroke is obtained by using Eq. (6.1). In this case, the best estimate of the push rod stroke is obtained to be $0.03381 \mathrm{~m}$ (1.3311 in) while the measured value of the stroke is $0.03114 \mathrm{~m}$ (1.2262 in). It can be observed that the normalized pressure residue corresponding to the actual stroke is around 1.007 which differs by $0.7 \%$ from the residue corresponding to the estimated stroke. In Fig. 48, the results obtained from a test run performed at a supply pressure of $722 \mathrm{kPa}$ (90 psig) on a different day from the above test run are presented. It is observed that the estimated push rod stroke in this case is $0.03684 \mathrm{~m}$ (1.4506 in) while the measured stroke is $0.03181 \mathrm{~m}$ (1.2525 in). It can be noted that the normalized pressure residue corresponding to the actual stroke is around 1.009, i.e., a difference of $0.9 \%$ from the 
minimum value.

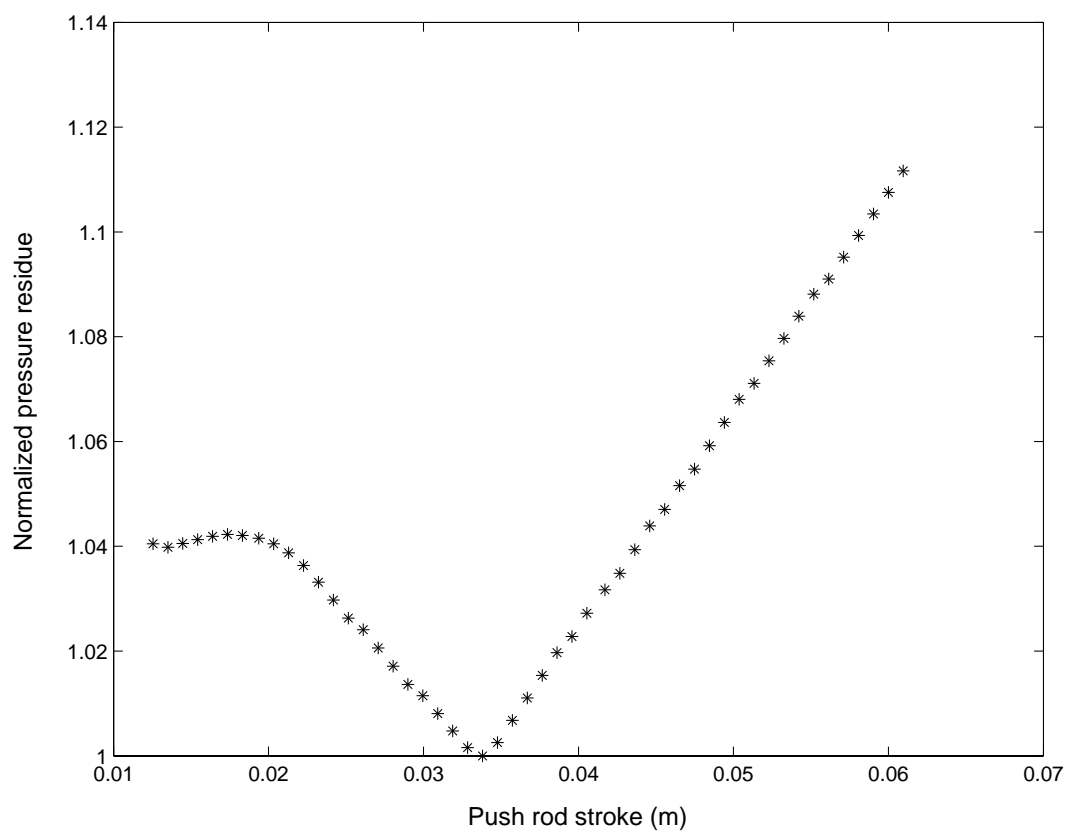

Fig. 47. Normalized pressure residue at $653 \mathrm{kPa}$ (80 psig) supply pressure

2. Scheme 2 - Detection of the transition from Mode 2 to Mode 3

In this section, a scheme is presented that utilizes the sequential nature of the response of the pneumatic subsystem of the air brake system for detecting the transition from Mode 2 to Mode 3. An estimate of the push rod stroke can be obtained once this transition is detected. The term "transition detection" used here refers to the process of identifying the interval of time during which the system switches from Mode 2 to Mode 3. For the purpose of detecting this transition, a time interval that is smaller than the minimum possible dwell time of the system in Mode 2 is considered. Since the measurements are acquired at a constant sampling time of 2 milliseconds, time intervals shall be represented in terms of the equivalent number of samples in this section. The following steps are involved in this scheme: 




Fig. 48. Normalized pressure residue at $722 \mathrm{kPa}$ (90 psig) supply pressure

1. Let $T_{1}$ denote the instant of time at which the transition occurs from Mode 1 to Mode 2. Since the focus is restricted to only Mode 2 and Mode 3, the data collected at this instant of time is represented by the sample number of 1 for convenience. In the first iteration, the estimate of $P_{c t}$ is taken to be equal to $P_{t h}$ and the governing equations for Modes 2 and 3 are solved numerically over the next $K$ time steps. The value of $K$ is chosen such that it is less than the minimum number of time steps that the system will spend in Mode 2. This can be obtained from experiments and in this case $K$ has been chosen to be 5 .

2. It is noted that the initial value of the pressure in Mode 3 will be $P_{c t}$. The input to the numerical scheme is the treadle valve plunger displacement over the time interval corresponding to these $K$ time steps. The governing equations in both modes are solved over $K$ time steps and then the following residue measures 
are calculated:

$$
\begin{aligned}
& e_{2}=\sum_{j=1}^{K}\left|P_{\text {meas }}(j)-P_{b 2}(j)\right|, \\
& e_{3}=\sum_{j=1}^{K}\left|P_{\text {meas }}(j)-P_{b 3}(j)\right|,
\end{aligned}
$$

where $P_{b 2}(j)$ and $P_{b 3}(j)$ are the solutions of the governing equations in Mode 2 and Mode 3 respectively.

3. If $e_{2}<e_{3}$, it can be concluded that the system is still in Mode 2. The value of $P_{c t}$ is updated to be equal to $P_{b 2}(K)$ and the previous step is repeated over the next $K$ time steps.

4. If $e_{2} \geq e_{3}$, it can be declared that a transition has taken place from Mode 2 to Mode 3. Then, the best estimate of $P_{c t}$ will be the value used at the start of this particular iteration. Once this is known, an estimate of the push rod stroke can be obtained from Eq. (6.1).

In Figs. 49 and 50, the results of this scheme are illustrated on the two test runs that have been considered in section 1 . The initial time interval is taken to be that corresponding to 50 time steps. This was picked on practical considerations since it is known that the clearance between the brake pads and the brake drum is never zero and usually a minimum stroke of around $0.0127 \mathrm{~m}(0.5 \mathrm{in})$ is needed to overcome this clearance. Such a choice also ensures that any initial disagreement between the model and the experiment at the end of Mode 1 will not affect the transition detection process. Additionally, it reduces the computation time involved.

In Table VIII, a comparison of the push rod stroke estimate obtained from these two schemes with the measured stroke is presented. It should be pointed out that the computation time involved in implementing Scheme 2 is much less than that of 
Scheme 1 and this would be beneficial for implementing the diagnostic scheme in practice. Also, the complexity of Scheme 1 will increase if more than one unknown parameter need to be estimated. For example, if the value of $P_{t h}$ were unknown in addition to that of $P_{c t}$, one needs to obtain the pressure residue measure for each possible pair of values of $P_{t h}$ and $P_{c t}$ using Scheme 1. But, using Scheme 2, an estimate of $P_{t h}$ can be obtained by detecting the transition from Mode 1 to Mode 2 .

Table VIII. Comparison of the actual and the estimated push rod stroke

\begin{tabular}{|l|c|c|c|}
\hline $\begin{array}{l}\text { Supply } \\
\text { Pressure }\end{array}$ & Actual Stroke (m/in) & Scheme 1 (m/in) & Scheme 2 (m/in) \\
$(\mathrm{kPa} / \mathrm{psig})$ & & & \\
\hline $653 / 80$ & $0.03114 / 1.2262$ & $0.03381 / 1.3311$ & $0.03526 / 1.3883$ \\
$722 / 90$ & $0.03181 / 1.2525$ & $0.03684 / 1.4506$ & $0.03755 / 1.4784$ \\
\hline
\end{tabular}

Thus, a reasonable estimate of the push rod stroke can be obtained by using these two schemes. Although it is difficult to pin-point a particular value of the push rod stroke as the best estimate (due to the experimental issues discussed above), one can provide a range of values for the best estimate depending on a chosen range for the tolerated normalized pressure residue. For example, using Scheme 1, one can identify the region of the push rod stroke estimate as that corresponding to the interval $[1$, 1.01] for the normalized pressure residue (i.e., till $1 \%$ more than the minimum). A range of possible estimates of the actual push rod stroke is practically valuable since one can determine the state of the push rod adjustment from it. 




Fig. 49. Transition detection at $653 \mathrm{kPa}$ (80 psig) supply pressure

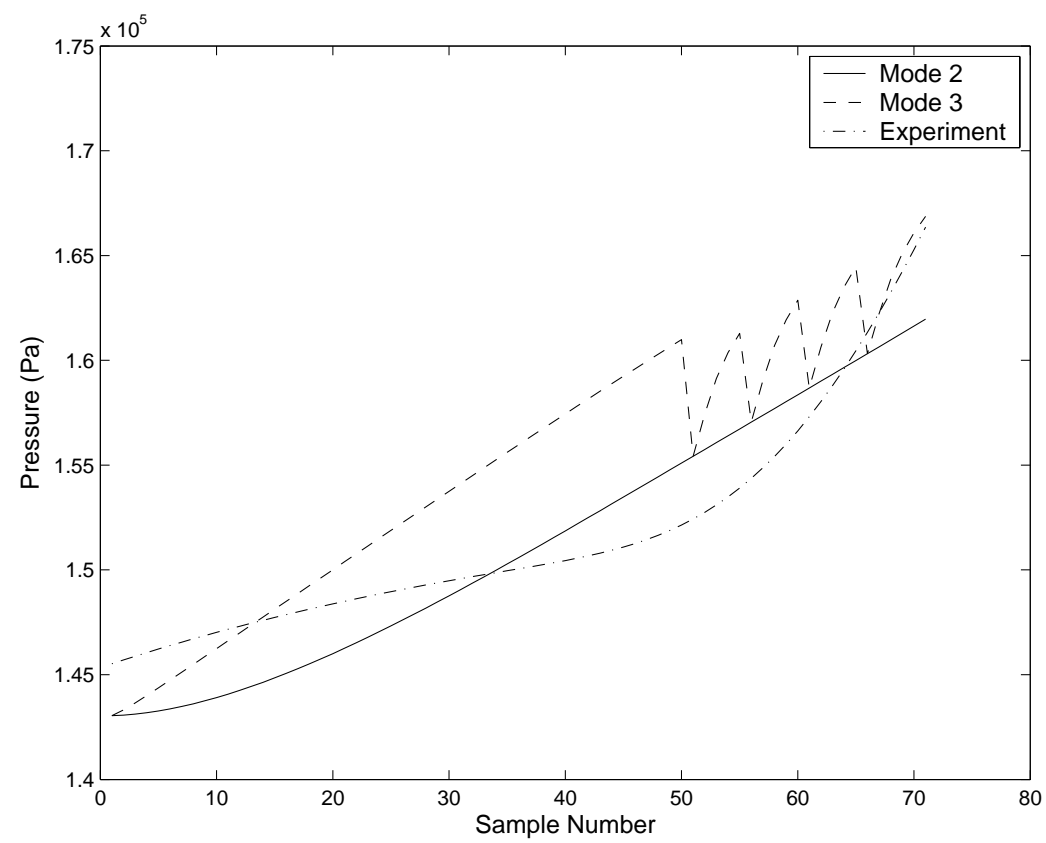

Fig. 50. Transition detection at $722 \mathrm{kPa}$ (90 psig) supply pressure 
C. Effect of leaks on the estimation of the push rod stroke

In this section, the effect of leaks on the estimation of the push rod stroke is illustrated with experimental data. It should be recalled that the steady state push rod stroke during a given brake application is made up of two components - the first part is required to overcome the clearance between the brake pads and the brake drum and the second part is a result of the deformation of the mechanical components of the brake system once contact is made between the brake pads and the brake drum. The schemes presented above provide an estimate of the parameter $P_{c t}$ and thus an estimate of the part of the total push rod stroke that is required to overcome the clearance between the brake pads and the brake drum. It has been observed from experiments that, for the brake chambers used in the experimental setup, the value of $P_{c t}$ is not likely to exceed $184.1 \mathrm{kPa}$ (12 psig). Hence, it can be observed that the influence of the clearance between the brake pads and the brake drum is reflected at comparatively low pressures in the brake system. Thus, the critical region of the pressure transients with regards to estimating the push rod stroke is Mode 2 (where there is a "flattening" of the pressure transients curve).

A set of experiments was performed at different supply pressures to observe the effect of leaks on Mode 2 of the pressure transients. The clearance between the brake pads and the brake drum was kept constant during these experimental test runs. The results of these tests are presented in Figs. 51 to 54.

It can be observed from Figs. 51 and 53 that the regions corresponding to Mode 2 of the pressure transients almost overlap one another in the presence and absence of a leak. The influence of the leak is felt in the high pressure regions of the pressure transients and the steady state pressure is lower in the presence of a leak when compared to the case when there is no leakage. It can be observed from Figs. 52 and 


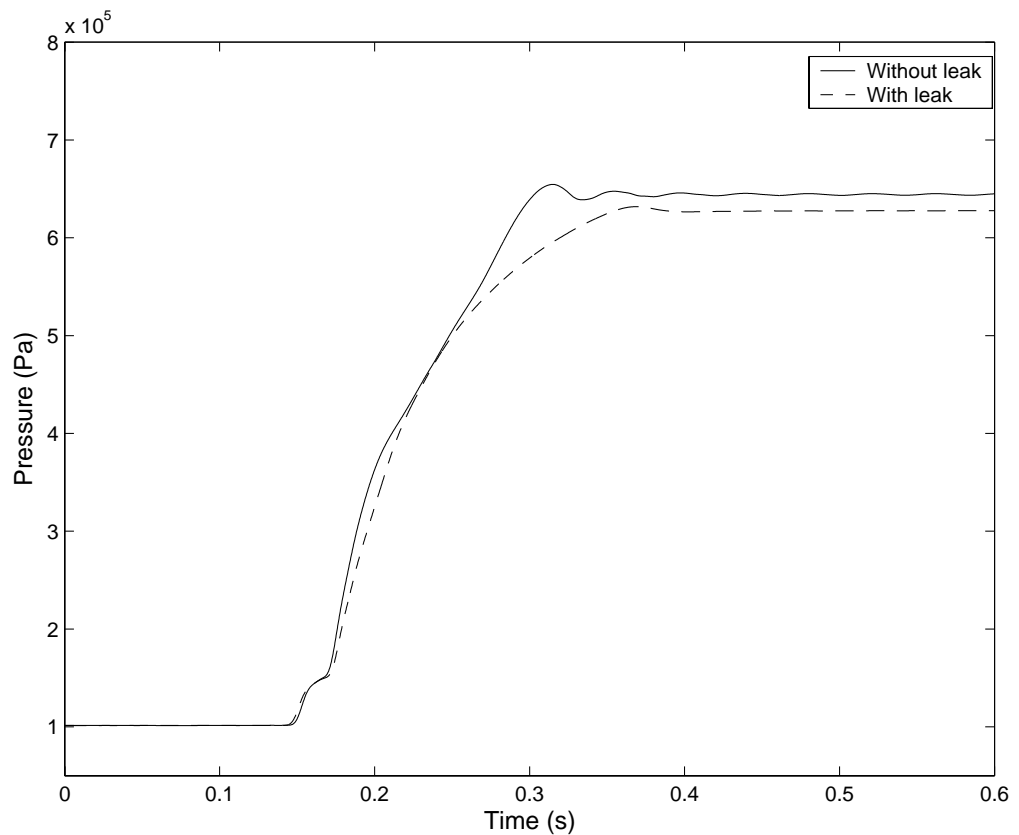

Fig. 51. Comparison of pressure transients with and without leaks at $653 \mathrm{kPa}$ (80 psig) supply pressure

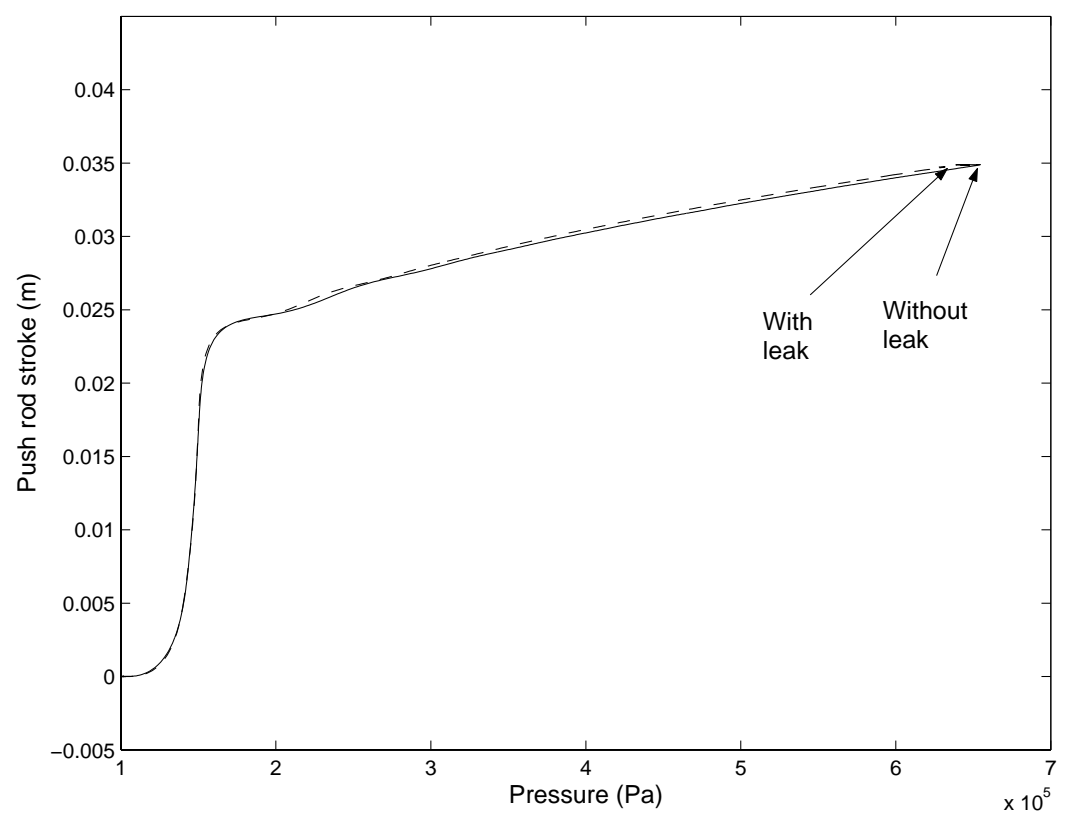

Fig. 52. Plots of push rod stroke and brake chamber pressure with and without leaks at $653 \mathrm{kPa}(80 \mathrm{psig})$ supply pressure 


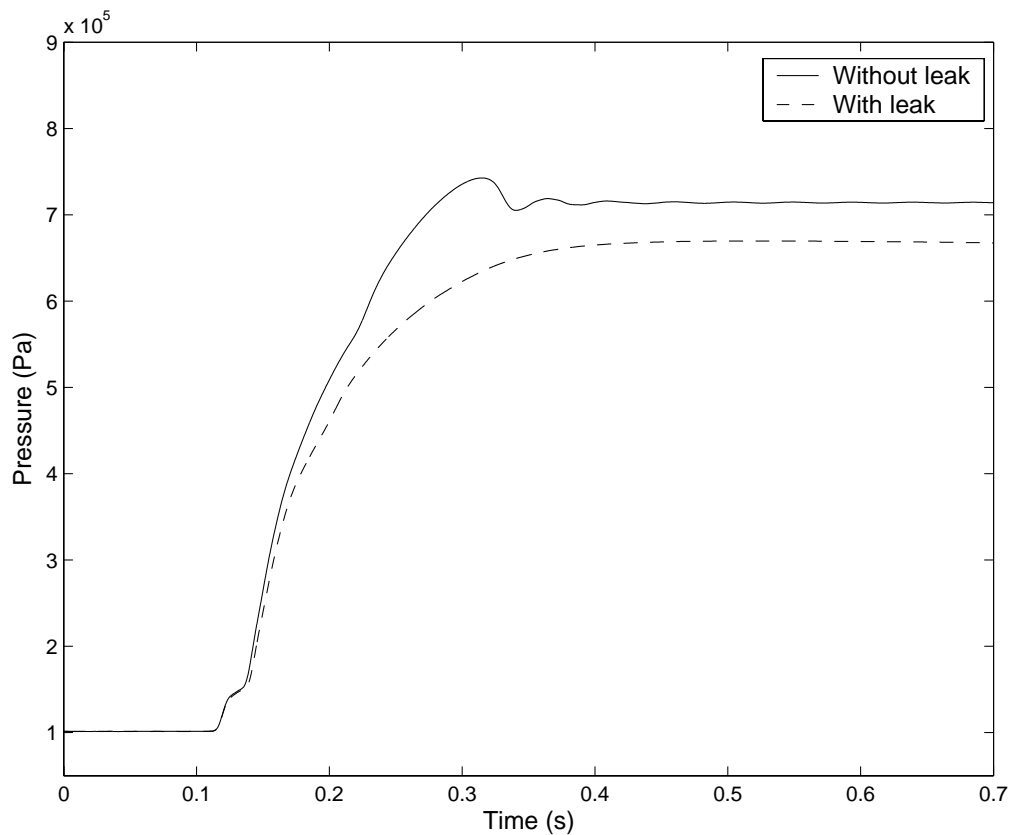

Fig. 53. Comparison of pressure transients with and without leaks at $722 \mathrm{kPa}$ (90 psig) supply pressure

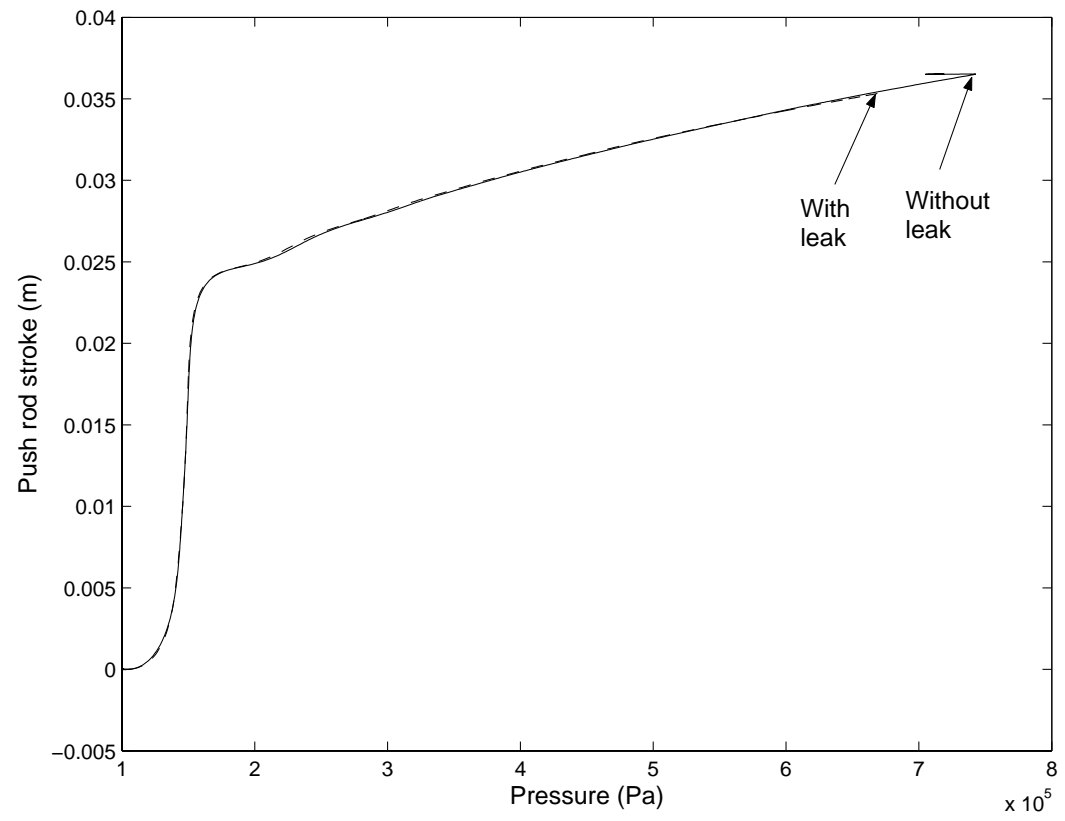

Fig. 54. Plots of push rod stroke and brake chamber pressure with and without leaks at $722 \mathrm{kPa}$ (90 psig) supply pressure 
54 that the steady state push rod stroke is lower in the presence of a leak due to this reason. Also, in these two figures, the regions corresponding to Mode 2 almost overlap one another in the presence and absence of a leak. The only major difference is in the steady state values (indicated by arrows in these two figures). Thus, the presence of a leak lowers the push rod stroke mainly due to the fact that the steady state pressure in lowered. 


\section{CHAPTER VII}

\section{PARAMETER ESTIMATION SCHEMES FOR A CLASS OF SEQUENTIAL HYBRID SYSTEMS}

The focus of this dissertation till the previous chapter has been on air brake systems. Based on the physical insight obtained in the development of diagnostic schemes for air brake systems, this chapter outlines the preliminary development of a few parameter estimation schemes for a class of sequential hybrid systems. In many physical systems, the values of certain parameters in the equations governing the response of those systems may not be available a priori. The values of these parameters are estimated by providing suitable input signals to the system and measuring the corresponding output signals. Such parameter estimation schemes often form a part of an adaptive control system that is used for regulating the performance of the physical system. A few examples of adaptive control include controlling robotic manipulators, aircrafts, chemical processes, automobiles, etc. Descriptions of various techniques used in the adaptive control of dynamic systems can be found in [97], [98].

The response of many physical systems is such that it can be represented by a hybrid model (as is the case with the response of the pneumatic subsystem of the air brake system). In chapter IV, some examples of automotive systems that have been recently represented by hybrid models were presented. In [99], the authors have presented conditions that ensure the asymptotic stability of a class of switched systems under any switching signal. They also address the problem of identifying classes of switching signals for which the response of the system under consideration will be asymptotically stable. In [100], the authors consider the problem of designing a Luenberger-like observer for a class of linear hybrid systems. They demonstrate that the existence of a common Lyapunov function for all the modes, such that a condition 
in the form of a Linear Matrix Inequality (LMI) is satisfied, to be sufficient for the state estimation errors to converge asymptotically to zero. Vidal et al. [101] have developed criteria for the observability of a class of linear discrete time hybrid systems. The problem of switching between several controllers for a linear time invariant system has been studied in [102].

In this chapter, the problem of designing parameter estimation schemes for a class of sequential hybrid systems is addressed. The class of sequential hybrid systems that is considered will be first described. Then, parameter estimation schemes for this class of sequential hybrid systems will be presented for the case when the transition conditions are known a priori. Then, a parameter estimation scheme will be developed for the case when the transition conditions are not known. Specifically, the case where the transition conditions are not known up to a constant will be considered. The performance of these schemes will be illustrated with some examples.

A. The class of systems under study

In this chapter, the class of sequential hybrid systems whose response is described by the following equations will be considered:

$$
\begin{gathered}
\dot{\mathbf{x}}(t)=\mathbf{A}_{i} \mathbf{x}(t)+\mathbf{B}_{i}\left[\phi_{i}(\mathbf{u}(t), \mathbf{y}(t)) \theta+\psi_{i}(\mathbf{u}(t), \mathbf{y}(t))\right], \\
\mathbf{y}(t)=\mathbf{C}_{i} \mathbf{x}(t), \quad i=1, \ldots, s
\end{gathered}
$$

where $\mathbf{x}(t) \in \mathbb{R}^{n}$ is the vector of state variables, $\mathbf{u}(t) \in \mathbb{R}^{m}$ is the input vector, $\mathbf{y}(t) \in \mathbb{R}^{p}$ is the output vector and $\theta \in \mathbb{R}^{q}$ is the vector of unknown (but constant) parameters that need to be estimated. The function $\phi_{i}(.,):. \mathbb{R}^{m} \times \mathbb{R}^{p} \rightarrow \mathbb{R}^{r \times q}$ and the function $\psi_{i}(.,):. \mathbb{R}^{m} \times \mathbb{R}^{p} \rightarrow \mathbb{R}^{r}$. The dot in the above equation represents the derivative with respect to time and the constant matrices $\mathbf{A}_{i}, \mathbf{B}_{i}$ and $\mathbf{C}_{i}$ are 
of the appropriate dimensions. The parameter $s$ is a positive integer representing the total number of modes. The input $\mathbf{u}(t)$ and the output $\mathbf{y}(t)$ are assumed to be bounded. It is also assumed that for bounded $\mathbf{u}$ and $\mathbf{y}$, and for all $i=1, \ldots, s$, the functions $\phi_{i}(\mathbf{u}, \mathbf{y})$ and $\psi_{i}(\mathbf{u}, \mathbf{y})$ are bounded . For convenience, the arguments in the parenthesis shall be suppressed after their first appearance. The transition of the system from mode $i$ to mode $(i+1)$ will occur when the condition $\alpha(\mathbf{y}) \geq \mu_{i}$ is satisfied. The function $\alpha():. \mathbb{R}^{p} \rightarrow \mathbb{R}$ and it is assumed that this function is a strictly increasing function of $\mathbf{y}$. There are instances of physical systems where the transition conditions fall under this category. For example, the forward transition from a lower gear to a higher gear will occur in an automatic transmission system only when the vehicle speed increases. In the pneumatic subsystem of an air brake system, the forward transition from one mode to the following mode occurs only when the pressure in the brake chamber increases and the backward transition from one mode to the previous mode will occur only when the pressure in the brake chamber decreases. In modeling the flow of traffic, the number of vehicles in a section must increase to cause a forward transition to a more congested regime [103]. The reverse transition from mode $(i+1)$ to mode $i$ will occur when $\alpha(\mathbf{y})<\mu_{i}$. In section B of this chapter, it will be assumed that the values of $\mu_{i}, i=1, \ldots,(s-1)$ are known a priori so that a complete knowledge of the transition conditions is available. In section $\mathrm{C}$ of this chapter, the case where the transition conditions are unknown, in the sense that the values of $\mu_{i}, i=1, \ldots,(s-1)$ are not known, will be considered. It should be noted that Eq. (7.1) is linear in $\theta$. This system is illustrated in Fig. 55.

The problem under study in section B of this chapter can be stated as follows: Consider the class of systems described by Eqs. (7.1) and (7.2). Given the input $\mathbf{u}$, the output $\mathbf{y}$ and a complete knowledge of the transition conditions (i.e., the values of $\mu_{i}, i=1, \ldots,(s-1)$, are known), obtain a parameter estimation scheme that will 


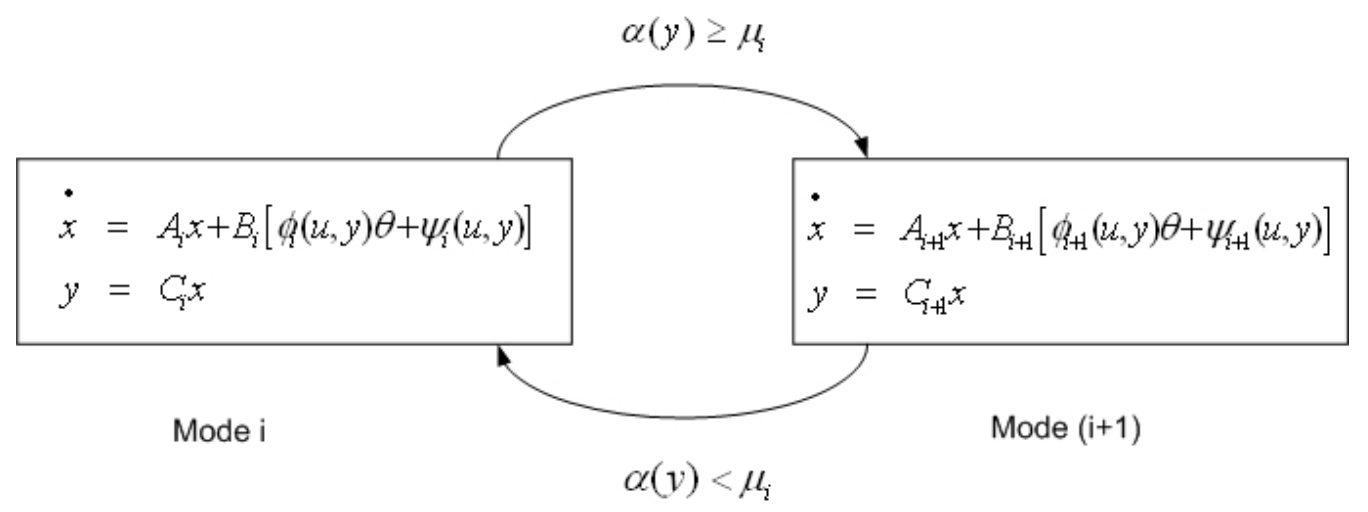

Fig. 55. The class of systems under study

guarantee bounded parameter estimation errors.

The problem under study in section $\mathrm{C}$ of this chapter can be stated as follows: Consider the class of systems described by Eqs. (7.1) and (7.2). Given the input $\mathbf{u}$ and the output $\mathbf{y}$, obtain a parameter estimation scheme that will guarantee bounded parameter estimation errors when only the bounds on the values of $\mu_{i}, i=1, \ldots,(s-$ 1), are known.

B. The proposed parameter estimation scheme when the transition conditions are known

In this section, a parameter estimation scheme for the above class of sequential hybrid systems when the transition conditions are known a priori is proposed. This scheme for estimating the unknown parameter vector $\theta$ will be obtained by introducing the variables $\mathbf{w}$ and $\hat{\mathbf{y}}(t)$ whose evolution is governed by the following equations:

$$
\begin{gathered}
\dot{\mathbf{w}}(t)=\mathbf{A}_{i} \mathbf{w}(t)+\mathbf{B}_{i}\left[\phi_{i}(\mathbf{u}(t), \mathbf{y}(t)) \hat{\theta}(t)+\psi_{i}(\mathbf{u}(t), \mathbf{y}(t))\right], \\
\hat{\mathbf{y}}(t)=\mathbf{C}_{i} \mathbf{w}(t), \quad i=1, \ldots, s
\end{gathered}
$$


where $\hat{\theta}(t)$ is the estimate of $\theta$ at time $t$. Next, the following variables are defined as:

$$
\begin{gathered}
\mathbf{e}_{o}(t)=\mathbf{y}(t)-\hat{\mathbf{y}}(t), \\
\mathbf{e}_{\theta}(t)=\theta^{*}-\hat{\theta}(t), \\
\mathbf{e}_{x}(t)=\mathbf{x}(t)-\mathbf{w}(t),
\end{gathered}
$$

where $\mathbf{e}_{\theta}(t)$ is the parameter estimation error and $\theta^{*}$ is the vector of the actual parameter values. The variable $\mathbf{e}_{o}(t)$ will be referred to as the output identification error. The following proposition then provides sufficient conditions and a parameter update scheme for estimating $\theta$.

Proposition 1: Consider the sequential hybrid system whose governing equations in the $i^{\text {th }}$ mode are given by Eqs. (7.1) and (7.2). Let a positive definite function $V(t)$ be defined through

$$
V(t)=\mathbf{P e}_{o} \cdot \mathbf{e}_{o}+\frac{1}{2} \mathbf{e}_{\theta} \cdot \mathbf{e}_{\theta}
$$

where $\mathbf{P}$ is a symmetric positive definite matrix. If for each $i=1, \ldots, s$, there exists a symmetric semi-positive definite matrix $\mathbf{Q}_{i}$ such that

$$
\mathbf{C}_{i}^{T} \mathbf{P} \mathbf{C}_{i} \mathbf{A}_{i}+\mathbf{A}_{i}^{T} \mathbf{C}_{i} \mathbf{P} \mathbf{C}_{i}=-\mathbf{Q}_{i}, \quad i=1, \ldots, s,
$$

then choosing

$$
\dot{\hat{\theta}}=2\left[\mathbf{P C}_{i} \mathbf{B}_{i} \phi_{i}\right]^{T} \mathbf{e}_{o}, \quad i=1, \ldots, s
$$

will lead to the parameter estimation error and the output identification error being bounded.

Proof: From the above definition of $V$, one obtains

$$
\dot{V}=\left[\mathbf{C}_{i}^{T} \mathbf{P} \mathbf{C}_{i} \mathbf{A}_{i}+\mathbf{A}_{i}^{T} \mathbf{C}_{i} \mathbf{P} \mathbf{C}_{i}\right] \mathbf{e}_{x} \cdot \mathbf{e}_{x}+\left[2\left[\mathbf{P} \mathbf{C}_{i} \mathbf{B}_{i} \phi_{i}\right]^{T} \mathbf{e}_{o}+\dot{\mathbf{e}}_{\theta}\right] . \mathbf{e}_{\theta}
$$


Using Eqs. (7.9) and (7.10), the above equation reduces to

$$
\dot{V}=-\mathbf{Q}_{i} \mathbf{e}_{x} \cdot \mathbf{e}_{x}
$$

Since $\mathbf{Q}_{i}$ is a symmetric semi-positive definite matrix for each $i=1, \ldots, s$, it can be observed that for all $t>0, \dot{V} \leq 0$ along the system trajectories given by Eqs. (7.1)(7.4) and Eq. (7.10). Thus, if one starts with non-zero initial conditions for $\mathbf{e}_{o}$ and $\mathbf{e}_{\theta}$, choosing a parameter update scheme given by Eq. (7.10) will lead to a bounded parameter estimation error and a bounded output identification error.

Remarks: The following features of the proposed parameter estimation scheme must be noted:

1. Let the system be in mode $i$ at time $t=0$ and let the system switch to mode $(i+1)$ at time $t=T$. Then, the values of the parameter estimates obtained at $t=T$ from the parameter estimation scheme implemented in mode $i$ will be taken as the initial values for the parameter estimation scheme implemented in mode $(i+1)$.

2. It can be noted that the above scheme allows for the use of different matrices $\mathbf{Q}_{i}$ for different modes. The matrices $\mathbf{P}$ and $\mathbf{Q}_{i}$ can be regarded as design parameters in obtaining a parameter estimation scheme for the sequential hybrid system under study. If it is possible to obtain a common matrix $\mathbf{Q}$ that satisfies Eq. (7.9) for all $i=1, \ldots, s$, then that matrix can be used for all the modes. If not, the proposed parametric scheme provides the flexibility of choosing a different matrix $\mathbf{Q}_{i}$ for each mode. This feature will be illustrated in the following examples. 
3. It can also be observed that the above proposition provides only sufficient conditions for the existence of a parameter estimation scheme that results in a bounded parameter estimation error.

The proposed parameter estimation scheme is illustrated in Fig. 56. The performance of the above parameter estimation scheme will be illustrated in Examples 1 and 2 .

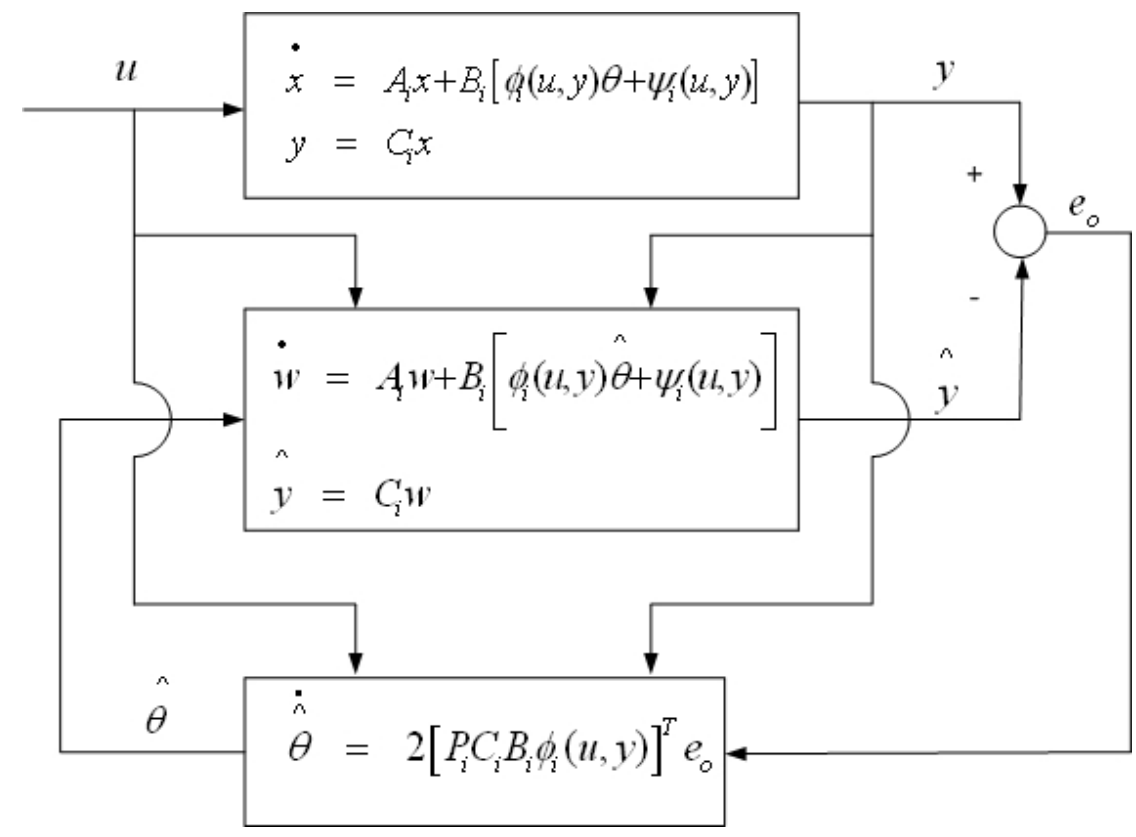

Fig. 56. The proposed parameter estimation scheme

Next, the case when all the states are measured is considered, i.e., $\mathbf{C}_{i}$ is the identity matrix in all the modes. Then, the equations governing the evolution of $\mathbf{x}$ and $\mathbf{w}$ become

$$
\begin{gathered}
\dot{\mathbf{x}}(t)=\mathbf{A}_{i} \mathbf{x}(t)+\mathbf{B}_{i}\left[\phi_{i}(\mathbf{u}(t), \mathbf{y}(t)) \theta+\psi_{i}(\mathbf{u}(t), \mathbf{y}(t))\right], \\
\mathbf{y}(t)=\mathbf{x}(t),
\end{gathered}
$$


and

$$
\begin{gathered}
\dot{\mathbf{w}}(t)=\mathbf{A}_{i} \mathbf{w}(t)+\mathbf{B}_{i}\left[\phi_{i}(\mathbf{u}(t), \mathbf{y}(t)) \hat{\theta}(t)+\psi_{i}(\mathbf{u}(t), \mathbf{y}(t))\right], \\
\hat{\mathbf{y}}(t)=\mathbf{w}(t) .
\end{gathered}
$$

Now, it should be noted that $\mathbf{e}_{o}=\mathbf{e}_{x}$. Then, the following proposition provides sufficient conditions and a parameter estimation scheme such that $\mathbf{e}_{o}$ asymptotically tends to $\mathbf{0}$.

Proposition 2: Consider the sequential hybrid system whose governing equations in the $i^{\text {th }}$ mode are given by Eqs. (7.13) and (7.14). Let a positive definite function $V(t)$ be defined through

$$
V(t)=\mathbf{P e}_{o} \cdot \mathbf{e}_{o}+\frac{1}{2} \mathbf{e}_{\theta} \cdot \mathbf{e}_{\theta}
$$

where $\mathbf{P}$ is a symmetric positive definite matrix. If for each $i=1, \ldots, s$, there exists a symmetric positive definite matrix $\mathbf{Q}_{i}$ such that

$$
\mathbf{P A}_{i}+\mathbf{A}_{i}^{T} \mathbf{P}=-\mathbf{Q}_{i}, \quad i=1, \ldots, s,
$$

then choosing

$$
\dot{\hat{\theta}}=2\left[\mathbf{P B}_{i} \phi_{i}\right]^{T} \mathbf{e}_{o}, \quad i=1, \ldots, s,
$$

will lead to the parameter estimation error being bounded. Further, for bounded input and output signals, the output identification error will tend to zero as $t \rightarrow \infty$.

Proof: From the above definition of $V$, one obtains

$$
\dot{V}=\left[\mathbf{P} \mathbf{A}_{i}+\mathbf{A}_{i}^{T} \mathbf{P}\right] \mathbf{e}_{x} \cdot \mathbf{e}_{x}+\left[2\left[\mathbf{P} \mathbf{B}_{i} \phi_{i}\right]^{T} \mathbf{e}_{o}+\dot{\mathbf{e}}_{\theta}\right] \cdot \mathbf{e}_{\theta} \cdot
$$

Using Eqs. (7.18) and (7.19), the above equation reduces to

$$
\dot{V}=-\mathbf{Q}_{i} \mathbf{e}_{o} \cdot \mathbf{e}_{o}
$$


Since $\mathbf{Q}_{i}$ is a symmetric positive definite matrix for each $i=1, \ldots, s$, one can conclude that for all $t>0, \dot{V} \leq 0$ along the system trajectories given by Eqs. (7.13)-(7.16) and Eq. (7.19). Thus, $V(t) \leq V(0) \forall t>0$. Thus, if one starts with non-zero initial conditions for $\mathbf{e}_{o}$ and $\mathbf{e}_{\theta}$, choosing a parameter update scheme given by Eq. (7.19) will lead to a bounded parameter estimation error and a bounded output identification error. Thus, $\mathbf{e}_{o} \in L_{\infty}$ and $\mathbf{e}_{\theta} \in L_{\infty}$.

Now, from Eq. (7.21), it can be obtained that for all $t>0$

$$
\int_{0}^{t} \dot{V} d t=-\int_{0}^{t} \mathbf{Q}_{i} \mathbf{e}_{o} \cdot \mathbf{e}_{o}
$$

Since $\mathbf{Q}_{i}$ is a positive definite matrix,

$$
\lambda_{\min }\left(\mathbf{Q}_{i}\right) \mathbf{e}_{o} \cdot \mathbf{e}_{o} \leq \mathbf{Q}_{i} \mathbf{e}_{o} \cdot \mathbf{e}_{o} \leq \lambda_{\max }\left(\mathbf{Q}_{i}\right) \mathbf{e}_{o} \cdot \mathbf{e}_{o}
$$

where $\lambda_{\min }\left(\mathbf{Q}_{i}\right)$ and $\lambda_{\max }\left(\mathbf{Q}_{i}\right)$ are the minimum and maximum eigenvalues of $\mathbf{Q}_{i}$ respectively. Let

$$
M:=\min _{i=1, \ldots, s} \lambda_{\min }\left(\mathbf{Q}_{i}\right)
$$

Using Eqs. (7.22), (7.23) and (7.24), it can be concluded that for all $t>0$

$$
\int_{0}^{t}\left\|\mathbf{e}_{o}\right\|_{2}^{2} d t \leq \frac{V(0)}{M} .
$$

Thus, $\mathbf{e}_{o} \in L_{2}$. Next, it is observed that

$$
\dot{\mathbf{e}}_{o}=\mathbf{A}_{i} \mathbf{e}_{o}+\mathbf{B}_{i} \phi_{i} \mathbf{e}_{\theta}
$$

Thus, for bounded inputs and outputs, $\dot{\mathbf{e}}_{o}$ will be bounded. Hence, $\dot{\mathbf{e}}_{o} \in L_{\infty}$.

Thus, it can be noted that $\mathbf{e}_{o} \in L_{2} \cap L_{\infty}$ and $\dot{\mathbf{e}}_{o} \in L_{\infty}$. Hence, using a corollary of Barbalat's Lemma (refer to page 19 of [98]), it can be concluded that $\mathbf{e}_{o} \rightarrow \mathbf{0}$ as $t \rightarrow \infty$ 
It should be noted that if a common $\mathbf{Q}$ that satisfies Eq. (7.18) exists for all the modes, then it can be used for obtaining the parameter update equations. Otherwise, the above parameter estimation scheme provides the flexibility of choosing a different $\mathbf{Q}_{i}$ in each mode such that Eq. (7.18) is satisfied. The performance of this scheme is illustrated in Example 3.

\section{Example 1}

In this example, the system illustrated in Fig. 57 will be considered. Let $x$ be the displacement of the mass $m$ from its initial position. A force $F$ is applied on it to move it from its initial position and let $L$ denote the value of $x$ at which the mass will make contact with the second set of spring and dashpot. There are two modes in this system - mode 1 is described by the condition $x<L$ and mode 2 is described by the condition $x \geq L$. It is assumed that all the springs and dashpots are linear and that both the displacement $(x)$ and the velocity $(\dot{x})$ are measured. Let it be supposed that the values of $c_{1}$ and $k_{2}$ are unknown and need to be estimated. Let the true values of all the parameters be $m=1 \mathrm{~kg}, k_{1}=3 \mathrm{~N} / \mathrm{m}, c_{1}=0.5 \mathrm{Ns} / \mathrm{m}, k_{2}=1 \mathrm{~N} / \mathrm{m}, c_{2}=2$ $\mathrm{Ns} / \mathrm{m}$ and $L=0.2 \mathrm{~m}$.

The equation of motion of the system in mode 1 is given by

$$
m \ddot{x}=F-k_{1} x-c_{1} \dot{x},
$$

and the equation of motion of the system in mode 2 is given by

$$
m \ddot{x}=F-k_{1} x-c_{1} \dot{x}-k_{2}(x-L)-c_{2} \dot{x} .
$$

The equation of motion in mode 1 can be re-written as (in order to identify it with 




Fig. 57. Schematic of the system under study in Example 1

Eqs. (7.1) and (7.2))

$$
\begin{gathered}
\left(\begin{array}{l}
\dot{x} \\
\ddot{x}
\end{array}\right)=\left(\begin{array}{cc}
0 & 1 \\
k_{1} & \\
-\frac{m}{m} & 0
\end{array}\right)\left(\begin{array}{l}
x \\
\dot{x}
\end{array}\right)+\left(\begin{array}{c}
0 \\
1 \\
\frac{m}{1}
\end{array}\right)\left(-\dot{y} c_{1}+F\right), \\
\left(\begin{array}{l}
y \\
\dot{y}
\end{array}\right)=\left(\begin{array}{ll}
1 & 0 \\
0 & 1
\end{array}\right)\left(\begin{array}{l}
x \\
\dot{x}
\end{array}\right) .
\end{gathered}
$$

The equation of motion in mode 2 can similarly be re-written as

$$
\begin{gathered}
\left(\begin{array}{c}
\dot{x} \\
\ddot{x}
\end{array}\right)=\left(\begin{array}{cc}
0 & 1 \\
k_{1} & c_{2} \\
-\frac{m}{m} & -\frac{1}{m}
\end{array}\right)\left(\begin{array}{l}
x \\
\dot{x}
\end{array}\right)+\left(\begin{array}{c}
0 \\
1 \\
\frac{m}{m}
\end{array}\right)\left(-\dot{y} c_{1}+(L-y) k_{2}+F\right), \\
\left(\begin{array}{l}
y \\
\dot{y}
\end{array}\right)=\left(\begin{array}{ll}
1 & 0 \\
0 & 1
\end{array}\right)\left(\begin{array}{l}
x \\
\dot{x}
\end{array}\right) .
\end{gathered}
$$

Thus, the transition from mode 1 to mode 2 will occur when $y \geq L$ and the tran- 
sition from mode 2 to mode 1 will occur when $y<L$. The procedure for implementing the proposed parameter estimation scheme is as follows:

1. Using the actual values of all the parameters and the known input $F$ (it is taken to be equal to $5 \sin (t) \mathrm{N})$, the governing equations of the system are solved to obtain the outputs. It can be observed shortly that choosing a sinusoidal input of the above form ensures that the system dwells in both modes for a sufficient period of time.

2. Then, the matrices $\mathbf{P}, \mathbf{Q}_{1}$ and $\mathbf{Q}_{2}$ that satisfy Eq. (7.9) are obtained.

3. The parameter update equations in each mode are then obtained through Eq. (7.10). Then, these equations are solved along with the equations governing the evolution of $\mathbf{w}$ to obtain the estimates of the unknown parameters.

Now, choosing $\mathbf{P}=\left(\begin{array}{cc}p_{11} & p_{12} \\ p_{12} & p_{22}\end{array}\right)$, one obtains

$$
\mathbf{C}_{1}^{T} \mathbf{P} \mathbf{C}_{1} \mathbf{A}_{1}+\mathbf{A}_{1}^{T} \mathbf{C}_{1} \mathbf{P} \mathbf{C}_{1}=\left(\begin{array}{cc}
-\frac{2 k_{1} p_{12}}{m} & p_{11}-\frac{k_{1} p_{22}}{m} \\
p_{11}-\frac{k_{1} p_{22}}{m} & 2 p_{12}
\end{array}\right)
$$

Similarly in mode 2, one obtains

$$
\mathbf{C}_{2}^{T} \mathbf{P} \mathbf{C}_{2} \mathbf{A}_{2}+\mathbf{A}_{2}^{T} \mathbf{C}_{2} \mathbf{P} \mathbf{C}_{2}=\left(\begin{array}{cc}
-\frac{2 k_{1} p_{12}}{m} & p_{11}-\frac{k_{1} p_{22}}{m}-\frac{c_{2} p_{12}}{m} \\
p_{11}-\frac{k_{1} p_{22}}{m}-\frac{c_{2} p_{12}}{m} & 2 p_{12}-\frac{2 c_{2} p_{22}}{m}
\end{array}\right)
$$

It can be seen that the only choice of $\mathbf{Q}_{1}$ that would ensure that Eq. (7.9) would be satisfied in mode 1 is the null matrix. Choosing $p_{22}=1$, one obtains $\mathbf{P}=\left(\begin{array}{ll}3 & 0 \\ 0 & 1\end{array}\right)$. 
Then, using Eq. (7.34), one obtains $\mathbf{Q}_{2}=\left(\begin{array}{cc}0 & 0 \\ 0 & 4\end{array}\right)$.

Then, using Eq. (7.10), the parameter update equations in mode 1 become

$$
\begin{array}{r}
\dot{\hat{c}}_{1}=-2 \dot{y}(\dot{x}-\dot{w}), \\
\dot{\hat{k}}_{2}=0 .
\end{array}
$$

It can be observed that the estimate of the parameter $k_{2}$ is not updated when the system is in mode 1 . In mode 2 , the parameter update equations are obtained as

$$
\begin{array}{r}
\dot{\hat{c}}_{1}=-2 \dot{y}(\dot{x}-\dot{w}), \\
\dot{\hat{k}}_{2}=2(L-y)(\dot{x}-\dot{w}) .
\end{array}
$$

These equations are solved with the initial conditions that $\hat{c}_{1}(0)=0$ and $\hat{k}_{2}(0)=0$ along with the equations governing the evolution of w (obtained using Eqs. (7.3) and (7.4)). The results of the numerical simulations are illustrated in Figs. 58 and 59 . In Fig. 59, the term $e_{y 1}$ denotes $(y-\hat{y})$ and the term $e_{y 2}$ denotes $(\dot{y}-\dot{\hat{y}})$. It can be noted from these two figures that both the parameter estimation errors and the output identification errors are bounded. The estimate of $k_{2}$ converges to the region around its true value of $1 \mathrm{~N} / \mathrm{m}$ and the estimate of $c_{1}$ converges to the region around its true value of $0.5 \mathrm{Ns} / \mathrm{m}$. Figure 60 illustrates the fact that the system switches between the two modes during this process in such a manner that it dwells in both modes for a sufficient amount of time.

\section{Example 2}

In this example, the same system illustrated in Fig. 57 is considered, the only difference being that the constitutive equation of the second spring is now assumed to be 


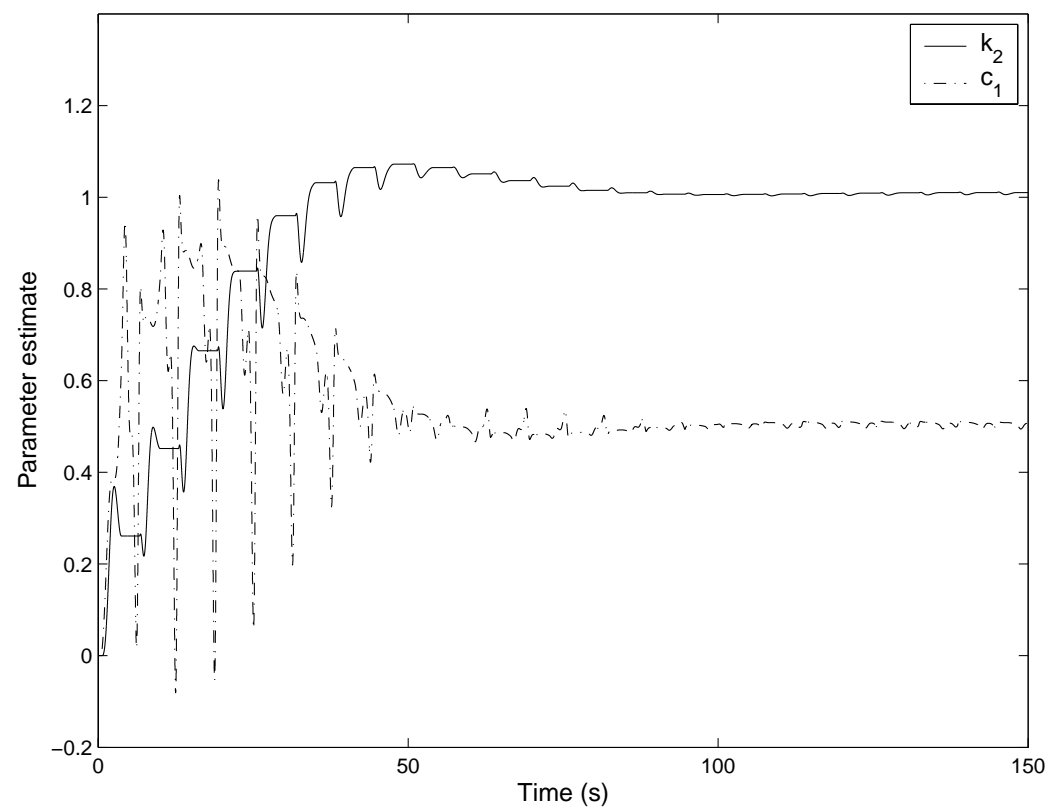

Fig. 58. Example 1 - Estimates of the unknown parameters

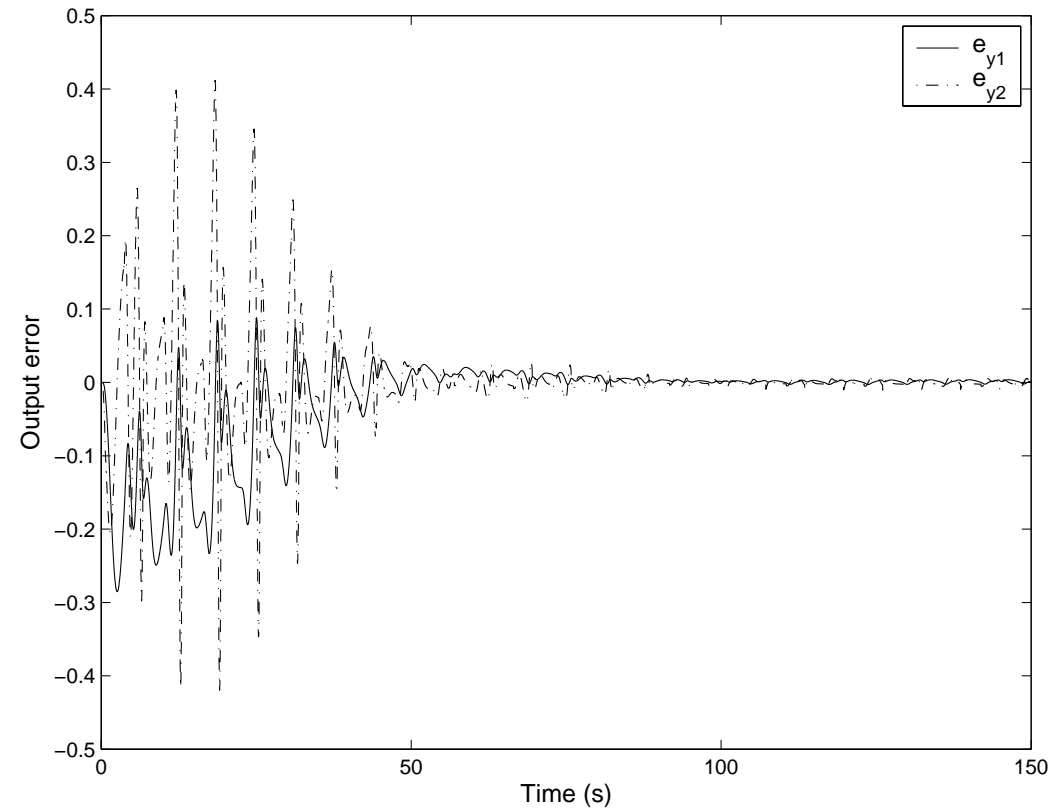

Fig. 59. Example 1 - Plots of the output identification errors 


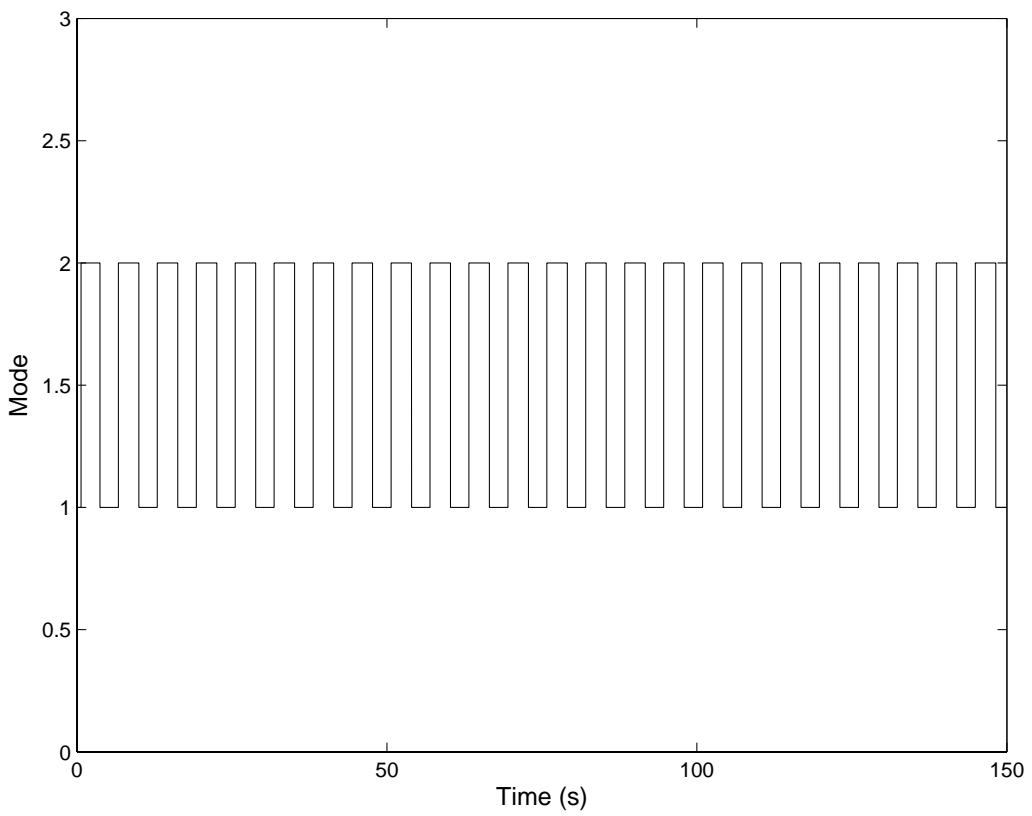

Fig. 60. Example 1 - Switching between the two modes

given by $F_{s 2}=k_{2}(x-L)^{3}$, where $F_{s 2}$ is the force applied on it. The effect of this non-linearity on the performance of the proposed parameter estimation scheme will be observed. It is still assumed that the true values of all the parameters are $m=1$ $\mathrm{kg}, k_{1}=3 \mathrm{~N} / \mathrm{m}, c_{1}=0.5 \mathrm{Ns} / \mathrm{m}, k_{2}=1 \mathrm{~N} / \mathrm{m}, c_{2}=2 \mathrm{Ns} / \mathrm{m}$ and $L=0.2 \mathrm{~m}$. It is once again assumed that the values of $c_{1}$ and $k_{2}$ are unknown and need to be estimated.

The equation of motion of the system in mode 1 is given by

$$
m \ddot{x}=F-k_{1} x-c_{1} \dot{x},
$$

and the equation of motion of the system in mode 2 is given by

$$
m \ddot{x}=F-k_{1} x-c_{1} \dot{x}-k_{2}(x-L)^{3}-c_{2} \dot{x} .
$$

Following the same procedure as in the previous example and making the same choices for $\mathbf{P}, \mathbf{Q}_{1}$ and $\mathbf{Q}_{2}$, the parameter update equations (using Eq. (7.10)) in mode 
1 are obtained to be

$$
\begin{array}{r}
\dot{\hat{c}}_{1}=-2 \dot{y}(\dot{x}-\dot{w}), \\
\dot{\hat{k}}_{2}=0 .
\end{array}
$$

As before, the estimate of the parameter $k_{2}$ is not updated when the system is in mode 1 . In mode 2 , the parameter update equations are obtained as

$$
\begin{array}{r}
\dot{\hat{c}}_{1}=-2 \dot{y}(\dot{x}-\dot{w}), \\
\dot{\hat{k}}_{2}=-2(y-L)^{3}(\dot{x}-\dot{w}) .
\end{array}
$$

These equations are solved with the initial conditions that $\hat{c}_{1}(0)=0$ and $\hat{k}_{2}(0)=0$ along with the equations governing the evolution of $\mathbf{w}$ (obtained using Eqs. (7.3) and (7.4)). The results of the numerical simulations are illustrated in Figs. 61 and 62. It can be noted from these two figures that both the parameter estimation errors and the output identification errors are bounded. The estimate of $k_{2}$ converges to the region around its true value of $1 \mathrm{~N} / \mathrm{m}$ and the estimate of $c_{1}$ converges to the region around its true value of $0.5 \mathrm{Ns} / \mathrm{m}$.

\section{Example 3}

The performance of the parameter estimation scheme proposed in Proposition 2 will be illustrated in this example. The same system illustrated in Fig. 57 is considered. Now, it is assumed that the only parameter that needs to be estimated is $k_{2}$. The same values for all the parameters are assumed as before. It is once again assumed that both $x$ and $\dot{x}$ are measured. 


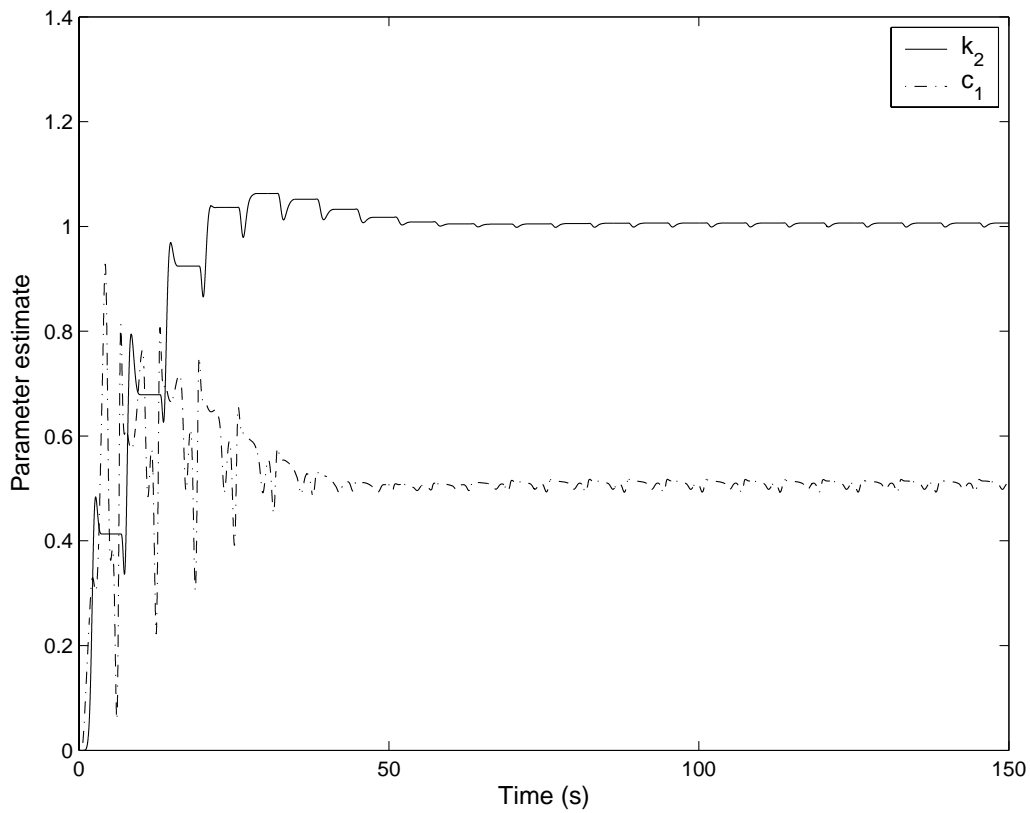

Fig. 61. Example 2 - Estimates of the unknown parameters

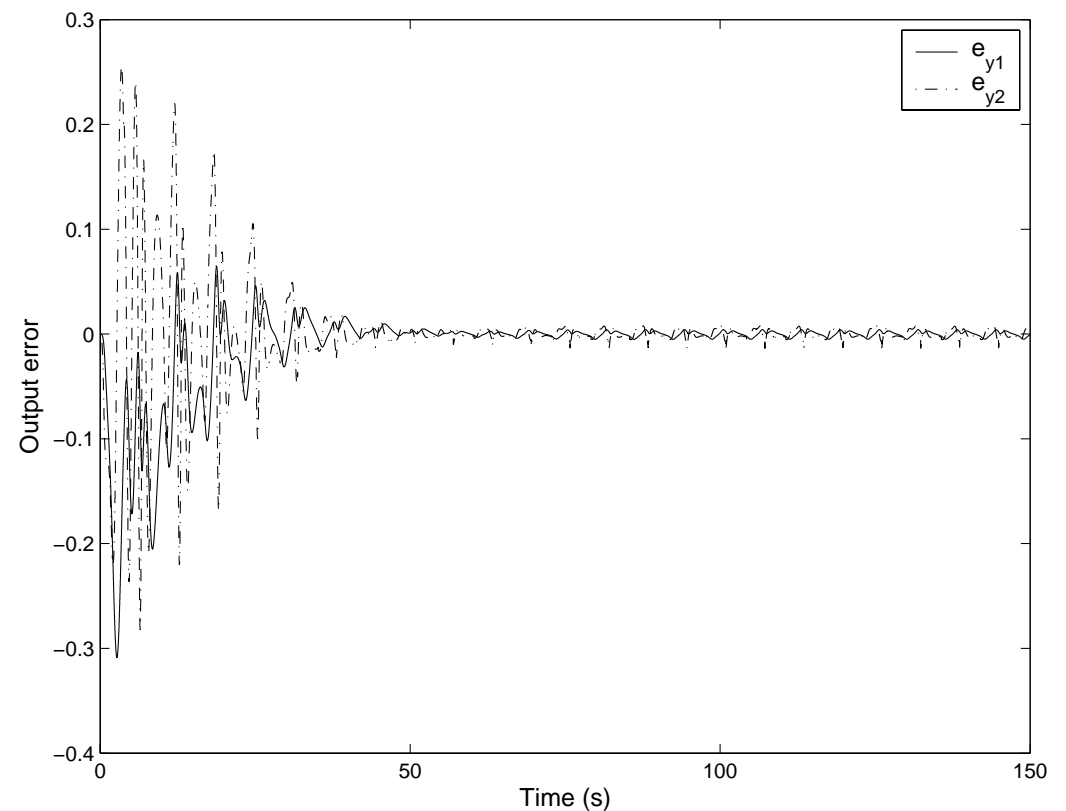

Fig. 62. Example 2 - Plots of the output identification errors 
The equation of motion in mode 1 can be written as

$$
\begin{aligned}
\left(\begin{array}{l}
\dot{x} \\
\ddot{x}
\end{array}\right)= & \left(\begin{array}{cc}
0 & 1 \\
k_{1} & c_{1} \\
-\frac{m}{m} & -\frac{1}{m}
\end{array}\right)\left(\begin{array}{l}
x \\
\dot{x}
\end{array}\right)+\left(\begin{array}{c}
0 \\
1 \\
\frac{m}{m}
\end{array}\right)(F), \\
& \left(\begin{array}{l}
y \\
\dot{y}
\end{array}\right)=\left(\begin{array}{ll}
1 & 0 \\
0 & 1
\end{array}\right)\left(\begin{array}{l}
x \\
\dot{x}
\end{array}\right) .
\end{aligned}
$$

The equation of motion in mode 2 can similarly be written as

$$
\begin{gathered}
\left(\begin{array}{c}
\dot{x} \\
\ddot{x}
\end{array}\right)=\left(\begin{array}{cc}
0 & 1 \\
k_{1} & -\frac{\left(c_{1}+c_{2}\right)}{m}
\end{array}\right)\left(\begin{array}{l}
x \\
\dot{x}
\end{array}\right)+\left(\begin{array}{c}
0 \\
\frac{1}{m}
\end{array}\right)\left((L-y) k_{2}+F\right), \\
\left(\begin{array}{c}
y \\
\dot{y}
\end{array}\right)=\left(\begin{array}{ll}
1 & 0 \\
0 & 1
\end{array}\right)\left(\begin{array}{l}
x \\
\dot{x}
\end{array}\right) .
\end{gathered}
$$

Now, choosing $\mathbf{P}=\left(\begin{array}{cc}p_{11} & p_{12} \\ p_{12} & p_{22}\end{array}\right)$, one obtains

$$
\mathbf{P A}_{1}+\mathbf{A}_{1}^{T} \mathbf{P}=\left(\begin{array}{cc}
-\frac{2 k_{1} p_{12}}{m} & p_{11}-\frac{c_{1} p_{12}}{m}-\frac{k_{1} p_{22}}{m} \\
p_{11}-\frac{c_{1} p_{12}}{m}-\frac{k_{1} p_{22}}{m} & 2 p_{12}-\frac{2 c_{1} p_{22}}{m}
\end{array}\right) .
$$

Similarly in mode 2, one obtains

$$
\mathbf{P A}_{2}+\mathbf{A}_{2}^{T} \mathbf{P}=\left(\begin{array}{cc}
-\frac{2 k_{1} p_{12}}{m} & p_{11}-\frac{\left(c_{1}+c_{2}\right) p_{12}}{m}-\frac{k_{1} p_{22}}{m} \\
p_{11}-\frac{\left(c_{1}+c_{2}\right) p_{12}}{m}-\frac{k_{1} p_{22}}{m} & 2 p_{12}-\frac{2\left(c_{1}+c_{2}\right) p_{22}}{m}
\end{array}\right) .
$$




$$
\text { Choosing } \mathbf{P}=\left(\begin{array}{cc}
9.5 & 1 \\
1 & 3
\end{array}\right), \mathbf{Q}_{1}=\left(\begin{array}{cc}
6 & 0 \\
0 & 1
\end{array}\right) \text { and } \mathbf{Q}_{2}=\left(\begin{array}{cc}
6 & 2 \\
2 & 13
\end{array}\right) \text { ensures that }
$$

Eq. (7.18) is satisfied for both modes. It can be noted that all the conditions listed in Proposition 2 are satisfied in this case. Thus, using Eq. (7.19), the parameter update equation in mode 1 is obtained to be

$$
\dot{\hat{k}}_{2}=0 \text {. }
$$

The parameter update equation in mode 2 is obtained to be

$$
\dot{\hat{k}}_{2}=2(L-y)(x-w)+6(L-y)(\dot{x}-\dot{w}) .
$$

The results of the numerical simulations in this case are presented in Figs. 63 and 64 . It can be observed that the output identification errors tend to zero asymptotically and the estimate of the parameter $k_{2}$ tends very nearly to its true value of $1 \mathrm{~N} / \mathrm{m}$. A faster convergence of the parameter estimate to the actual value is observed in this case when compared with Example 1 (compare with Figs. 58 and 59).

C. The proposed parameter estimation scheme when the transition conditions are unknown

In this section, a parameter estimation scheme is developed for the class of systems given by Eqs. (7.13) and (7.14) when the transition conditions are not known. In particular, it will be assumed that the values of $\mu_{i}, i=1, \ldots,(s-1)$, are not known but the bounds on each of them are known. In this case, the vector of unknown parameters $\theta$ also includes $\mu_{1}, \ldots, \mu_{s-1}$. It is assumed that $\alpha($.$) is a strictly increasing$ function of $\mathbf{y}$. It is assumed that the initial mode of the system is known. The lower bound on $\mu_{i}$ is denoted by $\beta_{i}$ and the upper bound on $\mu_{i}$ is denoted by $\delta_{i}$. It is 


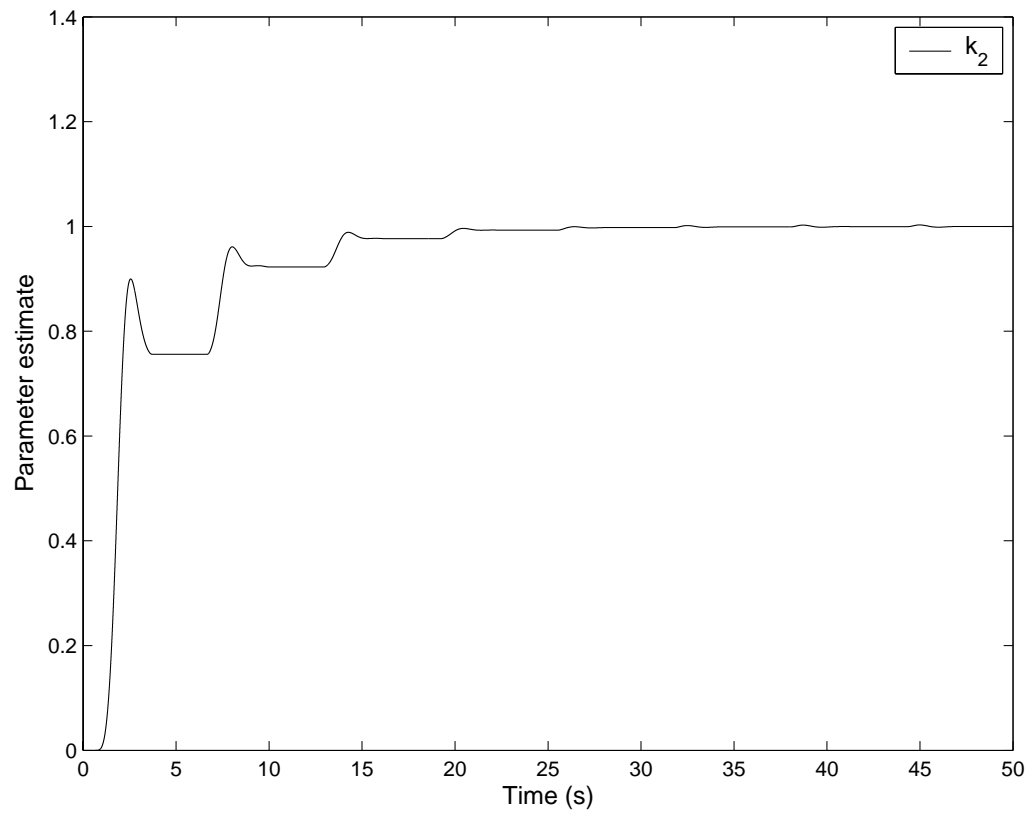

Fig. 63. Example 3 - Estimate of the unknown parameter

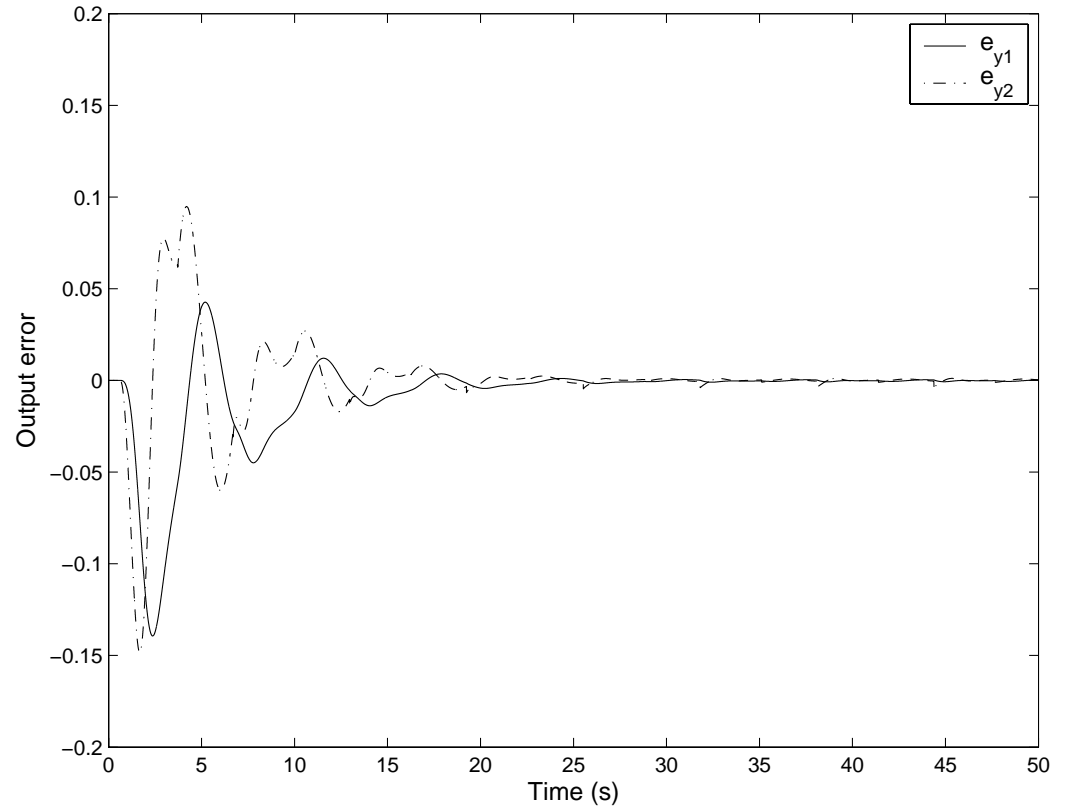

Fig. 64. Example 3 - Plots of the output identification errors 
assumed that the bounds are such that the following inequality holds:

$$
\ldots \beta_{i-1} \leq \mu_{i-1} \leq \delta_{i-1}<\beta_{i} \leq \mu_{i} \leq \delta_{i}<\beta_{i+1} \leq \mu_{i+1} \leq \delta_{i+1} \ldots
$$

It is assumed that one is able to find the matrices $\mathbf{P}$ and $\mathbf{Q}_{i}, i=1, \ldots, s$, such that Eq. (7.18) is satisfied. Then, the parameter update scheme given by Eq. (7.19) is used to evaluate the unknown parameters. But the issue here is to estimate the mode of the system at each instant of time so that the appropriate parameter update equations can be used at that instant of time. Let the system initially reside in mode $k$. Then, the following scheme is proposed to obtain an estimate of the system mode at the next instant of time:

1. Now, at the next instant of time, if $\alpha(\mathbf{y}) \geq \delta_{k}$, then it can be concluded that the system has switched to mode $(k+1)$.

2. If $\beta_{k} \leq \alpha(\mathbf{y})<\delta_{k}$, then there exists the possibility that the system might either remain in mode $k$ or switch to mode $(k+1)$. In this case, the following error measures associated with both modes are calculated:

$$
e_{k}(t)=\sum_{j=1}^{p}\left|y_{j}(t)-\hat{y}_{j}^{k}(t)\right|,
$$

where $\hat{\mathbf{y}}^{k}(t)$ is obtained by using the system equations in the $k^{t h}$ mode, and

$$
e_{k+1}(t)=\sum_{j=1}^{p}\left|y_{j}(t)-\hat{y}_{j}^{k+1}(t)\right|,
$$

where $\hat{\mathbf{y}}^{k+1}(t)$ is obtained by using the system equations in the $(k+1)^{t h}$ mode. Then, the estimate of the system mode (denoted by $\hat{i}(t)$ ) is obtained through

$$
\hat{i}(t)=\operatorname{argmin}_{j=k, k+1} e_{j}(t) .
$$

3. If $\delta_{k-1} \leq \alpha(\mathbf{y})<\beta_{k}$, then it can be concluded that the system will remain in 
mode $k$ at the next instant of time.

4. If $\beta_{k-1} \leq \alpha(\mathbf{y})<\delta_{k-1}$, then there exists the possibility that the system might either remain in mode $k$ or switch to mode $(k-1)$. In this case, the following error measures associated with both modes are calculated:

$$
e_{k}(t)=\sum_{j=1}^{p}\left|y_{j}(t)-\hat{y}_{j}^{k}(t)\right|,
$$

where $\hat{\mathbf{y}}^{k}(t)$ is obtained by using the system equations in the $k^{t h}$ mode, and

$$
e_{k-1}(t)=\sum_{j=1}^{p}\left|y_{j}(t)-\hat{y}_{j}^{k-1}(t)\right|,
$$

where $\hat{\mathbf{y}}^{k-1}(t)$ is obtained by using the system equations in the $(k-1)^{t h}$ mode. Then, the estimate of the system mode (denoted by $\hat{i}(t)$ ) is obtained through

$$
\hat{i}(t)=\operatorname{argmin}_{j=k, k-1} e_{j}(t) .
$$

5. If $\alpha(\mathbf{y})<\beta_{k-1}$, then it can be concluded that the system has switched to mode $(k-1)$.

Once an estimate of the mode is obtained, the parameter update equations corresponding to that estimated mode are used to obtain the parameter estimates at the next instant of time. The above steps are repeated at each instant of time to obtain estimates of both the system modes and the parameters. This scheme is illustrated in the following example.

\section{Example 4}

The performance of the parameter estimation scheme proposed above is illustrated in this example. The same system illustrated in Fig. 57 is considered. Now, it is assumed that the only parameter that needs to be estimated is $L$. The same values 
for all the parameters are assumed as before. It is once again assumed that both $x$ and $\dot{x}$ are measured. It is further assumed that the actual value of $L$ lies between 0.1 $\mathrm{m}$ and $0.3 \mathrm{~m}$.

The equation of motion in mode 1 can be written as

$$
\begin{aligned}
\left(\begin{array}{l}
\dot{x} \\
\ddot{x}
\end{array}\right)= & \left(\begin{array}{cc}
0 & 1 \\
k_{1} & c_{1} \\
-\frac{m}{m} & -\frac{1}{m}
\end{array}\right)\left(\begin{array}{l}
x \\
\dot{x}
\end{array}\right)+\left(\begin{array}{c}
0 \\
1 \\
\frac{m}{m}
\end{array}\right)(F), \\
& \left(\begin{array}{l}
y \\
\dot{y}
\end{array}\right)=\left(\begin{array}{ll}
1 & 0 \\
0 & 1
\end{array}\right)\left(\begin{array}{l}
x \\
\dot{x}
\end{array}\right) .
\end{aligned}
$$

The equation of motion in mode 2 can similarly be written as

$$
\begin{aligned}
\left(\begin{array}{c}
\dot{x} \\
\ddot{x}
\end{array}\right)=\left(\begin{array}{cc}
0 & 1 \\
-\frac{\left(k_{1}+k_{2}\right)}{m} & -\frac{\left(c_{1}+c_{2}\right)}{m}
\end{array}\right)\left(\begin{array}{l}
x \\
\dot{x}
\end{array}\right)+\left(\begin{array}{c}
0 \\
1 \\
\frac{m}{m}
\end{array}\right)\left(k_{2} L+F\right), \\
\left(\begin{array}{c}
y \\
\dot{y}
\end{array}\right)=\left(\begin{array}{cc}
1 & 0 \\
0 & 1
\end{array}\right)\left(\begin{array}{c}
x \\
\dot{x}
\end{array}\right) \cdot \\
\text { Now, choosing } \mathbf{P}=\left(\begin{array}{cc}
p_{11} & p_{12} \\
p_{12} & p_{22}
\end{array}\right), \text { one obtains } \\
\mathbf{P A}_{1}+\mathbf{A}_{1}^{T} \mathbf{P}=\left(\begin{array}{ccc}
\frac{2 k_{1} p_{12}}{m} & p_{11}-\frac{c_{1} p_{12}}{m}-\frac{k_{1} p_{22}}{m} \\
p_{11}-\frac{c_{1} p_{12}}{m}-\frac{k_{1} p_{22}}{m} & 2 p_{12}-\frac{2 c_{1} p_{22}}{m}
\end{array}\right) .
\end{aligned}
$$


Similarly in mode 2, one obtains

$$
\begin{gathered}
\mathbf{P A}_{2}+\mathbf{A}_{2}^{T} \mathbf{P}=\left(\begin{array}{cc}
2\left(k_{1}+k_{2}\right) p_{12} & p_{11}-\frac{\left(c_{1}+c_{2}\right) p_{12}}{m}-\frac{\left(k_{1}+k_{2}\right) p_{22}}{m} \\
p_{11}-\frac{\left(c_{1}+c_{2}\right) p_{12}}{m}-\frac{\left(k_{1}+k_{2}\right) p_{22}}{m} & 2 p_{12}-\frac{2\left(c_{1}+c_{2}\right) p_{22}}{m}
\end{array}\right) . \\
\text { Choosing } \mathbf{P}=\left(\begin{array}{cc}
9.5 & 1 \\
1 & 3
\end{array}\right), \mathbf{Q}_{1}=\left(\begin{array}{cc}
6 & 0 \\
0 & 1
\end{array}\right) \text { and } \mathbf{Q}_{2}=\left(\begin{array}{cc}
8 & 5 \\
5 & 13
\end{array}\right) \text { ensures that }
\end{gathered}
$$

Eq. (7.18) is satisfied for both modes. It can be noted that all the conditions listed in Proposition 2 are satisfied in this case. Thus, using Eq. (7.19), the parameter update equation in mode 1 is obtained to be

$$
\dot{\hat{L}}=0
$$

The parameter update equation in mode 2 is obtained to be

$$
\dot{\hat{L}}=2 k_{2}(x-w)+6 k_{2}(\dot{x}-\dot{w})
$$

It is assumed that the system starts in mode 1 and the initial value of $\hat{L}$ is taken to be $0.1 \mathrm{~m}$. The results of the numerical simulations in this case are presented in Figs. 65 to 67 . It can be observed that the output identification errors tend to zero asymptotically and the estimate of the parameter $L$ tends very nearly to its true value of $0.2 \mathrm{~m}$. It can also be noted from Fig. 67, that the estimated modes tend to the actual modes in a relatively short period of time. 


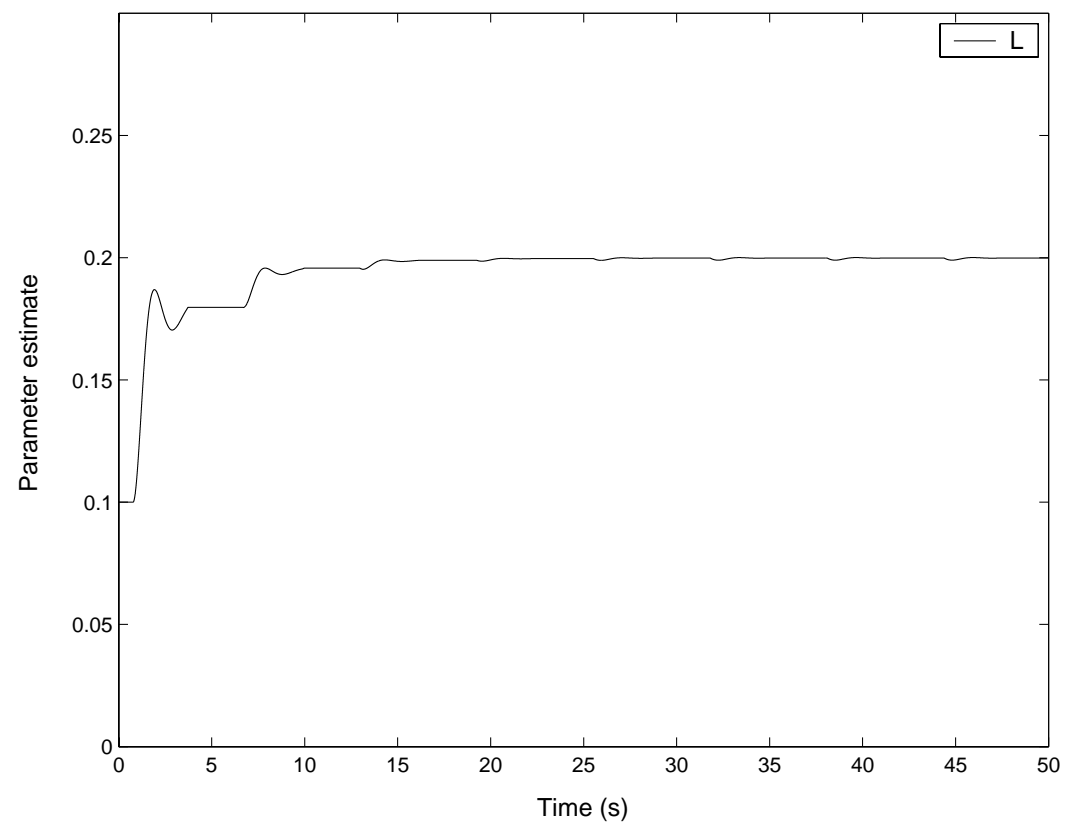

Fig. 65. Example 4 - Estimate of the unknown parameter

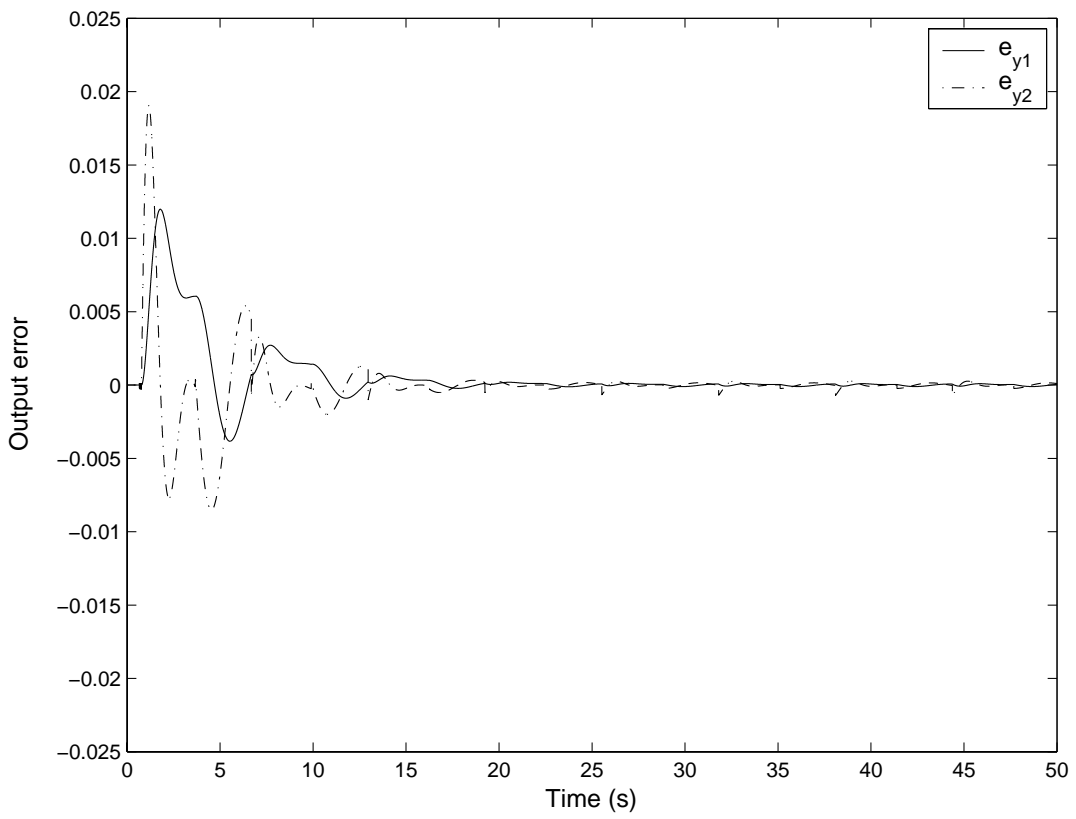

Fig. 66. Example 4 - Plots of the output identification errors 




Fig. 67. Example 4 - Switching between the two modes 


\section{CHAPTER VIII}

\section{CONCLUSIONS}

In this dissertation, model-based diagnostic schemes have been presented that will automatically monitor the air brake system used in commercial vehicles for leaks and out-of-adjustment of push rods. A model for predicting the pressure transients in the brake chamber of the air brake system by using the measurements of the treadle valve plunger displacement and the supply pressure to the treadle valve has been presented. The diagnostic schemes have been developed to conform to existing FMCSA guidelines for inspecting the air brake system. The diagnostic scheme proposed for leak detection utilizes the measurement of the steady state brake chamber pressure and compares it with the supply pressure to infer the presence or the absence of leakage. Two schemes have been proposed to estimate the stroke of the push rod. These schemes utilize the hybrid model for the pressure transients to obtain an estimate of the push rod stroke. These schemes present a method for estimating unknown parameters and detecting transitions in sequential hybrid systems. A general class of sequential hybrid systems has been considered and parameter estimation schemes have been developed for them. The performance of these schemes has been illustrated with a few examples.

To summarize, the diagnostic schemes presented in this dissertation utilize the data collected during a full brake application carried out with a supply pressure between $653 \mathrm{kPa}(80 \mathrm{psig})$ and $722 \mathrm{kPa}$ (90 psig). The push rod stroke required to overcome the clearance between the brake pads and the brake drum is estimated using the hybrid model for the pressure transients. It has been observed that the effect of this portion of the push rod stroke is reflected in the low pressure region of the pressure transients (within a pressure of $184.1 \mathrm{kPa}$ (12 psig) in the brake chamber). The push rod stroke due to the deformation of the mechanical components of the brake system 
once the brake pads contact the brake drum, is obtained from the measurement of the steady state brake chamber pressure. An estimate of the total push rod stroke is obtained by adding the part that is required to overcome the clearance between the brake pads and the brake drum and the part that results from the deformation of the mechanical components of the brake system once the brake pads contact the brake drum. The measurement of the steady state brake chamber pressure is also compared with the supply pressure to monitor the brake system for leaks.

\section{A. Potential impact of this dissertation}

It is hoped that the diagnostic schemes developed in this dissertation can be incorporated into an on-board / portable diagnostic tool to inspect air brake systems. Such a diagnostic tool will lead to fast, reliable and automated inspections of air brakes in commercial vehicles. The main impact will be in terms of improved safety due to the presence of a well diagnosed and maintained brake system. This will decrease the risk of accidents and the resulting loss of life and property. Such a tool will also have a positive economic impact through the reduction in the risk of accidents and reduced inspection times. The analytical tools developed in this dissertation provide methods for transition detection and parameter estimation in a class of sequential hybrid systems. It is hoped that the schemes developed in this dissertation can be applied to systems having similar characteristics.

\section{B. Scope of future work}

This dissertation presented a preliminary attempt to develop model-based diagnostic schemes for detecting leaks and out-of-adjustment of push rods in air brake systems. The configuration of the brake system considered here is the one where the delivery 
port of the primary circuit is directly connected to a front brake chamber. These diagnostic schemes need to be extended so as to cover the entire air brake system. Models for the remaining components in the air brake system such as the relay valve, the quick release valve, etc., need to be incorporated together with the model of the treadle valve in order to obtain diagnostic schemes for the entire air brake system. These schemes need to be carefully tested on the air brake system of an actual commercial vehicle. Some of the foreseeable challenges in the way of incorporating these diagnostic schemes include:

1. One of the major challenges is the absence of pressure transducers for measuring the brake chamber pressure in existing commercial vehicles. It has been observed from the data presented in this dissertation that the pressure transients in the brake chamber can provide information about leakage and out-ofadjustment of push rods. It is hoped that pressure transducers to measure the brake chamber pressure will be installed in the following generations of commercial vehicles. Such a step will not only help in diagnosing the air brake system, but will also help in controlling the brake system as part of emerging technologies like Autonomous Intelligent Cruise Control (AICC) systems for commercial vehicles.

2. Another issue that might play a significant role in implementing these diagnostic schemes, particularly in tractor-trailer combinations, is that of the compatibility between the brake system in the tractor and the trailer [104]. This might be important since different trailers (possibly with varying components and brake system layouts) may be attached to a tractor during its operation. A possible solution is to develop the diagnostic tools separately for the tractor and the trailer. Also, it should be noted that the values of most of the parameters used 
in the model and diagnostic schemes presented in this dissertation hold true only for the components used in the experimental setup. Different vehicles may use different components (with possibly varying parameter values) and this should be taken into account while developing a diagnostic tool. For example, if certain valves used in the experimental setup are replaced by alternate products, the corresponding parameters for the new valves must be obtained and used in the model and diagnostic schemes. 


\section{REFERENCES}

[1] T. K. Garrett, K. Newton, and W. Steeds, The Motor Vehicle, 13rd ed. Warrendale, Pennsylvania: Society of Automotive Engineers, 2001.

[2] R. Limpert, Brake Design and Safety, 2nd ed. Warrendale, Pennsylvania: Society of Automotive Engineers, 1999.

[3] "Federal motor carrier safety regulations: Part 390," Code of Federal Regulations, Title 49, Part 390, October 2003.

[4] S. F. Williams and R. R. Knipling, "Automatic slack adjusters for heavy vehicle air brake systems," National Highway Traffic Safety Administration, Washington, D. C., Tech. Rep. DOT HS 807 724, February 1991.

[5] D. Blower and K. L. Campbell, "The large truck crash causation study," Federal Motor Carrier Safety Administration, Washington, D. C., Tech. Rep. UMTRI2002-31, November 2002.

[6] "Safety report: Analysis of intrastate trucking operations," National Transportation Safety Board, Washington, D. C., Tech. Rep. NTSB/SR-02/01, March 2002.

[7] "Special study - commercial motor vehicle braking," National Transportation Safety Board, Washington, D. C., Tech. Rep. NTSB-HSS-72-5, November 1972.

[8] A. Matteson, D. Blower, and J. Woodrooffe, "Trucks involved in fatal accidents factbook 2002," Transportation Research Institute, University of Michigan, Ann Arbor, Michigan, Tech. Rep. UMTRI-2004-34, October 2004. 
[9] R. W. Radlinski, "Braking performance of heavy U.S. vehicles," paper No. 870492, Transactions of the Society of Automotive Engineers, 1987.

[10] — - "Heavy vehicle braking - U. S. versus Europe," paper No. 892504, Transactions of the Society of Automotive Engineers, 1989.

[11] "Motor vehicle safety standard no. 121: Air brake systems," Code of Federal Regulations, Title 49, Part 571, Section 121, October 2003.

[12] "Federal motor carrier safety regulations: Part 393," Code of Federal Regulations, Title 49, Part 393, October 2003.

[13] S. J. Shaffer and R. W. Radlinski, "Braking capability requirements for in-use commercial vehicles - a chronology," paper No. 2003-01-3397, Transactions of the Society of Automotive Engineers, 2003.

[14] S. J. Shaffer and G. H. Alexander, "Commercial vehicle brake testing - Part 1: Visual inspection versus performance-based test," paper No. 952671, Transactions of the Society of Automotive Engineers, 1995.

[15] —, "Commercial vehicle brake testing - Part 2: Preliminary results of performance-based test program," paper No. 952672, Transactions of the Society of Automotive Engineers, 1995.

[16] R. M. Braswell, J. F. Broder, P. J. Fisher, R. D. Flesher, D. Foster, S. Gooch, K. F. Johnson, H. T. Pannella, R. L. Rak, G. H. Rood, J. Salas, C. O. Summer, V. Suski, and J. Thrift, "Tomorrow's trucks: A progress review and reappraisal of future needs," paper No. 932975, Transactions of the Society of Automotive Engineers, 1993. 
[17] R. J. Morse, "Brake system performance at low operating pressures," paper No. 700512, Transactions of the Society of Automotive Engineers, 1970.

[18] P. Fancher, Z. Bareket, D. Blower, C. Mink, and K. Campbell, "Evaluation of brake adjustment criteria for heavy trucks," Federal Highway Administration, Washington, D. C., Tech. Rep. FHWA-MC-94-016, February 1995.

[19] R. M. Clarke, W. A. Leasure, Jr., R. W. Radlinski, and M. Smith, "Heavy truck safety study," National Highway Traffic Safety Administration, Washington, D. C., Tech. Rep. DOT HS 807 109, March 1987.

[20] R. B. Heusser, "Heavy truck deceleration rates as a function of brake adjustment," paper No. 910126, Transactions of the Society of Automotive Engineers, 1991.

[21] — - "Air brake inspections of five axle combinations," paper No. 922443, Transactions of the Society of Automotive Engineers, 1992.

[22] "Braking deficiencies on heavy trucks in 32 selected accidents," National Transportation Safety Board, Washington, D. C., Tech. Rep. NTSB/SS-88/06, November 1988.

[23] S. C. Subramanian, S. Darbha, and K. R. Rajagopal, "Modeling the pneumatic subsystem of an S-cam air brake system," ASME Journal of Dynamic Systems, Measurement and Control, vol. 126, pp. 36-46, March 2004.

[24] "Minimum periodic inspection standards," http://www.fmcsa.dot.gov/ rules-regulations/administration/fmcsr/appng.htm, Accessed April 2005.

[25] "Bendix ASA-5 automatic slack adjuster," http://www.bendix.com/ downloads/service_data_sheet/051269.pdf, Accessed April 2005. 
[26] D. Middleton and J. Rowe, "Feasibility of standardized diagnostic device for maintenance and inspection of commercial motor vehicles," Transportation Research Record, vol. 1560, pp. 48-56, 1996.

[27] E. Zaloshnja and T. Miller, "Revised costs of large truck-and bus-involved crashes," Federal Motor Carrier Safety Administration, Washington, D. C., Tech. Rep., November 2002.

[28] "Commodity flow survey," 1997 Economic Census, U. S. Census Bureau, 1997.

[29] A. Barber, Pneumatic Handbook, 8th ed. Oxford, United Kingdom: Elsevier Advanced Technology, 1997.

[30] W. H. Kruse, Jr., "The history and development of railroad braking," B.S. Thesis, University of Cincinnati, 1948.

[31] W. V. Turner, The Air Brake as Related to Progress in Locomotion. Pittsburg, Pennsylvania: Westinghouse Air Brake Company, 1910.

[32] F. H. Wells, "The development of the modern air brake," M.E. Thesis, Massachussetts Institute of Technology, 1920.

[33] H. G. Prout, A Life of George Westinghouse. New York: The American Society of Mechanical Engineers, 1921.

[34] F. E. Leupp, George Westinghouse: His Life and Achievements. Boston: Little, Brown, and Company, 1918.

[35] P. Synnestvedt, Evolution of the Air Brake. New York: Locomotive Engineering, 1895. 
[36] — Diseases of the Air Brake System: Their Causes, Symptoms and Cures. Chicago: The W. F. Hall Printing Company, 1896.

[37] G. A. Harper, Brakes and Friction Materials: The History and Development of the Technologies. London, UK: Mechanical Engineering Publications Limited, 1998.

[38] D. G. Blaine, Modern Freight Car Air Brakes. Omaha, Nebraska: SimmonsBoardman Publishing Corporation, 1979.

[39] L. C. Buckman, "Commercial vehicle braking systems: Air brakes, ABS and beyond," Society of Automotive Engineers, Indianapolis, the 43rd L. Ray Buckendale Lecture, International Truck and Bus Meeting and Exposition, Indianapolis, Society of Automotive Engineers, November, 1998.

[40] "Heavy vehicle airbrake performance," National Transportation Safety Board, Washington, D. C., Tech. Rep. NTSB/SS-92/01, April 1992.

[41] S. Tanaka, K. Kubota, T. Iwasaki, and H. Hatanaka, "The compatibility of air disc brakes and S-cam brakes installed on combination vehicles," paper No. 902201, Transactions of the Society of Automotive Engineers, 1990.

[42] E. Gohring and E. C. Von Glasner, "Performance comparison of drum and disc brakes for heavy duty commercial vehicles," paper No. 902206, Transactions of the Society of Automotive Engineers, 1990.

[43] A. C. Esteves, L. Winocq, and J. Berthaud, "Disc brakes for trucks: A technical innovation for heavy vehicles," paper No. 925059, Transactions of the Society of Automotive Engineers, 1992. 
[44] W. A. Leasure, Jr. and S. F. Williams, Jr., "Antilock systems for air-braked vehicles," paper No. 890113, The Thirty-Fifth L. Ray Buckendale Lecture, Transactions of the Society of Automotive Engineers, 1989.

[45] G. P. Mathews, "Art and science of braking heavy duty vehicles," paper No. 640795, The Tenth L. Ray Buckendale Lecture, Transactions of the Society of Automotive Engineers, 1964.

[46] D. Kramer, D. Roper, and E. Trachman, "Drive axle antilock for heavy vehicle stability," paper No. 871572, Transactions of the Society of Automotive Engineers, 1987.

[47] P. Berg, Compressed-Air Systems for Commercial Vehicles: 1 - Basic Principles, Systems and Schematic Diagrams, 3rd ed. Stuttgart, Germany: Robert Bosch, 1999.

[48] E. Peterson, E. Reinecke, and P. Liermann, "Anti-lock braking systems (ABS) with integrated drive slip control (ASR) for commercial vehicles," paper No. 861961, Transactions of the Society of Automotive Engineers, 1986.

[49] H. Decker and J. Wrede, "Brake-by-wire: Solutions, advantages and the need for standardization," paper No. 94C039, Transactions of the Society of Automotive Engineers, 1994.

[50] C. Wiehen and D. Neuhaus, "Potential of electronically controlled brake systems," paper No. 952278, Transactions of the Society of Automotive Engineers, 1995.

[51] K. Linderman, E. Peterson, M. Schult, and A. Korn, "EBS and tractor trailer 
brake compatibility," paper No. 973283, Transactions of the Society of Automotive Engineers, 1997.

[52] J. E. Fent, "U.S.A. commercial vehicle air brake systems - 1991 overview," paper No. 918013, Transactions of the Society of Automotive Engineers, 1991.

[53] "Front wheel brake safety facts," Department of Transportation, Federal Highway Administration, Washington, D. C., 1987.

[54] "EC series electric cylinders: User's manual," PN CUS10050, Version 1.0, Industrial Devices Corporation/Danaher Motion, Rockford, Illinois.

[55] "B8501: Brushless analog position control manual supplement," PN PCW-4712, Rev. 1.01, Industrial Devices Corporation/Danaher Motion, Rockford, Illinois, June 1995.

[56] "B8001 brushless servo drive: Operator's manual," PN PCW-4679, Rev. 1.5, Industrial Devices Corporation/Danaher Motion, Rockford, Illinois, May 1998.

[57] "IDC Servo Tuner: Operator's manual," P/N PCW-4710, Rev. 1.00, Industrial Devices Corporation/Danaher Motion, Rockford, Illinois, April 1995.

[58] J. Tal, Step-by-Step Design of Motion Control Systems. Sunnyvale, California: Galil Motion Control, Inc., 1994.

[59] "PCI E series user manual: Multifunction I/O devices for PCI bus computers," National Instruments, Austin, Texas, July 2002.

[60] G. W. Johnson and R. Jennings, Labview Graphical Programming, 3rd ed. New York: McGraw-Hill, 2001. 
[61] J. C. Gerdes and J. K. Hedrick, "Brake system modeling for simulation and control," ASME Journal of Dynamic Systems, Measurement and Control, vol. 121, pp. 496-503, September 1999.

[62] Y. Khan, P. Kulkarni, and K. Youcef-Toumi, "Modeling, experimentation and simulation of a brake apply system," ASME Journal of Dynamic Systems, Measurement and Control, vol. 116, pp. 111-122, March 1994.

[63] D. K. Fisher, "Brake system component dynamic performance measurement and analysis," paper No. 700373, Transactions of the Society of Automotive Engineers, 1970.

[64] L. Johnson, P. S. Fancher, and T. D. Gillespie, "An empirical model for the prediction of the torque output of commercial vehicle air brakes," Highway Safety Research Institute, University of Michigan, Ann Arbor, Michigan, Tech. Rep. UM-HSRI-78-53, December 1978.

[65] T. M. Post, P. S. Fancher, and J. E. Bernard, "Torque characteristics of commercial vehicle brakes," paper No. 750210, Transactions of the Society of Automotive Engineers, 1975.

[66] P. G. Reinhall and R. R. Scheibe, "Development of an intelligent air brake warning system for commercial vehicles," IDEA Program, Transportation Research Board, National Research Council, Washington, D. C., Tech. Rep. ITS-13, May 1996.

[67] T. Acarman, U. Ozguner, C. Hatipoglu, and A. M. Igusky, "Pneumatic brake system modeling for systems analysis," paper No. 2000-01-3414, Transactions of the Society of Automotive Engineers, 2000. 
[68] A. L. Dunn, G. J. Heydinger, G. Rizzoni, and D. A. Guenther, "New model for simulating the dynamics of pneumatic heavy truck brakes with integrated anti-lock control," paper No. 2003-01-1322, Transactions of the Society of Automotive Engineers, 2003.

[69] L. D. Kandt, P. G. Reinhall, and R. R. Scheibe, "Determination of air brake adjustment from air pressure data," Proc. Institution of Mechanical Engineers, Part D: Journal of Automobile Engineering, vol. 215, pp. 21-29, 2001.

[70] B. W. Anderson, The Analysis and Design of Pneumatic Systems. New York: John Wiley \& Sons, Inc., 1967.

[71] H. E. Merritt, Hydraulic Control Systems. New York: John Wiley \& Sons, 1967.

[72] W. Bolton, Pneumatic and Hydraulic Systems. Oxford, England: ButterworthHeinemann, 1997.

[73] A. Balluchi, L. Benvenuti, M. D. Di Benedetto, C. Pinello, and A. L. Sangiovanni-Vincentelli, "Automotive engine control and hybrid systems: Challenges and opportunities," Proc. IEEE, vol. 88, no. 7, pp. 888-912, 2000.

[74] F. Borrelli, A. Bemporad, M. Fodor, and D. Hrovat, "A hybrid control approach to traction control," in Hybrid Systems: Computation and Control, ser. Lecture Notes in Computer Science, M. D. Di Benedetto and A. Sangiovanni-Vincentelli, Eds., vol. 2034. Berlin, Germany: Springer-Verlag, 2001, pp. 162-174.

[75] C. Altafini, A. Speranzon, and K. H. Johansson, "Hybrid control of a truck and trailer vehicle," in Hybrid Systems: Computation and Control, ser. Lecture 
Notes in Computer Science, C. J. Tomlin and M. R. Greenstreet, Eds., vol. 2289. Berlin, Germany: Springer-Verlag, 2002, pp. 21-34.

[76] A. Balluchi, L. Benvenuti, M. D. Di Benedetto, and A. L. SangiovanniVincentelli, "A hybrid observer for the driveline dynamics," in Proc. European Control Conference, Porto, Portugal, 2001, pp. 618-623.

[77] S. J. Sobolak, "Simulation of the Ford vehicle speed control system," paper No. 820777, Transactions of the Society of Automotive Engineers, 1982.

[78] P. G. Blaney, "Improvements to cruise controls utilizing microprocessor technology," paper No. 830662, Transactions of the Society of Automotive Engineers, 1983.

[79] Y. Harada, H. Miyata, Y. Hayakawa, and S. Fujii, "Cruise control system using adaptive control theory," paper No. 931917, Transactions of the Society of Automotive Engineers, 1993.

[80] P. Martin, "Autonomous intelligent cruise control incorporating automatic braking," paper No. 930510, Transactions of the Society of Automotive Engineers, 1993.

[81] D. Wuh, "Design and comparison of autonomous intelligent cruise control systems," paper No. 942405, Transactions of the Society of Automotive Engineers, 1994.

[82] P. Francher, Z. Bareket, S. Bogard, C. MacAdam, and R. Ervin, "Tests characterizing performance of an adaptive cruise control system," paper No. 970458, Transactions of the Society of Automotive Engineers, 1997. 
[83] B. Riley, G. Kuo, B. Schwartz, J. Zumberge, and K. Shipp, "Development of a controlled braking strategy for vehicle adaptive cruise control," paper No. 2000-01-0109, Transactions of the Society of Automotive Engineers, 2000.

[84] J. D. Woll, "Radar-based adaptive cruise control for truck applications," paper No. 973184, Transactions of the Society of Automotive Engineers, 1997.

[85] B. R. Murphy, "Anti-lock braking systems for north american buses, coaches and motorhomes," paper No. 973248, Transactions of the Society of Automotive Engineers, 1997.

[86] C. L. Bowlin, S. C. Subramanian, S. Darbha, and K. R. Rajagopal, "A pressure control scheme for air brakes in commercial vehicles," accepted for publication in the IEE Proc. Intelligent Transportation Systems, 2006.

[87] A. S. Willsky, "A survey of design methods for failure detection in dynamic systems," Automatica, vol. 12, pp. 601-611, 1976.

[88] J. Gertler, "Residual generation in model-based fault diagnosis," ControlTheory and Advanced Technology, vol. 9, no. 1, pp. 259-285, 1993.

[89] J. J. Gertler, Fault Detection and Diagnosis in Engineering Systems. New York: Markel Dekker, Inc., 1998.

[90] M. Basseville, "Detecting changes in signals and systems - a survey," Automatica, vol. 24, no. 3, pp. 309-326, 1988.

[91] R. Isermann, "Process fault detection based on modeling and estimation methods - a survey," Automatica, vol. 20, no. 4, pp. 387-404, 1984. 
[92] P. M. Frank, "Fault diagnosis in dynamic systems using analytical and knowledge-based redundancy - a survey and some new results," Automatica, vol. 26, no. 3, pp. 459-474, 1990.

[93] "FMCSA rule for PBBTs," http://www.dot.gov/affairs/fmcsa1502.htm, Accessed August 2004.

[94] "US patents," http://www.uspto.gov, Accessed August 2004.

[95] "Personal communication," personal communication with Professor Pravin Varaiya, 2004.

[96] "Bendix brake chambers," http://www.bendix.com/downloads/service_data_ sheet/021302.pdf, Accessed April 2005.

[97] J. J. E. Slotine and W. Li, Applied Nonlinear Control. Englewood Cliffs, New Jersey: Prentice Hall, 1991.

[98] S. Sastry and M. Bodson, Adaptive Control: Stability, Convergence and Robustness. $\quad$ Englewood Cliffs, New Jersey: Prentice Hall, 1989.

[99] D. Liberzon and A. S. Morse, "Basic problems in stability and design of switched systems," IEEE Control Systems Magazine, vol. 19, no. 5, pp. 59-70, October 1999.

[100] A. Alessandri and P. Coletta, "Design of Luenberger observers for a class of hybrid linear systems," in Hybrid Systems: Computation and Control, ser. Lecture Notes in Computer Science, M. D. D. Benedetto and A. Sangiovanni-Vincentelli, Eds., vol. 2034. Berlin, Germany: Springer-Verlag, 2001, pp. 7-18.

[101] R. Vidal, A. Chiuso, S. Soatto, and S. Sastry, "Observability of linear hybrid systems," in Hybrid Systems: Computation and Control, ser. Lecture Notes in 
Computer Science, O. Maler and A. Pnueli, Eds., vol. 2623. Berlin, Germany: Springer-Verlag, 2003, pp. 526-539.

[102] J. P. Hespanha and A. S. Morse, "Switching between stabilizing controllers," Automatica, vol. 38, pp. 1905-1917, 2002.

[103] D. Swaroop and K. R. Rajagopal, "Limit of a collection of dynamical systems: An application to modeling the dynamics of flow of traffic," Mathematical Models and Methods in Applied Sciences, vol. 12, no. 10, pp. 1381-1399, 2002.

[104] R. W. Radlinski and M. A. Flick, "Tractor and trailer brake system compatibility," paper No. 861942, Transactions of the Society of Automotive Engineers, 1986. 


\section{VITA}

Shankar Ram Coimbatore Subramanian was born in the south Indian state of Tamilnadu. He was brought up in the city of Chennai and completed high school there. He obtained his Bachelor of Engineering in mechanical engineering from the University of Allahabad, Allahabad, India, in May 2000. He joined the Department of Mechanical Engineering at Texas A\&M University in August 2000 to pursue his Master of Science in mechanical engineering and graduated with the same in May 2003. Then, he continued pursuing his Ph.D. in mechanical engineering at Texas A\&M University and graduated with the same in May 2006. He may be contacted through Professor K. R. Rajagopal, Department of Mechanical Engineering, Texas A\&M University, College Station, Texas 77843, USA.

The typist for this dissertation was Shankar Ram Coimbatore Subramanian. 